\title{
Deficiency of the adrenomedullin-RAMP3 system suppresses metastasis through modification of cancer-associated fibroblasts
}

\author{
Kun Dai ${ }^{1,2^{*}}$, Megumu Tanaka ${ }^{1,2 *}$, Akiko Kamiyoshi ${ }^{1,2}$, Takayuki Sakurai ${ }^{1,2}$, \\ Yuka Ichikawa-Shindo ${ }^{1,2}$, Hisaka Kawate ${ }^{1,2}$, Nanqi Cui ${ }^{1,2}$, Yangxuan Wei ${ }^{1,2}$, \\ Masaaki Tanaka $^{1,3}$, Shinji Kakihara ${ }^{1,3}$, Shuhei Matsui ${ }^{1,4}$, Takayuki Shindo ${ }^{1,2+}$
}

${ }^{1}$ Department of Life Innovation, Institute for Biomedical Sciences, Interdisciplinary Cluster for Cutting Edge Research, Shinshu University, Japan

${ }^{2}$ Department of Cardiovascular Research, Shinshu University School of Medicine, Japan

${ }^{3}$ Department of Ophthalmology, Shinshu University School of Medicine, Japan

${ }^{4}$ Department of Anesthesiology, Shinshu University School of Medicine, Japan

*These authors contributed equally: Kun Dai and Megumu Tanaka.

\section{Running title}

RAMP3 deficiency suppresses metastasis by modulating CAF

\section{Competing Interests statement}

The authors declare that they have no conflict of interest.

\section{${ }^{+}$Address for correspondence}

Takayuki Shindo, MD, PhD

Department of Cardiovascular Research,

Shinshu University School of Medicine

Asahi 3-1-1, Matsumoto, Nagano, 390-8621, Japan

Tel: $+81-263-37-2578$

Fax: +81-263-37-3437

Email: tshindo@shinshu-u.ac.jp 
RAMP3 deficiency suppresses metastasis by modulating CAF

\section{Abstract}

Tumor metastasis is a primary source of morbidity and mortality in cancer. Adrenomedullin (AM) is a multifunctional peptide regulated by receptor activity-modifying proteins (RAMPs). We previously reported that the AM-RAMP2 system is involved in tumor angiogenesis, but the function of the AM-RAMP3 system remains largely unknown. Here, we investigated the actions of the AM-RAMP2 and 3 systems in the tumor microenvironment and their impact on metastasis. PAN02 pancreatic cancer cells were injected into the spleens of mice, leading to spontaneous liver metastasis. Tumor metastasis was enhanced in vascular endothelial cell-specific RAMP2 knockout mice (DI-E-RAMP2-/-). By contrast, metastasis was suppressed in RAMP3-/- mice, where the number of podoplanin (PDPN)-positive cancer-associated fibroblasts (CAFs) was reduced in the periphery of tumors at metastatic sites. Because PDPN-positive CAFs are a hallmark of tumor malignancy, we assessed the regulation of PDPN and found that Src/Cas/PDPN signaling is mediated by RAMP3. In fact, RAMP3 deficiency CAFs suppressed migration, proliferation and metastasis in co-cultures with tumor cells in vitro and in vivo. Moreover, activation of RAMP2 in RAMP3-/- mice suppressed both tumor growth and metastasis.

Based on these results, we suggest that upregulation of PDPN in DI-E-RAMP2-/- mice increases malignancy, while downregulation of PDPN in RAMP3-/- mice reduces it. Selective activation of RAMP2 and inhibition of RAMP3 would therefore be expected to suppress tumor metastasis. This study provides the first evidence that understanding and targeting to AM-RAMP systems could 
RAMP3 deficiency suppresses metastasis by modulating CAF

contribute to the development of novel therapeutics against metastasis. 
RAMP3 deficiency suppresses metastasis by modulating CAF

\section{Introduction}

Decades of cancer studies have unraveled the genetic and molecular pathways mediating cancer progression. This has revealed a variety of plausible therapeutic targets, many of which hold great promise for improving clinical outcomes.

Nonetheless, tumor metastasis, a highly complex, dynamic process involving multiple steps, is still responsible for more than $90 \%$ of cancer-related deaths [1], and there is a critical need to develop more effective therapies to combat the metastatic process. The tumor microenvironment and cell-cell interactions significantly influence cancer cell metastasis and cancer progression [1]. It is well known, for example, that cancer-associated fibroblasts (CAFs) constitute a large proportion of the stromal cells within the tumor microenvironment and that they provide critical signals that support tumor progression [2]. Moreover, recent data indicate that the presence of CAFs in the microenvironment surrounding cancer cells is associated with a poor clinical prognosis in breast[3, 4], lung[5, 6], and pancreatic cancer[7, 8], among others. Similarly, CAFs expressing podoplanin (PDPN), a marker of lymphatic endothelial cells and lymphangiogenesis, are associated with a poor prognosis in various types of cancers [9-11]. However, the mechanisms by which interactions between tumors and their microenvironment affect cancer metastasis and prognosis are still not completely understood [12]. Understanding and targeting CAFs could provide a novel treatment strategy for cancer metastasis.

Adrenomedullin (AM), a member of the calcitonin peptide superfamily, is involved in both the pathogenesis of cardiovascular diseases and circulatory 
RAMP3 deficiency suppresses metastasis by modulating CAF

homeostasis [13]. Interestingly, AM and its family members share a common G-protein-coupled receptor, calcitonin receptor-like receptor (CLR). The ligand-specific functions of CLR are regulated by a group of three membrane proteins, receptor activity-modifying proteins 1-3 (RAMP1-3), which bind CLR one-to-one [14]. CLR combined with RAMP2 or RAMP3 functions as an AM receptor $[15,16]$. Notably, AM and its receptors have been detected in many types of cancers, including cancers of lung [17], breast [18] and pancreas [19, 20].

We previously used homozygous AM knockout (AM-/-) and RAMP2 knockout (RAMP2-/-) mice to demonstrate the essential roles played by the AM-RAMP2 system in blood vessel development [21]. Because AM-/- and RAMP2-/- mice die in utero due to abnormalities in their cardiovascular development, we used drug-inducible endothelial cell-specific RAMP2 knockout mice (DI-E-RAMP2-/-) to investigate the contribution made by the endogenous AM-RAMP2 system to tumor angiogenesis and metastasis [22]. We found that tumor growth and angiogenesis were suppressed in DI-E-RAMP2-/- mice, but tumor metastasis was enhanced [22]. Following transplantation of melanoma cells into hindlimb footpads, spontaneous metastasis to the lung was enhanced in DI-E-RAMP2-/- mice. Within the lungs of DI-E-RAMP2-/- mice, pulmonary endothelial cells were deformed, and inflammatory cells infiltrated the vessel walls and expressed the chemotactic factors S100A8/9 and SAA3, which attracted tumor cells and mediated formation of a pre-metastatic niche [22]. These findings demonstrate how critical the AM-RAMP2 system is for vascular integrity, which works to suppress tumor metastasis. 
RAMP3 deficiency suppresses metastasis by modulating CAF

Compared to the AM-RAMP2 system, little is known about the function of the AM-RAMP3 system in tumor progression. In the present study, we used DI-E-RAMP2-/- and RAMP3-/- mice to reveal the roles of endogenous AM-RAMP2 and AM-RAMP3 systems in metastasis. 


\section{Results}

Tumor growth and angiogenesis are suppressed but metastasis is enhanced in

\section{DI-E-RAMP2-/- mice}

To investigate the role of the endogenous AM-RAMP2 system in liver metastasis, PAN02 cells were injected into the spleen, which enabled spontaneous liver metastasis. The time course over which the spontaneous metastasis model was implemented is shown in Figure 1A. Four weeks after injection of the PAN02 cells, the resultant tumor in the spleen and the metastatic lesion in the liver were removed and analyzed. In DI-E-RAMP2-/- mice, tumor growth was suppressed at both the injection sites in the spleen and the metastatic sites (Figure 1B). By contrast, the incidence of tumor metastasis was significantly enhanced in DI-E-RAMP2-/- mice (Figure 1C), which is consistent with our previous observation of spontaneous metastasis of melanoma to the lung [22]. We next evaluated tumor angiogenesis by fluorescently immunostaining for CD34. Compared to control, DI-E-RAMP2-/- mice showed poor tumor angiogenesis at both the tumor cell injection sites and metastatic sites (Figure 1D). This finding was confirmed by gene expression analysis, which showed significant suppression of CD34 expression in DI-E-RAMP2-/- mice (Figure 1E). Evaluation of angiogenesis-related and lymphangiogenesis-related factors revealed that PDPN expression was markedly higher in metastatic livers than normal livers (Figure 1F). Similarly, expression of AM was upregulated in the metastatic liver, as was expression of both RAMP2 and RAMP3, though RAMP3 expression was increased to a 10 times greater extent than RAMP2 expression. 


\section{PDPN expression is elevated in aSMA-positive CAFs in the peripheral regions of}

\section{metastatic tumors}

Expression of the well-known lymph vessel marker PDPN is reportedly elevated in human breast and pancreatic cancer samples [23-25]. In particular, PDPN is highly expressed in CAFs [9-11]. We therefore focused on the periphery of tumors at metastatic sites, where abundant CAFs were present. Masson's trichrome staining of tumor peripheries showed that the degree of fibrosis was greater in DI-E-RAMP2-/- than control livers (Figure 2A). In addition, immunostaining for the CAF marker $\alpha$ SMA [26] revealed much greater numbers $\alpha$ SMA-positive cells in the tumor periphery in DI-E-RAMP2-/- than control mice. Notably, most of these aSMA-positive cells were also positive for PDPN (Figure 2B). Expression levels of RAMP3, the CAF markers PDPN and $\alpha$ SMA, and the known tumor chemoattractant factors S100A8/9 $[27,28]$ were all significantly elevated in the metastatic tumor periphery in DI-E-RAMP2-/- mice 3 to 4 weeks after PAN02 cell transplantation (Figure 2C). These results suggest that increases in the numbers of PDPN-positive CAFs in the tumor periphery may contribute to the enhanced malignant phenotype seen in DI-E-RAMP2-/- mice.

Tumor metastasis is suppressed by decreasing CAFs and downregulating tumor chemoattractant factors in RAMP3-/- mice 
RAMP3 deficiency suppresses metastasis by modulating CAF

To further evaluate the pathological impact of elevated RAMP3 at metastasis sites, we next used RAMP3-/- mice in the same liver metastasis model. Tumor weights at the injection site (spleen) did not differ between RAMP3+/+ and RAMP3-/- mice (Figure 3A, left). On the other hand, liver tumor weights (Figure 3A, right) and the incidence of liver metastasis (Figure 3B) were both significantly reduced in RAMP3-/- mice. This observation is the opposite of what was seen with DI-E-RAMP2-/- mice, which exhibited increased liver metastasis. In addition, tumor angiogenesis was not affected at either the injection or metastasis site in RAMP3-/mice (Supplementary Figure 1), indicating the observed reduction in metastasis is not explained by an alteration in angiogenesis.

We found less fibrosis (Figure 3C) and fewer aSMA- and PDPN-positive cells in the tumor periphery in RAMP3-/- mice (Figure 3D). Moreover, expression levels of CAF-related and tumor chemoattractant-related factors were downregulated 3 to 4 weeks after PAN02 cell transplantation in RAMP3-/- mice (Figure 3E). From these data, we speculate that the reduction in PDPN-positive CAFs mitigated the malignant phenotype in RAMP3-/- mice.

\section{RAMP3 deficiency suppresses tumor growth and metastasis in vitro and in vivo}

To evaluate the role of the AM-RAMP3 system in CAFs within the tumor microenvironment, we characterized CAFs isolated from the tumor periphery at the metastasis site. We found that all CAFs grown in vitro had a homogenous spindle-shaped fibroblastic morphology. These cells were also positive for the 
RAMP3 deficiency suppresses metastasis by modulating CAF

fibroblast markers $\alpha$ SMA, FSP-1 and vimentin. Contamination of the cultures by epithelial cells was excluded by confirming the absence of positive staining for the epithelial cell markers E-cadherin and CK19 (Supplementary Figure 2A). Expression of these markers was found to be comparable after several passages (data not shown). And reduced expression of RAMP3 was confirmed in RAMP3-/- CAFs (Supplementary Figure 2B, left).

To determine whether RAMP3 is involved in regulating tumor malignancy, we used scratch assays to assess the proliferation and migration of primary CAFs and MEFs. We found that when they were cocultured with PAN02 cells, the area covered by RAMP3-/- CAFs was significantly smaller than that covered by RAMP3+/+ CAFs (Figure 4A). Similar results were obtained with MEFs treated with medium conditioned by PAN02 cells (Figure 4B). Even after their proliferation was suppressed using mitomycin C, the RAMP3-/- CAF / PAN02 cell mixture covered significantly less area than the RAMP3+/+ CAF / PAN02 cell mixture. This confirms that migration capacity was lower in RAMP3-/- cells (Supplementary Figure 3).

In scratch assays with PAN02 cells, we similarly found that there was significantly less cell-coverage when the cells were stimulated with conditioned medium (CM) from RAMP3-/- than RAMP3+/+ CAFs (Supplementary Figure 4A). PAN02 cells stimulated with CM from RAMP3+/+ CAFs showed high expression of the mesenchymal marker vimentin, suggesting the occurrence of epithelial-mesenchymal transition (EMT) (Supplementary Figure 4B). By contrast, 
RAMP3 deficiency suppresses metastasis by modulating CAF

little vimentin expression was detected in cells treated with CM from RAMP3-/CAFs.

To determine whether these in vitro assays have any bearing on tumorigenicity in vivo, we applied the subcutaneous tumor transplantation model. PAN02 cells mixed with equal numbers of RAMP3+/+ or RAMP3-/- CAFs or PAN02 cells alone (total $2 \times 10^{6}$ cells) were subcutaneously injected into the bilateral axillary regions of RAMP3+/+ mice. Five weeks later, tumor weights in the RAMP3-/- CAF / PAN02 group were significantly lower than in the RAMP3+/+ CAF / PAN02 or PAN02 only group (Figure 4C). Thus, RAMP3 deficiency in the transplanted CAFs contributes to reducing tumor growth. We next fluorescently immunostained tissues from the RAMP3+/+ CAF / PAN02 and RAMP3-/- CAF / PAN02 tumors grown in RAMP3+/+ mice (Figure 4D). As expected, we found lower numbers of aSMA- and PDPN-positive CAFs in the RAMP3-/- CAF/PAN02 tissue samples. In addition, numbers of cells positive for the proliferation marker Ki67 were significantly lower in RAMP3-/- CAF / PAN02 tumor samples than RAMP3+/+ CAF / PAN02 tumor samples (Figure 4E). We also used the aforementioned spontaneous liver metastasis model but with splenic injection of a mixture of PAN02 cells and an equal number of RAMP3+/+ or RAMP3-/- CAFs (total $2 \times 10^{6}$ cells) into RAMP3+/+ mice. In that model under those conditions, the liver tumor weights (Figure 4F) and incidence of liver metastasis (Figure 4G) were significantly lower with the RAMP3-/- CAF / PAN02 cell mixture than the RAMP3+/+ CAF / PAN02 cell mixture or PAN02 only. This further confirms our conclusion that RAMP3-/- CAFs suppress both tumor 
growth and metastasis. It thus appears that RAMP3 deficiency in CAFs suppresses tumor progression both in vitro and in vivo.

\section{RAMP3-/- myofibroblasts show altered cellular morphology and gene expression}

Continuing to focus on the changes to RAMP3-/- fibroblasts, we observed that aSMA expression was decreased in cultured CAFs (Figure 5A) and MEFs (Figure 5B) from RAMP3-/- mice. Levels of another myofibroblast marker, SM22 $\alpha$, were also reduced in CAFs (Figure 5C) and MEFs (Figure 5D) from RAMP3-/- mice.

Given the reduced migration of RAMP3-/- CAFs, we hypothesized that RAMP3 deletion from CAFs influences actin cytoskeleton formation. To test this idea, we examined the F-actin distribution in both CAFs (Figure 5E) and MEFs (Figure 5F). Cytoplasmic actin bundle formation was diminished, while cortical actin ring formation under the plasma membrane was enhanced in RAMP3-/- myofibroblasts. Quantification of the central actin fiber density revealed it to be significantly reduced in RAMP3-/- MEFs (Supplementary Figure 5). These cellular modifications may partly explain the reduced migration and malignancy in RAMP3-/- mice.

CAFs release a variety of growth factor known to influence tumor invasion/metastasis, we therefore carried out a comprehensive gene expression analysis of RAMP3+/+ and RAMP3-/- CAFs (Figure 5G, Supplementary Figure 6). RAMP3-/- CAFs showed upregulation of tumor suppressors (Inhbb and Bmp10)[29, 30], while tumor promoters ( $\mathrm{Bmp} 7$ and $\operatorname{Igf1}$ ) and an epithelial-mesenchymal transition 
(EMT) inducer $(F g f 4)[31-33]$ were downregulated. This gene expression profile further supports the idea that RAMP3-/- CAFs have lower malignant potential.

\section{Reduction of RAMP3 suppresses PDPN expression and p-Src/Cas signaling}

Our findings suggest PDPN expression is reduced in CAFs from RAMP3-/mice, which may reduce tumor malignancy, whereas compensatory upregulation of RAMP3 and PDPN in DI-E-RAMP2-/- CAFs may enhance tumor malignancy. We also found that PDPN is downregulated in RAMP3-/- MEFs (Figure 6A) and CAFs (Supplementary Figure 2B, right). This prompted us to speculate that PDPN expression is mediated via the AM-RAMP3 system. Consistent with that idea, knocking down RAMP3 expression by transfecting RAMP3+/+ MEFs with RAMP3 siRNA significantly decreased expression of not only RAMP3 but also PDPN $24 \mathrm{~h}$ after transfection (Figure 6B).

PDPN reportedly exerts effects downstream of Src and Cas by activating RhoA, which is involved in cytoskeletal remodeling and mediates EMT [34, 35]. We therefore used Western blotting to assess levels of Src and Cas. As shown in Figure 6C, levels of both p-Src and total Cas in subcutaneously transplanted tumor tissues (mixture of CAFs and PAN02 cells) were significantly decreased in RAMP3-/-. A similar result was obtained with RAMP3-/- MEFs cultured in medium conditioned by PAN02 cells (Figure 6D). Taken together, these results suggest the decreased malignancy in RAMP3-/- is mediated by downregulation of $\mathrm{p}-\mathrm{Src} / \mathrm{Cas} / \mathrm{PDPN}$ signaling. 
RAMP3 deficiency suppresses metastasis by modulating CAF

\section{Activation of the AM-RAMP2 system and inhibition of AM-RAMP3 system suppresses metastasis and tumor growth}

The results summarized above suggest that activation of the AM-RAMP2 system and inhibition of AM-RAMP3 system can suppress tumor malignancy. In that case, activation of the AM-RAMP2 system in RAMP3-/- mice using exogenously administered AM should further suppress tumor malignancy. Using subcutaneously implanted osmotic pumps, recombinant AM was continuously administered to mice beginning 1 day prior to tumor cell transplantation into the spleen. As is shown in Figure 7A, the metastasis rate was lower among RAMP3-/- mice treated with AM than among untreated RAMP3-/- mice. The weights of tumors at both the injection sites and the metastatic sites were also lower in RAMP3-/- mice treated with AM than in intreated RAMP3-/- mice (Figure 7B). In addition, levels of PDPN and S100A8/9 expression in the tumor periphery were significantly lower in RAMP3-/- mice treated with AM than in untreated RAMP3-/- mice (Figure 7C). These results clearly indicate that selective activation of the AM-RAMP2 system and inhibition of the AM-RAMP3 system suppresses the malignant phenotype of the tumor. 
RAMP3 deficiency suppresses metastasis by modulating CAF

\section{Discussion}

At present, tumor metastasis continues to be responsible for the majority of cancer-related deaths, and there is an unmet medical need for more effective strategies to prevent and treat metastatic cancer. Nojiri et al reported that atrial natriuretic peptide (ANP), previously defined as a vasodilating and natriuretic peptide, prevents cancer metastasis by modulating the activity of endothelial cells [36]. This suggests that bioactive molecules in the cardiovascular system, which, up to now, have not been noticed in the field of cancer research, could be novel therapeutic targets in cancer metastasis.

Like ANP, AM was originally identified as a vasodilating peptide. However, AM and its receptor modifying proteins, RAMPs, have been detected in cancers of the lung [17], breast [18], and pancreas [19, 20]. Given the angiogenic functions of AM, its role in tumor angiogenesis has attracted attention [37]. Ouafik et al. reported that blockade of AM or its receptor using specific antibodies suppresses tumor cell proliferation and tumor growth in human tumor xenografts in mice [38, 39]. Tumor growth was also suppressed due to poorer angiogenesis in $\mathrm{AM}+/-$ mice [40]. Nevertheless, a limitation of these studies is that they only evaluated local growth of implanted tumors; the effect of AM on tumor metastasis had remained unexplored.

Our previous study revealed the stimulatory effect of AM-RAMP2 on tumor angiogenesis, but its suppression of tumor metastasis [22]. We also showed that by destabilizing the vascular structure and inducing inflammation, RAMP2 deletion promotes formation of pre-metastatic niches within distant organs. The results we 
RAMP3 deficiency suppresses metastasis by modulating CAF

obtained with DI-E-RAMP2-/- mice in the present study are identical to those we obtained previously - i.e., liver metastasis was increased while growth of the tumors at the injection sites were suppressed in DI-E-RAMP2-/- mice [22]. That earlier study focused on the mechanism underlying formation of the pre-metastatic niches that support the enhanced metastasis seen in DI-E-RAMP2-/- mice. We found that in DI-E-RAMP2-/- mice, upregulated S100A8/9 act as tumor chemoattractants and trigger pre-metastatic niche formation $[27,28]$. In the present study, we also found upregulation of S100A8/9 in the periphery of metastatic liver tumors in DI-E-RAMP2-/- mice, which indicates that pre-metastatic niche formation is also involved in enhancing liver metastasis.

We also focused on the enhanced fibrosis and obvious upregulation of RAMP3 and PDPN in the tumor periphery in DI-E-RAMP2-/- mice. Fibrosis can contribute to scar tissue formation and organ dysfunction, and is strongly linked to cancer for its impact on tumorigenesis and metastasis [41-43]. We speculated that fibrosis is another major contributor to the enhanced tumor malignancy in DI-E-RAMP2-/- mice.

Fibroblasts, or CAFs in cancer, are the primary mediators of fibrosis $[12,41,44]$. Pancreatic tumors contain high numbers of CAFs [45], and many of the cancer-promoting and therapy-resistant properties of the disease can be attributed to the activity of CAFs $[41,46]$.

Although there is currently no marker that completely and exclusively defines CAFs, $\alpha \mathrm{SMA}$ is recognized as a robust CAF marker, and is the marker usually used to identify CAFs [47]. Upon stimulation, fibroblasts proliferate and differentiate into 
RAMP3 deficiency suppresses metastasis by modulating CAF

myofibroblasts, a process associated with de novo expression of $\alpha$ SMA [41]. The induced $\alpha$ SMA expression alters cytoskeletal organization, increasing the migration ability of myofibroblasts [48].

Because the small type-1 transmembrane sialomucin-like glycoprotein PDPN is expressed on lymphatic but not on blood vessel endothelium, it is widely used as a specific marker for lymphatic endothelial cells and lymphangiogenesis [49]. On the other hand, PDPN contributes to a signaling pathway mediating cell migration and invasion in vivo and in vitro [50]. Expression of PDPN is upregulated in a number of human cancers $[50,51]$. We found that expression of both RAMP3 and PDPN is significantly enhanced in pancreatic tumor tissue as compared with normal tissues, which is consistent with earlier studies $[52,53]$. This suggests elevated RAMP3 and PDPN levels in the tumor periphery play a protumorigenic role in DI-E-RAMP2-/mice. Interestingly, the presence of PDPN-expressing CAFs is reportedly associated with poorer prognosis in cancers patients [9-11]. Induction of PDPN expression is thought to result in multiple adjustments of intracellular signaling pathways, leading to the modulation of Rho family GTPase activities, the phosphorylation of ERM proteins (ezrin, radixin, moesin), rearrangement of the actin cytoskeleton, and enhanced cell migration and invasion [50, 54].

The PAN02 pancreatic cancer cells used here do not express PDPN, but high PDPN expression was detected in the tumor periphery. This suggests PDPN expression can be attributed mainly to CAFs. This was confirmed by the observation that $\alpha$ SMA and PDPN nearly always colocalized within cells. We therefore suggest 
RAMP3 deficiency suppresses metastasis by modulating CAF

that PDPN-expressing CAFs observed at metastasis sites contribute to the enhanced malignancy seen in DI-E-RAMP2-/- mice. Consistent with that idea, in the tumor periphery in RAMP3-/- mice, where tumor metastasis was significantly diminished, the number of PDPN-expressing CAFs was correspondingly reduced, as were the levels of PDPN and aSMA gene expression.

To further evaluate the roles of RAMP3 in CAFs, we cultured primary CAFs from RAMP3-/- mice to test the effect of RAMP3 deficiency on tumor cell migration, proliferation and metastasis in co-cultures with tumor cells in vitro and in vivo. We found that migration and proliferation was reduced in RAMP3-/- CAFs cocultured with PAN02 cells. Similarly, RAMP3-/- MEFs cultured in medium conditioned by PAN02 cells exhibited less migration. It is also noteworthy that tumor weight of RAMP3-/- CAF/PAN02 cell mixture transplanted into RAMP3+/+ mice was significantly lower than in the RAMP3+/+ CAF/PAN02 or PAN02 only group. Thus, RAMP3 deficiency in the transplanted CAFs contributes to reducing tumor growth and metastasis.

EMT plays a critical role in cancer progression and metastasis by causing cells to lose adhesion and gain a capacity for migration $[55,56]$. An important hallmark of EMT is an increase in cell motility with actin cytoskeletal rearrangement. Cytoskeletal reorganization is the key mechanical feature that drives the morphology change and invasive properties of metastatic cells [57]. In a similar vein, we found that actin polymerization in RAMP3-/- myofibroblasts was in disarray, with decreased cytoplasmic actin bundle formation but enhanced cortical actin ring formation under 
RAMP3 deficiency suppresses metastasis by modulating CAF

the plasma membrane. These cellular modifications may explain the decreased migration and malignancy of CAFs from RAMP3-/- mice. In addition, knocking down RAMP3 in MEFs was associated with a corresponding suppression of PDPN expression. It has been reported that PDPN acts downstream of Src and

Crk-associated substrate (Cas), and activates RhoA, which is involved in cytoskeletal remodeling $[34,35]$. Our findings thus suggest Src/Cas/PDPN signaling is mediated by RAMP3.

In the final part of our study, we evaluated the effect of administering AM to RAMP3-/- mice. This enabled selective activation of AM-RAMP2 against a background of AM-RAMP3 deficiency. The metastasis rate, tumor weights at the injection and metastatic sites, and level of PDPN expression were all was lower in RAMP3-/- mice treated with AM than untreated RAMP3-/- mice. This is consistent with our earlier finding that endothelial cell-specific RAMP2 overexpression reduced lung metastasis and promoted survival in a mouse lung metastasis model [22]. We therefore propose that AM-RAMP systems are effective therapeutic targets for controlling metastatic disease. Because RAMP is a low molecular weight protein, structural analysis and synthesis of specific agonists or antagonists are much more feasible than with CLR, which is a seven-transmembrane domain GPCR. In that context, our findings provide a clear rationale for development of drugs to selectively modulate each RAMP subisoform.

A limitation of the present study is that we used endothelial cell-specific RAMP2-/- mice but conventional RAMP3-/- mice. This is because conventional 
RAMP3 deficiency suppresses metastasis by modulating CAF

RAMP2-/- mice die in utero. We anticipate that future analyses using additional tissue type-specific knockout mice will further clarify the roles of AM-RAMP systems in cancer metastasis.

Figure 8 summarizes the actions and therapeutic potential of the AM-RAMP2 and 3 systems. PDPN expression and tumor malignancy were reduced in RAMP3-/mice, whereas compensatory upregulation of RAMP3 and PDPN in DI-E-RAMP2-/mice enhanced tumor malignancy. Selective activation of RAMP2 and inhibition of RAMP3 is expected to suppress tumor metastasis. Future studies focusing on examining expression of AM-RAMP systems in cancer patients along with parallel molecular studies to investigate in more detail the mechanisms underlying the effects AM-RAMP signaling on tumor development are still needed. We anticipate that these studies will reveal AM-RAMP systems to be promising therapeutic targets and novel prognostic biomarkers for human cancers. 
RAMP3 deficiency suppresses metastasis by modulating CAF

\section{Materials and Methods}

\section{Generation of gene-engineered mice}

Tamoxifen drug-inducible (DI) vascular endothelial cell-specific RAMP2 knockout (DI-E-RAMP2-/-) and RAMP3 knockout (RAMP3-/-) mice were previously generated in our group $[22,58,59]$. The following mice were used in this study: 8 - to 9-week-old male DI-E-RAMP2-/-, control, RAMP3-/- and RAMP3+/+ mice. The background of all the mice used in this study was C57BL/6J. All mice were maintained according to a strict procedure under specific pathogen-free conditions in an environmentally controlled $\left(12 \mathrm{~h}\right.$ light/dark cycle; room temperature, $22 \pm 2^{\circ} \mathrm{C}$ ) breeding room at the Division of Laboratory Animal Research, Department of Life Science, Research Center for Human and Environmental Sciences, Shinshu University. All animal experiments were conducted in accordance with the ethical guidelines of Shinshu University. All animal handling procedures were performed in accordance with protocols approved by the Ethics Committee for Animal Care at Shinshu University.

\section{Cell culture}

The PAN02 murine pancreatic adenocarcinoma cell line was purchased from the Frederick National Laboratory for Cancer Research (Frederick, MD). PAN02 cells were maintained in RPMI 1640 (Wako, Osaka, Japan) supplemented with 10\% fetal bovine serum (FBS) (Thermo Fisher Scientific, Waltham, MA) and 1\% 
RAMP3 deficiency suppresses metastasis by modulating CAF

penicillin-streptomycin (Thermo Fisher Scientific). Cell cultures were maintained in a humidified incubator at $37^{\circ} \mathrm{C}$ under $5 \% \mathrm{CO}_{2}$.

\section{Spontaneous liver metastasis model}

Before the operative procedures, mice were anesthetized through intraperitoneal injection of a combination anesthetic that included $0.3 \mathrm{mg} / \mathrm{kg}$ medetomidine (Nippon Zenyaku Kogyo Co. Ltd., Koriyama Japan), 4.0 mg/kg midazolam (Astellas Pharma Inc. Tokyo Japan) and $5.0 \mathrm{mg} / \mathrm{kg}$ butorphanol (Meiji Seika Pharma Co. Ltd., Tokyo Japan). Thereafter, $2 \times 10^{6}$ PAN02 cells in $50 \mu$ of Hank's balanced salt solution (HBSS) were implanted in the spleens of the anesthetized mice. Three to four weeks after the operation, the mice were sacrificed and examined for liver metastasis. The spleen (tumor cell injection site) and liver (metastatic site) were removed from each mouse, weighed and used for later experiments.

\section{Subcutaneous tumor cell transplantation}

PAN02 cells $\left(2 \times 10^{6}\right)$ were suspended in $100 \mu$ of HBSS and subcutaneously injected into bilateral axillary regions of mice. After 5 weeks, the mice were sacrificed and the tumors were collected for analysis.

Primary CAFs were collected from mice, after which $1 \times 10^{6}$ CAFs were mixed with $1 \times 10^{6}$ PAN02 cells in $100 \mu 1$ of HBSS and subcutaneously injected into the bilateral axillary regions of mice. After 5 weeks, the mice were sacrificed and the tumors were collected for analysis. 
RAMP3 deficiency suppresses metastasis by modulating CAF

\section{Administration of AM to mice}

AM was administered as described previously [60]. Mice in the AM-treated group received continuous subcutaneous administration of recombinant human AM (Peptide Institute, Inc., Osaka, Japan) in saline at a delivery rate of $0.05 \mu \mathrm{g} / \mathrm{kg} / \mathrm{min}$ using osmotic pumps (Alzet; DURECT Co, Cupertino, CA). AM administration began 1 day before tumor cell implantation and continued for 4 weeks.

\section{Histology}

Tissues were fixed overnight in 10\% paraformaldehyde and embedded in paraffin, after which they were cut into 5 - $\mu$ m-thick sections. The sections were then deparaffinized for hematoxylin/eosin (H\&E) and Masson trichrome staining and immunohistochemistry. Immunostaining was performed using anti-CD34 (Abcam, Cambridge, England), anti- $\alpha$ SMA (Abcam), anti-FSP-1 (Millipore, Burlington, MA), anti-CK19 (Abcam), anti-E-cadherin (Gene Tex, Irvine, CA), anti-vimentin (Abcam), anti-SM22 $\alpha$ (Abcam), and anti-PDPN (Fitzgerald Industries International, Acton, MA) antibodies followed by Alexa Fluor 488- or 568-conjugated anti-rabbit and anti-hamster secondary antibodies (Thermo Fisher Scientific). For immunostaining using anti-Ki67 antibody (Abcam), a biotin-conjugated secondary antibody and 3,3'-diaminobenzidine (DAB) (Histofine kit, Nichirei, Tokyo, Japan) were used to visualize labeling, and the nuclei were counterstained with hematoxylin. The area of 
RAMP3 deficiency suppresses metastasis by modulating CAF

interest was quantified using the BZ-H3C module with a BZ-X710 microscope (KEYENCE).

Intracellular actin filaments were stained using rhodamine phalloidin (Thermo Fisher Scientific), and nuclei were stained using DAPI (Thermo Fisher Scientific). Fluorescence was observed using a KEYENCE model BZ-X710 fluorescence microscope (Osaka, Japan) equipped with the appropriate filter sets. Fluorescence intensities were measured as described previously [61]. Additional quantification of central actin fiber density was performed using Image $J$ as described previously [62] with some modification - i.e., a line was drawn through the cell centers (excluding cortical actin at cell contacts), across which the density ratio was determined.

\section{Quantitative real-time RT-PCR analysis}

Quantitative real-time RT-PCR was carried out using an Applied Biosystems 7300 real-time PCR System (Thermo Fisher Scientific) with SYBR green (Toyobo, Osaka, Japan) or Realtime PCR Master Mix (Toyobo) and TaqMan probes (MBL, Nagoya, Japan). The primers and probes used are listed in Table 1. Values were normalized to mouse GAPDH (Pre-Developed TaqMan assay reagents (Thermo Fisher Scientific).

\section{Real-time RT-PCR array analysis}

RT-PCR array analysis was performed as described previously [63]. A PCR array (RT2 Profiler PCR Array; Qiagen, Hilden, Germany) was used to assess expression of 
RAMP3 deficiency suppresses metastasis by modulating CAF

a focused panel of genes. After $1 \mathrm{mg}$ of total RNA was converted to cDNA using a RT2 First Strand Kit (Qiagen), levels of specific transcripts were assessed using a Mouse Growth Factors PCR Array (Qiagen) according to the manufacturer's protocols. All PCRs were run on a StepOnePlus Real-Time PCR System (Thermo Fisher Scientific). RT2 Profiler PCR Array data were analyzed using RT2 Profiler Array Data Analysis version 3.5 software (Thermo Fisher Scientific).

\section{Western blotting}

Western blot analysis was carried out using protein extracts from tumor samples and cells. The lysates were subjected to electrophoresis using TGX gel (Bio-Rad Laboratories), transferred to PVDF membranes (Bio-Rad Laboratories), and probed using anti-Src, anti-phospho-Src (p-Src) (Cell Signaling Technology, Danvers, MA) and anti-Cas (Santa Cruz Biotechnology, Dallas, TX) antibodies. Anti- $\beta$-actin antibody (Abcam) served as a loading control. The blots were developed using an ImageQuant LAS 4000 (GE Healthcare, Chicago, IL).

\section{Primary culture}

Mouse embryonic fibroblasts (MEFs) from RAMP3+/+ or RAMP3-/- mice were obtained as described previously [64]. Mouse embryos were isolated between E15 and E18. After the heads, tails, limbs, and most of the internal organs were removed, the embryos were minced and trypsinized for $20 \mathrm{~min}$. The tissue was then seeded into 10-cm dishes in $10 \mathrm{ml}$ of Dulbecco's modified Eagle's medium (DMEM) 
RAMP3 deficiency suppresses metastasis by modulating CAF

supplemented with $10 \%$ FBS. The cells were split at a ratio of 1:2-1:3 when freshly confluent, passaged two or three times to obtain a morphologically homogenous culture, and then frozen or expanded for further studies. Passages 2-4 were used in subsequent studies. MEFs were maintained in DMEM supplemented with 10\% FBS and $1 \%$ penicillin-streptomycin.

CAFs from RAMP3+/+ or RAMP3-/- mice were established as described previously [65]. Fresh samples collected from a peripheral metastatic site 3 weeks after PAN02 cell transplantation were washed with serum-free DMEM/F-12 medium (Wako) and finely minced into small pieces of approximately $0.2 \times 0.2 \mathrm{~mm}$. The minced tissue was incubated for $24 \mathrm{~h}$ in fresh culture medium to allow attachment to the culture plate. After removing the unattached tissue, the remaining samples were allowed to grow on the plate for 2-3 weeks. During this period, the medium was replenished every 2 days until the fibroblasts started to grow out of the tissue. To ensure there was no contamination by other cell types prior to their use in experiments, the putative CAFs were tested to confirm that $>90 \%$ stained positively for the fibroblast markers aSMA, fibroblast-specific protein-1 (FSP-1) and vimentin, and were negative for the epithelial cell marker E-cadherin. CAFs with no more than 5 passages were used for experiments. CAFs were maintained in DMEM/F-12 supplemented with $10 \%$ FBS and 1\% penicillin-streptomycin.

\section{Conditioned medium}

Cancer cells or CAFs were grown as described above to $80 \%-90 \%$ confluency in 
RAMP3 deficiency suppresses metastasis by modulating CAF

10-cm plates, rinsed with phosphate buffered saline (PBS), then cultured in DMEM supplemented with $2.5 \%$ FBS. Medium collected from PAN02 cells or CAFs after incubation for $48 \mathrm{~h}$ was centrifuged for $10 \mathrm{~min}$ at 5000 r.p.m. to remove cell debris, then stored at $-80^{\circ} \mathrm{C}$ for later experiments. Medium from PAN02 cells or CAFs mixed (1:1) with fresh DMEM supplemented with 10\% FBS was used as conditioned medium (CM).

\section{Scratch assay}

For scratch assays, mixtures of CAFs and PAN02 cells (1:1) or PAN02 cells only were plated in 6-well plates at $5 \times 10^{5}$ cells/well and grown into a monolayer. Alternatively, MEFs were plated in 6-well plates at $2 \times 10^{5}$ cells/well and grown into a monolayer. The assay was performed as described previously [66]. Briefly, a linear scratch/wound was made on the cell monolayers using a sterile pipette.

Photomicrographs were taken of live cells at 100x magnification, and the distance migrated was observed within an appropriate time. In some instances, $10 \mu \mathrm{g} / \mathrm{ml}$ mitomycin C (Kyowa Kirin, Tokyo, Japan) was added to the medium to block cell proliferation, enabling selective evaluation of cell migration only. Experiments were performed 3 times independently.

\section{SiRNA transfection}

MEFs were transfected with siRNA as described previously [67]. In brief, on the day before use in experiments, MEFs were seeded into a 96-well plate at a density of 
RAMP3 deficiency suppresses metastasis by modulating CAF

$5 \times 10^{3}$ cells/well. Twenty four hours later, the cells were treated with $1 \mu \mathrm{M}$

RAMP3-siRNA oligos (CGUGUAUUAUGAAAGCUUC,

CUCGGUUCCCUAGUUUCUA, GGACCAGGCAUGGAAAUCA,

UGUUGCUGCUUUGUGGUGA) in $100 \mu$ of Accell siRNA Delivery Media (GE

Healthcare Dharmacon, Lafayette CO). Cells in Accell siRNA Delivery Media

without siRNA treatment were used as an experimental control. After $24 \mathrm{~h}$ of

transfection, cells were harvested and silencing analyses were performed.

\section{Statistical analysis}

Statistical analysis was performed using The SPSS 17.0 software package (IBM, Armonk, NY). Values are expressed as means \pm SEM. The Mann-Whitney U test, Student's t-test or $\chi^{2}$ test was used to evaluate the significance of differences. Values of $\mathrm{P}<0.05$ were considered significant. 
RAMP3 deficiency suppresses metastasis by modulating CAF

\section{Acknowledgement}

This study was supported by Grants-in-Aid for Scientific Research (KAKENHI) from the Core Research for Evolutionary Science and Technology (CREST) of Japan Science and Technology Agency (JST) and the Japan Agency for Medical Research and Development (AMED), and research grants from Bristol-Myers Squibb Company, Japan Foundation for Applied Enzymology, the Naito Foundation, the Public Foundation of Chubu Science and Technology Center, Yamaguchi Endocrine Research Foundation, Hoyu Science Foundation, Takahashi Industrial and Economic Research Foundation, Akaeda Medical Research Foundation, Shinshu Public Utility Foundation for Promotion of Medial Sciences, and Japan Heart Foundation.

Kun Dai received a scholarship from Otsuka Toshimi Scholarship Foundation. The authors are grateful to Professor Sachie Hiratsuka for valuable comments and tumor cells.

\section{Compliance with ethical standards}

All animal experiments were conducted in accordance with the ethical guidelines of Shinshu University. All animal handling procedures were performed in accordance with protocols approved by the Ethics Committee for Animal Care at Shinshu University.

\section{Competing Interests}

The authors declare that they have no conflict of interest. 


\section{References}

1 Steeg PS. Tumor metastasis: mechanistic insights and clinical challenges. Nat Med 2006; 12: 895-904.

2 Komohara Y, Takeya M. CAFs and TAMs: maestros of the tumour microenvironment. J Pathol 2017; 241: 313-315.

3 Marusyk A, Tabassum DP, Janiszewska M, Place AE, Trinh A, Rozhok AI et al. Spatial Proximity to Fibroblasts Impacts Molecular Features and Therapeutic Sensitivity of Breast Cancer Cells Influencing Clinical Outcomes. Cancer Res 2016; 76: 6495-6506.

4 Ren Y, Jia HH, Xu YQ, Zhou X, Zhao XH, Wang YF et al. Paracrine and epigenetic control of CAF-induced metastasis: the role of HOTAIR stimulated by TGF-ss1 secretion. Mol Cancer 2018; 17: 5.

5 Koukourakis MI, Kalamida D, Mitrakas AG, Liousia M, Pouliliou S, Sivridis E et al. Metabolic cooperation between co-cultured lung cancer cells and lung fibroblasts. Lab Invest 2017; 97: 1321-1331.

6 Yoshida $\mathrm{T}$, Ishii $\mathrm{G}$, Goto $\mathrm{K}$, Neri $\mathrm{S}$, Hashimoto $\mathrm{H}$, Yoh $\mathrm{K}$ et al. Podoplanin-positive cancer-associated fibroblasts in the tumor microenvironment induce primary resistance to EGFR-TKIs in lung adenocarcinoma with EGFR mutation. Clin Cancer Res 2015; 21: 642-651.

7 Dauer P, Zhao X, Gupta VK, Sharma N, Kesh K, Gnamlin P et al. Inactivation of Cancer-Associated-Fibroblasts Disrupts Oncogenic Signaling in Pancreatic Cancer Cells and Promotes Its Regression. Cancer Res 2018; 78: 1321-1333.

8 Zhang D, Li L, Jiang H, Li Q, Wang-Gillam A, Yu J et al. Tumor-Stroma IL1beta-IRAK4 Feedforward Circuitry Drives Tumor Fibrosis, Chemoresistance, and Poor Prognosis in Pancreatic Cancer. Cancer Res 2018; 78: $1700-1712$.

9 Schoppmann SF, Berghoff A, Dinhof C, Jakesz R, Gnant M, Dubsky P et al. Podoplanin-expressing cancer-associated fibroblasts are associated with poor prognosis in invasive breast cancer. Breast Cancer Res Treat 2012; 134 : 237-244.

10 Neri S, Ishii G, Hashimoto $\mathrm{H}$, Kuwata $\mathrm{T}$, Nagai $\mathrm{K}$, Date $\mathrm{H}$ et al. Podoplanin-expressing cancer-associated fibroblasts lead and enhance the local invasion of cancer cells in lung adenocarcinoma. Int J Cancer 2015; 137 : 784-796. 
11 Shindo K, Aishima S, Ohuchida K, Fujiwara K, Fujino M, Mizuuchi Y et al. Podoplanin expression in cancer-associated fibroblasts enhances tumor progression of invasive ductal carcinoma of the pancreas. Mol Cancer 2013; 12: 168 .

12 Kalluri R. The biology and function of fibroblasts in cancer. Nat Rev Cancer 2016; 16: 582-598.

13 Shindo T, Tanaka M, Kamiyoshi A, Ichikawa-Shindo Y, Kawate H, Yamauchi A et al. Regulation of cardiovascular development and homeostasis by the adrenomedullin-RAMP system. Peptides 2019; 111: 55-61.

14 McLatchie LM, Fraser NJ, Main MJ, Wise A, Brown J, Thompson N et al. RAMPs regulate the transport and ligand specificity of the calcitonin-receptor-like receptor. Nature 1998; 393: 333-339.

15 Sexton PM, Albiston A, Morfis M, Tilakaratne N. Receptor activity modifying proteins. Cell Signal 2001; 13: 73-83.

16 Sexton PM, Morfis M, Tilakaratne N, Hay DL, Udawela M, Christopoulos G et al. Complexing receptor pharmacology: modulation of family B G protein-coupled receptor function by RAMPs. Annals of the New York Academy of Sciences (Research Support, Non-U.S. Gov't Review) 2006; 1070: 90-104.

17 Miller MJ, Martinez A, Unsworth EJ, Thiele CJ, Moody TW, Elsasser T et al. Adrenomedullin expression in human tumor cell lines. Its potential role as an autocrine growth factor. J Biol Chem 1996; 271: 23345-23351.

18 Siclari VA, Mohammad KS, Tompkins DR, Davis H, McKenna CR, Peng X et al. Tumor-expressed adrenomedullin accelerates breast cancer bone metastasis. Breast Cancer Res 2014; 16: 458.

19 Ramachandran V, Arumugam T, Hwang RF, Greenson JK, Simeone DM, Logsdon CD. Adrenomedullin is expressed in pancreatic cancer and stimulates cell proliferation and invasion in an autocrine manner via the adrenomedullin receptor, ADMR. Cancer Res 2007; 67: 2666-2675.

20 Ramachandran V, Arumugam T, Langley R, Hwang RF, Vivas-Mejia P, Sood $\mathrm{AK}$ et al. The ADMR receptor mediates the effects of adrenomedullin on pancreatic cancer cells and on cells of the tumor microenvironment. PLoS One 2009; 4: e7502.

21 Koyama T, Ochoa-Callejero L, Sakurai T, Kamiyoshi A, Ichikawa-Shindo Y, 
Iinuma $\mathrm{N}$ et al. Vascular endothelial adrenomedullin-RAMP2 system is essential for vascular integrity and organ homeostasis. Circulation 2013; 127 : 842-853.

22 Tanaka M, Koyama T, Sakurai T, Kamiyoshi A, Ichikawa-Shindo Y, Kawate H et al. The endothelial adrenomedullin-RAMP2 system regulates vascular integrity and suppresses tumour metastasis. Cardiovasc Res 2016; 111: 398-409.

23 Ugorski M, Dziegiel P, Suchanski J. Podoplanin - a small glycoprotein with many faces. Am J Cancer Res 2016; 6: 370-386.

24 Suchanski J, Tejchman A, Zacharski M, Piotrowska A, Grzegrzolka J, Chodaczek $\mathrm{G}$ et al. Podoplanin increases the migration of human fibroblasts and affects the endothelial cell network formation: A possible role for cancer-associated fibroblasts in breast cancer progression. PLoS One 2017; 12: e0184970.

25 Hirayama K, Kono H, Nakata Y, Akazawa Y, Wakana H, Fukushima H et al. Expression of podoplanin in stromal fibroblasts plays a pivotal role in the prognosis of patients with pancreatic cancer. Surg Today 2018; 48: 110-118.

26 Desmouliere A, Darby IA, Gabbiani G. Normal and pathologic soft tissue remodeling: role of the myofibroblast, with special emphasis on liver and kidney fibrosis. Lab Invest 2003; 83: 1689-1707.

27 Hiratsuka S, Watanabe A, Aburatani H, Maru Y. Tumour-mediated upregulation of chemoattractants and recruitment of myeloid cells predetermines lung metastasis. Nat Cell Biol 2006; 8: 1369-1375.

28 Hiratsuka S, Watanabe A, Sakurai Y, Akashi-Takamura S, Ishibashi S, Miyake $\mathrm{K}$ et al. The S100A8-serum amyloid A3-TLR4 paracrine cascade establishes a pre-metastatic phase. Nat Cell Biol 2008; 10: 1349-1355.

29 Zou G, Ren B, Liu Y, Fu Y, Chen P, Li X et al. Inhibin B suppresses anoikis resistance and migration through the transforming growth factor-beta signaling pathway in nasopharyngeal carcinoma. Cancer Sci 2018; 109: 3416-3427.

30 Ye L, Bokobza S, Li J, Moazzam M, Chen J, Mansel RE et al. Bone morphogenetic protein-10 (BMP-10) inhibits aggressiveness of breast cancer cells and correlates with poor prognosis in breast cancer. Cancer Sci 2010; 101: 2137-2144.

31 Aoki M, Ishigami S, Uenosono Y, Arigami T, Uchikado Y, Kita Y et al. 
Expression of BMP-7 in human gastric cancer and its clinical significance. $\mathrm{Br}$ J Cancer 2011; 104: 714-718.

32 Zhang XH, Jin X, Malladi S, Zou Y, Wen YH, Brogi E et al. Selection of bone metastasis seeds by mesenchymal signals in the primary tumor stroma. Cell 2013; 154: 1060-1073.

33 Qi L, Song W, Li L, Cao L, Yu Y, Song C et al. FGF4 induces epithelial-mesenchymal transition by inducing store-operated calcium entry in lung adenocarcinoma. Oncotarget 2016; 7: 74015-74030.

34 Inoue $\mathrm{H}$, Miyazaki Y, Kikuchi K, Yoshida N, Ide F, Ohmori Y et al. Podoplanin promotes cell migration via the EGF-Src-Cas pathway in oral squamous cell carcinoma cell lines. J Oral Sci 2012; 54: 241-250.

35 Nakashima Y, Yoshinaga K, Kitao H, Ando K, Kimura Y, Saeki H et al. Podoplanin is expressed at the invasive front of esophageal squamous cell carcinomas and is involved in collective cell invasion. Cancer Sci 2013; 104 : 1718-1725.

36 Nojiri T, Hosoda H, Tokudome T, Miura K, Ishikane S, Otani K et al. Atrial natriuretic peptide prevents cancer metastasis through vascular endothelial cells. Proc Natl Acad Sci U S A 2015; 112: 4086-4091.

37 Shindo T, Kurihara Y, Nishimatsu H, Moriyama N, Kakoki M, Wang Y et al. Vascular abnormalities and elevated blood pressure in mice lacking adrenomedullin gene. Circulation 2001; 104: 1964-1971.

38 Berenguer-Daize C, Boudouresque F, Bastide C, Tounsi A, Benyahia Z, Acunzo $\mathrm{J}$ et al. Adrenomedullin blockade suppresses growth of human hormone-independent prostate tumor xenograft in mice. Clin Cancer Res 2013; 19: 6138-6150.

39 Kaafarani I, Fernandez-Sauze S, Berenguer C, Chinot O, Delfino C, Dussert C et al. Targeting adrenomedullin receptors with systemic delivery of neutralizing antibodies inhibits tumor angiogenesis and suppresses growth of human tumor xenografts in mice. FASEB J 2009; 23: 3424-3435.

40 Iimuro S, Shindo T, Moriyama N, Amaki T, Niu P, Takeda N et al. Angiogenic effects of adrenomedullin in ischemia and tumor growth. Circ Res 2004; 95: 415-423.

41 Ohlund D, Elyada E, Tuveson D. Fibroblast heterogeneity in the cancer wound. J Exp Med 2014; 211: 1503-1523. 
42 Friedman SL, Sheppard D, Duffield JS, Violette S. Therapy for fibrotic diseases: nearing the starting line. Sci Transl Med 2013; 5: 167sr161.

43 Yazdani S, Bansal R, Prakash J. Drug targeting to myofibroblasts: Implications for fibrosis and cancer. Adv Drug Deliv Rev 2017; 121: 101-116.

44 Prakash J, Pinzani M. Fibroblasts and extracellular matrix: Targeting and therapeutic tools in fibrosis and cancer. Adv Drug Deliv Rev 2017; 121: 1-2.

45 Neesse A, Algul H, Tuveson DA, Gress TM. Stromal biology and therapy in pancreatic cancer: a changing paradigm. Gut 2015; 64: 1476-1484.

46 Hanahan D, Weinberg RA. Hallmarks of cancer: the next generation. Cell 2011; 144: 646-674.

47 Desmouliere A, Guyot C, Gabbiani G. The stroma reaction myofibroblast: a key player in the control of tumor cell behavior. Int J Dev Biol 2004; 48: 509-517.

48 Hinz B, Celetta G, Tomasek JJ, Gabbiani G, Chaponnier C. Alpha-smooth muscle actin expression upregulates fibroblast contractile activity. Mol Biol Cell 2001; 12: 2730-2741.

49 Breiteneder-Geleff S, Soleiman A, Kowalski H, Horvat R, Amann G, Kriehuber E et al. Angiosarcomas express mixed endothelial phenotypes of blood and lymphatic capillaries: podoplanin as a specific marker for lymphatic endothelium. Am J Pathol 1999; 154: 385-394.

50 Wicki A, Lehembre F, Wick N, Hantusch B, Kerjaschki D, Christofori G. Tumor invasion in the absence of epithelial-mesenchymal transition: podoplanin-mediated remodeling of the actin cytoskeleton. Cancer Cell 2006; 9: 261-272.

51 Schacht V, Dadras SS, Johnson LA, Jackson DG, Hong YK, Detmar M. Up-regulation of the lymphatic marker podoplanin, a mucin-type transmembrane glycoprotein, in human squamous cell carcinomas and germ cell tumors. Am J Pathol 2005; 166: 913-921.

52 Hikosaka T, Tsuruda T, Nagata S, Kuwasako K, Tsuchiya K, Hoshiko S et al. Adrenomedullin production is increased in colorectal adenocarcinomas; its relation to matrix metalloproteinase-9. Peptides 2011; 32: 1825-1831.

53 Nouguerede E, Berenguer C, Garcia S, Bennani B, Delfino C, Nanni I et al. 
RAMP3 deficiency suppresses metastasis by modulating CAF

Expression of adrenomedullin in human colorectal tumors and its role in cell growth and invasion in vitro and in xenograft growth in vivo. Cancer Med 2013; 2: 196-207.

54 Martin-Villar E, Megias D, Castel S, Yurrita MM, Vilaro S, Quintanilla M. Podoplanin binds ERM proteins to activate RhoA and promote epithelial-mesenchymal transition. J Cell Sci 2006; 119: 4541-4553.

55 Thiery JP. Epithelial-mesenchymal transitions in tumour progression. Nat Rev Cancer 2002; 2: 442-454.

56 Yang J, Weinberg RA. Epithelial-mesenchymal transition: at the crossroads of development and tumor metastasis. Dev Cell 2008; 14: 818-829.

57 Yilmaz M, Christofori G. EMT, the cytoskeleton, and cancer cell invasion. Cancer Metastasis Rev 2009; 28: 15-33.

58 Liu T, Kamiyoshi A, Tanaka M, Iida S, Sakurai T, Ichikawa-Shindo Y et al. RAMP3 deficiency enhances postmenopausal obesity and metabolic disorders. Peptides 2018; 110: 10-18.

59 Yamauchi A, Sakurai T, Kamiyoshi A, Ichikawa-Shindo Y, Kawate H, Igarashi $\mathrm{K}$ et al. Functional differentiation of RAMP2 and RAMP3 in their regulation of the vascular system. J Mol Cell Cardiol 2014; 77: 73-85.

60 Murakami S, Nagaya N, Itoh T, Iwase T, Fujisato T, Nishioka K et al. Adrenomedullin regenerates alveoli and vasculature in elastase-induced pulmonary emphysema in mice. Am J Respir Crit Care Med 2005; 172: 581-589.

61 Conner MT, Conner AC, Brown JE, Bill RM. Membrane trafficking of aquaporin 1 is mediated by protein kinase $\mathrm{C}$ via microtubules and regulated by tonicity. Biochemistry 2010; 49: 821-823.

62 Peacock JG, Miller AL, Bradley WD, Rodriguez OC, Webb DJ, Koleske AJ. The Abl-related gene tyrosine kinase acts through p190RhoGAP to inhibit actomyosin contractility and regulate focal adhesion dynamics upon adhesion to fibronectin. Mol Biol Cell 2007; 18: 3860-3872.

63 Hirabayashi K, Tanaka M, Imai A, Toriyama Y, Iesato Y, Sakurai T et al. Development of a Novel Model of Central Retinal Vascular Occlusion and the Therapeutic Potential of the Adrenomedullin-Receptor Activity-Modifying Protein 2 System. Am J Pathol 2019; 189: 449-466. 
RAMP3 deficiency suppresses metastasis by modulating CAF

64 Singhal PK, Sassi S, Lan L, Au P, Halvorsen SC, Fukumura D et al. Mouse embryonic fibroblasts exhibit extensive developmental and phenotypic diversity. Proc Natl Acad Sci U S A 2016; 113: 122-127.

65 Lau EY, Lo J, Cheng BY, Ma MK, Lee JM, Ng JK et al. Cancer-Associated Fibroblasts Regulate Tumor-Initiating Cell Plasticity in Hepatocellular Carcinoma through c-Met/FRA1/HEY1 Signaling. Cell Rep 2016; 15: $1175-1189$

66 Iesato Y, Toriyama Y, Sakurai T, Kamiyoshi A, Ichikawa-Shindo Y, Kawate H et al. Adrenomedullin-RAMP2 system is crucially involved in retinal angiogenesis. Am J Pathol 2013; 182: 2380-2390.

67 Raof NA, Rajamani D, Chu HC, Gurav A, Johnson JM, LoGerfo FW et al. The effects of transfection reagent polyethyleneimine (PEI) and non-targeting control siRNAs on global gene expression in human aortic smooth muscle cells. BMC Genomics 2016; 17: 20. 


\section{Figure Legend}

\section{Figure 1}

\section{Tumor growth and angiogenesis is suppressed while metastasis is enhanced in} DI-E-RAMP2-/- mice, with elevation of RAMP3 and PDPN at the metastatic site

A, Procedure for establishing tamoxifen drug-inducible (DI) vascular endothelial cell-specific RAMP2 knockout (DI-E-RAMP2-/-) mice and inducting the spontaneous liver metastasis model. B, Representative images and tumor weights at the tumor cell injection (spleen) and metastatic (liver) sites in control and DI-E-RAMP2-/- mice ( $\mathrm{n}=11$ for control and $\mathrm{n}=16$ for DI-E-RAMP2-/-). C, Spontaneous liver metastasis was enhanced in DI-E-RAMP2-/- mice relative to control 4 weeks after PAN02 cells were transplanted into the spleen ( $\mathrm{n}=23$ for control [metastasis rate: $48 \%$ ] and $n=20$ for DI-E-RAMP2-/- [metastasis rate: 80\%]). D, Angiogenesis in spleen tumors (upper panels) and liver tumors (lower panels) evaluated by fluorescently immunostaining for CD34 (green), a vascular endothelial cell marker, and DAPI (blue), a nuclear marker. Scale bars $=50 \mu \mathrm{m}$. CD34-postive / DAPI-positive area ratios in the sections are shown on the right ( $\mathrm{n}=9$ in spleen and $\mathrm{n}=7$ in liver). E, Quantitative real-time PCR analysis of AM-RAMP systems, PDPN, and CD34 in the splenic tumor (upper panel) ( $n=8$ for control and $n=13$ for DI-E-RAMP2-/-) and liver tumor (lower panel) $(n=11$ for control and $n=16$ for DI-E-RAMP2-/-). The mean of the control group was assigned a value of 1. F, Quantitative real-time PCR analysis of AM-RAMP systems and PDPN in the liver tumor core in control and DI-E-RAMP2-/- mice compared to a baseline group (normal liver) ( $\mathrm{n}=9$ each for the baseline groups, $\mathrm{n}=11$ for control and 
$\mathrm{n}=16$ for DI-E-RAMP2-/-). The mean of the baseline control groups was assigned a value of 1 . Bars are means $\pm \mathrm{SEM} . * \mathrm{P}<0.05, * * \mathrm{P}<0.01, * * * \mathrm{P}<0.001$. P-values were calculated using the Mann-Whitney $U$ test $(\mathbf{B}, \mathbf{D}, \mathbf{E}, \mathbf{F})$ and $\chi^{2}$ test $(\mathbf{C})$.

\section{Figure 2}

\section{Increased CAFs and expression of tumor chemoattractant factors in the liver}

\section{tumor periphery in DI-E-RAMP2-/- mice}

A, Representative photomicrographs of tumor peripheral tissues stained with Masson's trichrome stain: left, control; right, DI-E-RAMP2-/-. Fibrosis is stained blue; nuclei are purple-black. Scale bars $=100 \mu \mathrm{m}$. Ratios of the Masson's trichrome stained area / field in the sections are shown on the right ( $\mathrm{n}=10$ in each). B, Stromal fibroblasts in sections of liver tumor periphery exhibit characteristics of CAFs.

Fluorescent immunostaining of section of liver tumor periphery. $\alpha$ SMA (red), PDPN (green), DAPI (blue). Scale bars $=100 \mu \mathrm{m}$. Ratios of PDPN-positive or aSMA-positive / DAPI-positive area in the sections are shown on the right ( $\mathrm{n}=8$ for control and n=9 for DI-E-RAMP2-/-). C, Quantitative real-time PCR analysis of liver tumor periphery 3 weeks ( $\mathrm{n}=4$ for control and $\mathrm{n}=5$ for DI-E-RAMP2-/-) and 4 weeks ( $n=6$ for control and $n=11-13$ for DI-E-RAMP2-/-) after PAN02 cell transplantation into the spleen. Relative gene expression levels of AM-RAMP systems, CAF markers, and tumor chemoattractant factors are shown. The mean of the control mice was assigned a value of 1 . Bars are means \pm SEM. $* \mathrm{P}<0.05, * * * \mathrm{P}<0.001$. P-values were calculated using the Mann-Whitney U test. 


\section{Figure 3}

\section{Tumor metastasis is suppressed in RAMP3-/- mice, while CAF numbers and expression of tumor chemoattractant factors are decreased}

A, Representative images and tumor weights at the tumor injected (spleen) and metastatic site (liver) in RAMP3+/+ and RAMP3-/- mice ( $\mathrm{n}=7$ for RAMP3+/+ and $\mathrm{n}=8$ for RAMP3-/-). B, Spontaneous liver metastasis was suppressed in RAMP3-/mice relative to RAMP3+/+ mice 4 weeks after PAN02 cells transplantation ( $\mathrm{n}=30$ for RAMP3+/+ [metastasis rate: $83 \%$ ] and $\mathrm{n}=29$ for RAMP3-/- [metastasis rate: $59 \%$ ]). C, Representative photomicrographs of tumor periphery tissues stained with Masson's trichrome stain: left, RAMP3+/+; right, RAMP3-/-. Scale bars $=100 \mu \mathrm{m}$. Ratios of Masson's trichrome stained area / field in the sections are shown on the right $(n=10$ in each). D, Fluorescent immunostaining of section of liver tumor periphery. $\alpha$ SMA (red), PDPN (green), DAPI (blue). Scale bars $=100 \mu \mathrm{m}$. Ratios of PDPN-positive or aSMA-positive / DAPI-positive area in the sections are shown on the right ( $\mathrm{n}=8$ for RAMP3+/+ and n=7 for RAMP3-/-). E, Quantitative real-time PCR analysis of the liver tumor periphery 3 weeks ( $n=3$ for RAMP3+/+ and $n=5$ for RAMP3-/-) and 4 weeks ( $\mathrm{n}=7$ for RAMP3+/+ and $\mathrm{n}=8$ for RAMP3-/-) after PAN02 cell transplantation. Relative gene expression levels of AM-RAMP systems, CAF markers, and tumor chemoattractant factors are shown. The mean of the RAMP3+/+ mice was assigned a value of 1 . Bars are means $\pm \mathrm{SEM} . * \mathrm{P}<0.05, * * \mathrm{P}<0.01, * * * \mathrm{P}<0.001$. P-values were calculated using the Mann-Whitney $U$ test $(\mathbf{A}, \mathbf{C}, \mathbf{D}, \mathbf{E})$ and $\chi^{2}$ test $(\mathbf{B})$. 


\section{Figure 4}

\section{RAMP3-/- myofibroblasts exhibit less migration and proliferation in vitro and in} vivo

A, B, Cells migration was assessed using scratch assays. Shown are representative photomicrographs of scratch assays with cocultures of CAFs and PAN02 cells (A) and RAMP3-/- MEFs stimulated with conditioned medium (CM) from PAN02 cells (B). Scale bars $=200 \mu \mathrm{m}$. Calculated percent cell-covered areas are displayed below. $\mathbf{C}$, PAN02 cells mixed (1:1) with RAMP3+/+ or RAMP3-/- CAFs were subcutaneously injected into bilateral axillary regions of RAMP3+/+ mice. Tumor weights were measured 5 weeks later. D, Fluorescent immunostaining of transplanted tumor tissues composed of the indicated cell mixtures subcutaneously injected into RAMP3+/+ mice. $\alpha$ SMA (red), PDPN (green), DAPI (blue). Scale bars $=50 \mu \mathrm{m}$. Ratios of PDPN-positive or $\alpha$ SMA-positive / DAPI-positive areas in the sections are displayed below ( $\mathrm{n}=8$ for RAMP3+/+ and $\mathrm{n}=7$ for RAMP3-/-). E, Ki67 immunostaining in tumor tissues composed of the indicated cell mixtures following their subcutaneous injection into RAMP3+/+ mice. Nuclei are counterstained with hematoxylin. Scale bars $=50 \mu \mathrm{m}$. Numbers of Ki67-positive cells / microscope field $(\mathrm{x} 400)$ in the sections are displayed below ( $\mathrm{n}=12$ in each). F, Representative images and tumor weights at the metastatic site (liver) after splenic injection of PAN02 cells mixed (1:1) with RAMP3+/+ or RAMP3-/- CAFs (total $2 \times 10^{6}$ cells) ( $\mathrm{n}=8$ in each). G, Spontaneous liver metastasis rate following splenic injection of the indicated cell 
mixtures. Metastasis was suppressed in the RAMP3-/- CAFs group compared to the RAMP3+/+ CAFs group 4 weeks after injection ( $\mathrm{n}=14$ for RAMP3+/+ / PAN02 [metastasis rate: 93\%]; $\mathrm{n}=30$ for PAN02 [metastasis rate: 83\%]); $\mathrm{n}=14$ for RAMP3-// PAN02 [metastasis rate: 71\%]). $* \mathrm{P}<0.05, * * \mathrm{P}<0.01, * * * \mathrm{P}<0.001$. P-values were calculated using the Mann-Whitney $U$ test $(\mathbf{A}-\mathbf{F})$ and $\chi^{2}$ test $(\mathbf{G})$.

\section{Figure 5}

\section{RAMP3-/- myofibroblasts show decreased malignancy}

A, B, Fluorescent immunostaining of CAFs (A) and MEFs $(\mathbf{B})$ in medium conditioned by PAN02 cells. $\alpha$ SMA (red), DAPI (blue). Scale bars $=50 \mu \mathrm{m}(\mathrm{CAFs})$ or $100 \mu \mathrm{m}$ (MEFs). Ratios of $\alpha$ SMA-positive / DAPI-positive areas are displayed below. (CAFs: $n=16$ views each from 3 cultured dishes, MEFs: $n=10$ views each from 3 cultured dishes). C, D, Fluorescent immunostaining of CAFs (C) and MEFs (D) in medium conditioned by PAN02 cells: green, SM22 $\alpha$; blue, DAPI. Scale bars $=50 \mu \mathrm{m}$ (CAFs) or $100 \mu \mathrm{m}$ (MEFs). Ratios of SM22 $\alpha$-positive / DAPI-positive areas are displayed below (CAFs: $n=12$ views each from 3 cultured dishes, MEFs: $n=12$ views each from 3 cultured dishes). E, Cytoplasmic F-actin distribution in RAMP3+/+ (upper panels) and RAMP3-/- (lower panels) CAFs. Scale bars $=20 \mu \mathrm{m}$. Fluorescence amplitudes (a.u., arbitrary units) along the line scans (in yellow on the images) are displayed graphically next to each image. F, Cytoplasmic F-actin distribution in RAMP3+/+ (upper panels) and RAMP3-/- (lower panels) MEFs. Scale bars $=20 \mu \mathrm{m}$. Fluorescence amplitudes along the line scans (in yellow on the images) are displayed 
graphically next to each image. G, Comprehensive gene expression analysis of RAMP3+/+ and RAMP3-/- CAFs ( $\mathrm{n}=3$ each). The dot plot shows the results of the real-time PCR array analysis. The horizontal axis shows the fold change $\left[\log _{2}\right.$ (fold change)], and the vertical axis shows the $\mathrm{P}$ value $\left[-\log _{10}(\mathrm{P}\right.$ value $\left.)\right]$. Dotted lines indicate the distribution of unchanged genes. Bars are means \pm SEM. ${ }^{*} \mathrm{P}<0.05,{ }^{* *} \mathrm{P}$ $<0.01, * * * \mathrm{P}<0.001$. P-values were calculated using the Mann-Whitney U test.

\section{Figure 6}

\section{RAMP3 deficiency downregulates PDPN expression and p-Src/Cas signaling}

A, Quantitative real-time PCR analysis of RAMP3 and PDPN in MEF cells ( $n=6$ each). The mean of the RAMP3+/+ MEFs was assigned a value of 1. B, Quantitative real-time PCR analysis of RAMP3 and PDPN in RAMP3+/+ MEFs treated for the indicated times with control (Accell siRNA Delivery Media only) or 50 nM Smart Pool Accell RAMP3 siRNA (12 h: $n=3$ for control and $n=2$ for siRAMP3; $24 \mathrm{~h}: \mathrm{n}=6$ for control and $n=3$ for siRAMP3). The mean of the control at each time point was assigned a value of 1 . C, Western blot analysis of total Src, p-Src and Cas expression in subcutaneous transplanted tumor tissues from CAF/PAN02 cell mixtures in RAMP3+/+ mice. $\beta$-actin was used as a loading control. Quantified optical densities are displayed next to the images ( $\mathrm{n}=5$ each). $\mathbf{D}$, Western blot analysis of total $\mathrm{Src}$, p-Src and Cas expression in MEFs in medium conditioned by PAN02 cells ( $\mathrm{n}=4$ each). $\beta$-actin was used as a loading control. Quantified optical densities are displayed next to image. Bars are means \pm SEM. $* \mathrm{P}<0.05, * * \mathrm{P}<0.01, * * * \mathrm{P}<0.001$. P-values were 
calculated using the Mann-Whitney U test (A, C, D) and Student's t-test (B).

\section{Figure 7}

Activation of the AM-RAMP2 system and inhibition of the AM-RAMP3 system suppresses metastasis and tumor growth

A, Rates of spontaneous liver metastasis at 4 weeks in RAMP3-/- (metastasis rate: $59 \%, \mathrm{n}=29$ ) and RAMP3 +/+ (metastasis rate: $83 \%, \mathrm{n}=30$ ) mice, and in RAMP3-/mice treated AM using an osmotic pump (metastasis rate: $42 \%, n=12$ ). B, Representative images and weights of tumors at the injection sites (spleen) and metastatic sites (liver) in RAMP3-/- mice $(n=8)$ and RAMP3-/- mice treated with AM $(n=4) . C$, Quantitative real-time PCR analysis of liver tumor periphery from RAMP3-/- mice $(n=8)$ and RAMP3-/- treated with AM ( $n=4)$. The mean of the RAMP3-/- mice was assigned a value of 1 . Bars are means \pm SEM. $* \mathrm{P}<0.05, * * \mathrm{P}$ $<0.01, * * * \mathrm{P}<0.001$. P-values were calculated using the Mann-Whitney U test $(\mathbf{B}, \mathbf{C})$ and $\chi^{2}$ test (A).

\section{Figure 8}

\section{Therapeutic potential of the AM-RAMP3 system in metastasis}

PDPN expression and tumor malignancy are reduced in RAMP3-/- mice, whereas compensatory upregulation of RAMP3 and PDPN in DI-E-RAMP2-/- enhance tumor malignancy. Enhancement of AM-RAMP2 signaling in RAMP3-/- suppresses liver metastasis. Selective activation of RAMP2 and inhibition of RAMP3 is expected to 
RAMP3 deficiency suppresses metastasis by modulating CAF

suppress tumor metastasis. 
RAMP3 deficiency suppresses metastasis by modulating CAF

Table 1. Primers used for quantitative real-time PCR

\begin{tabular}{lll}
\hline Gene & Primer & \\
\hline AM & Forward & GGACACTGCAGGGCCAGAT \\
& Reverse & GTAGTTCCCTCTTCCCACGACTTA \\
RAMP2 & Forward & GCAGCCCACCTTCTCTGATC \\
& Reverse & AACGGGATGAGGCAGATGG \\
& Probe & CCCAGAGGATGTGCTCCTGGCCAT \\
RAMP3 & Forward & AAAGCCTTCGCTGACATGATG \\
& Reverse & ATCTCGGTGCAGTTAGTGAAGCT \\
S100A8 & Forward & TGAGCAACCTCATTGATGTCTACC \\
& Reverse & ATGCCACACCCACTTTTATCACC \\
S100A9 & Forward & GAAGAAAGAGAAGAGAAATGAAGCC \\
& Reverse & CTTTGCCATCAGCATCATACACTCC \\
PODOPLANIN & Forward & TGGCAAGGCACCTCTGGTA \\
& Reverse & TGAGGTGGACAGTTCCTCTAAGG \\
$\mathbf{\alpha S M A}$ & Forward & CCACCGCAAATGCTTCTAAGT \\
& Reverse & GGCAGGAATGATTTGGAAAGG \\
CD34 & Forward & ACCACAGACTTCCCCAACTG \\
& Reverse & CGGATTCCAGAGCATTTGAT \\
\hline
\end{tabular}




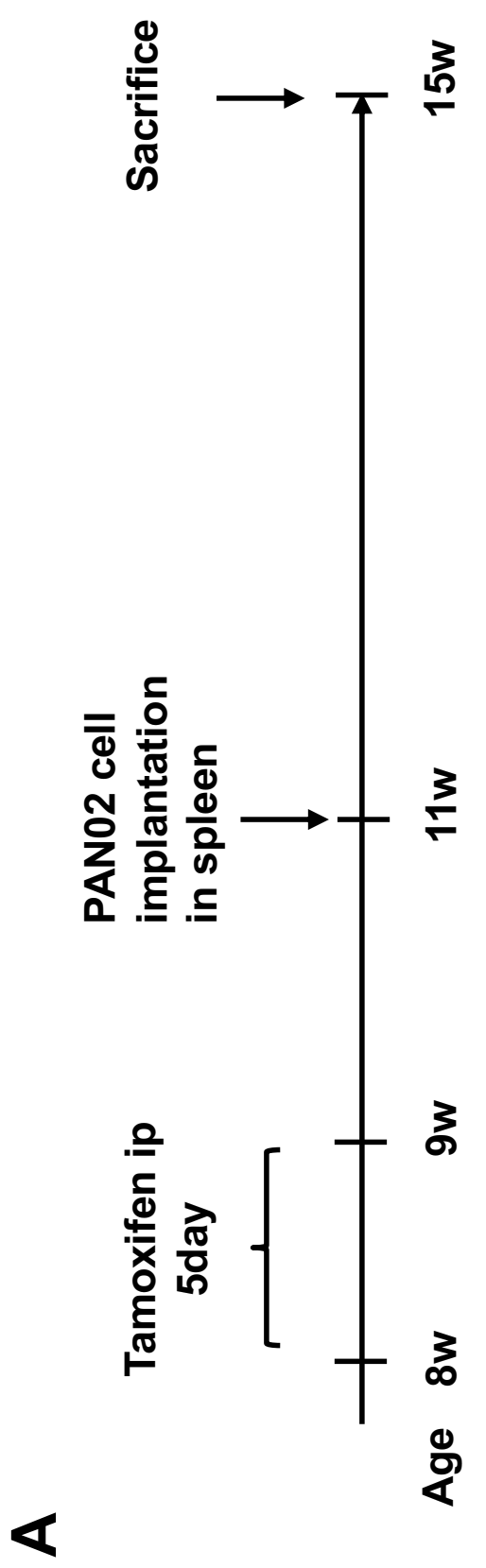

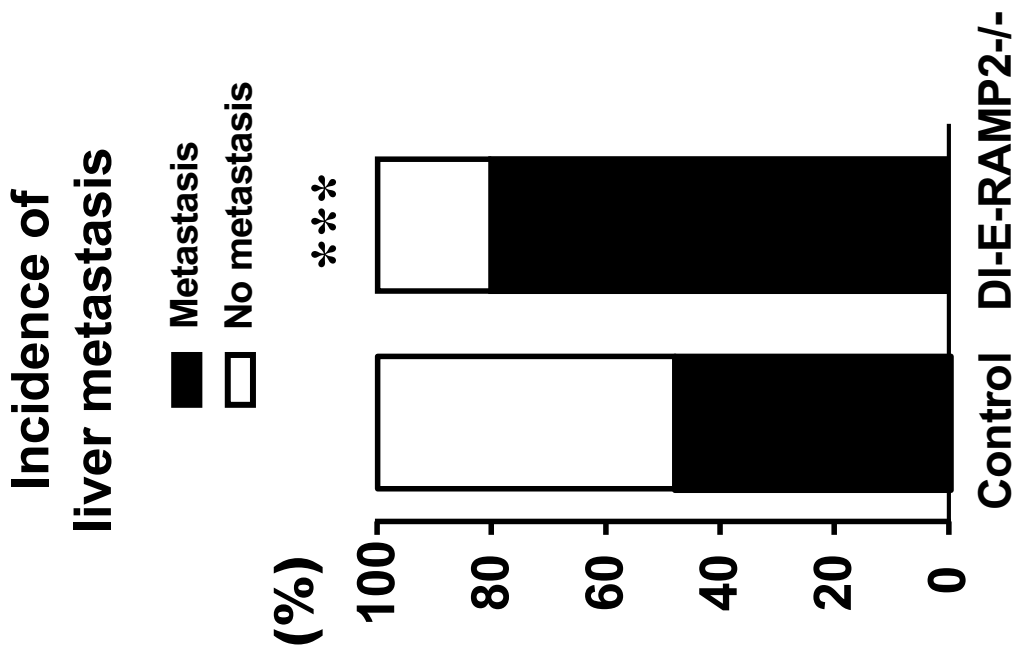

0
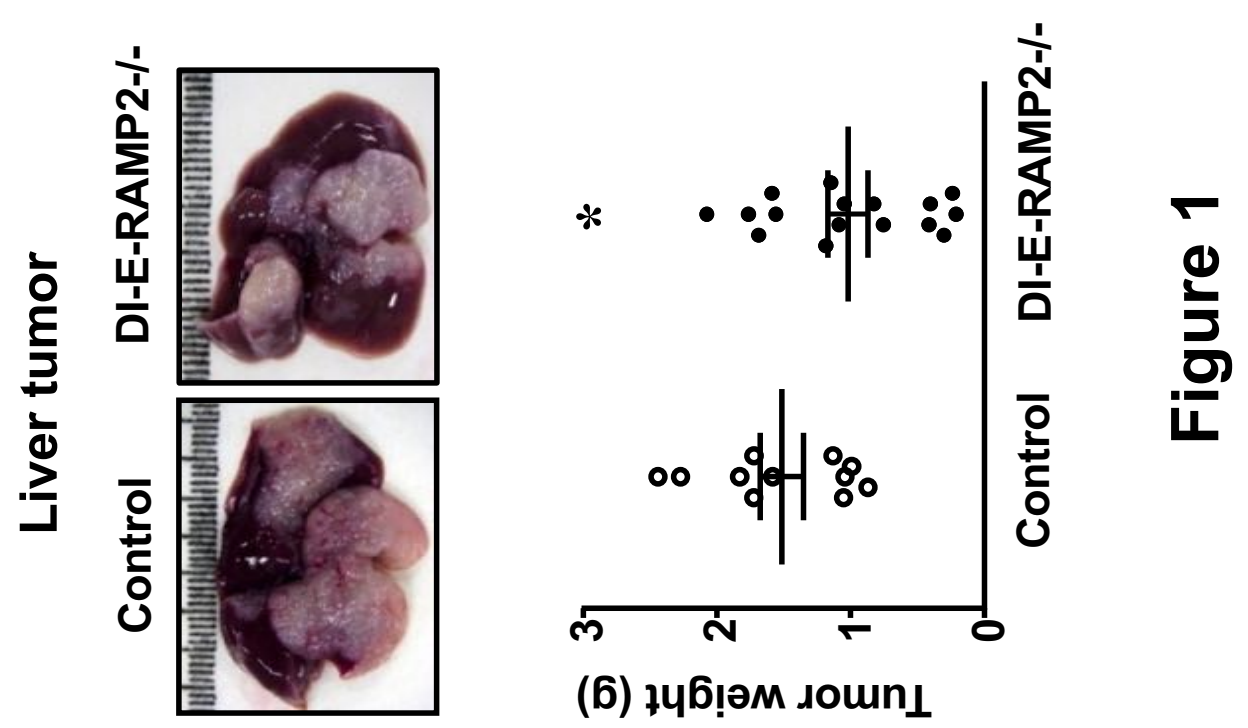

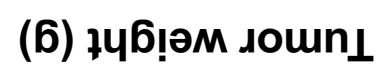

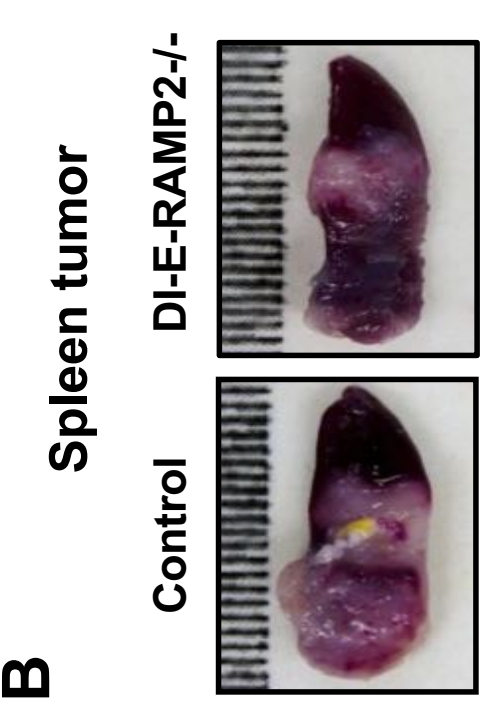

(6) $\nmid 46 ! \mid$ 

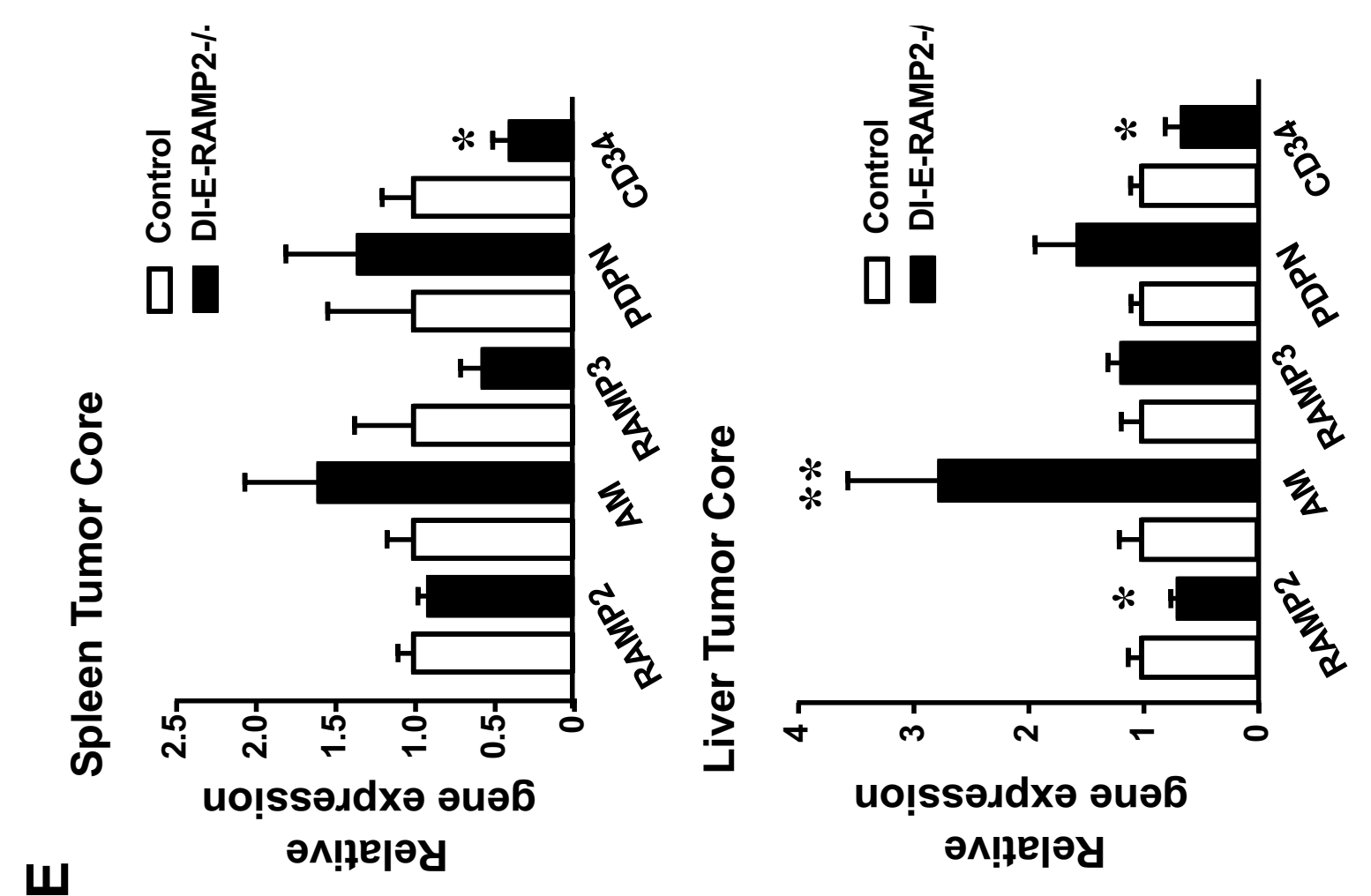

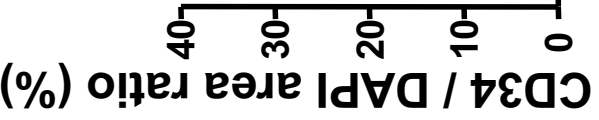
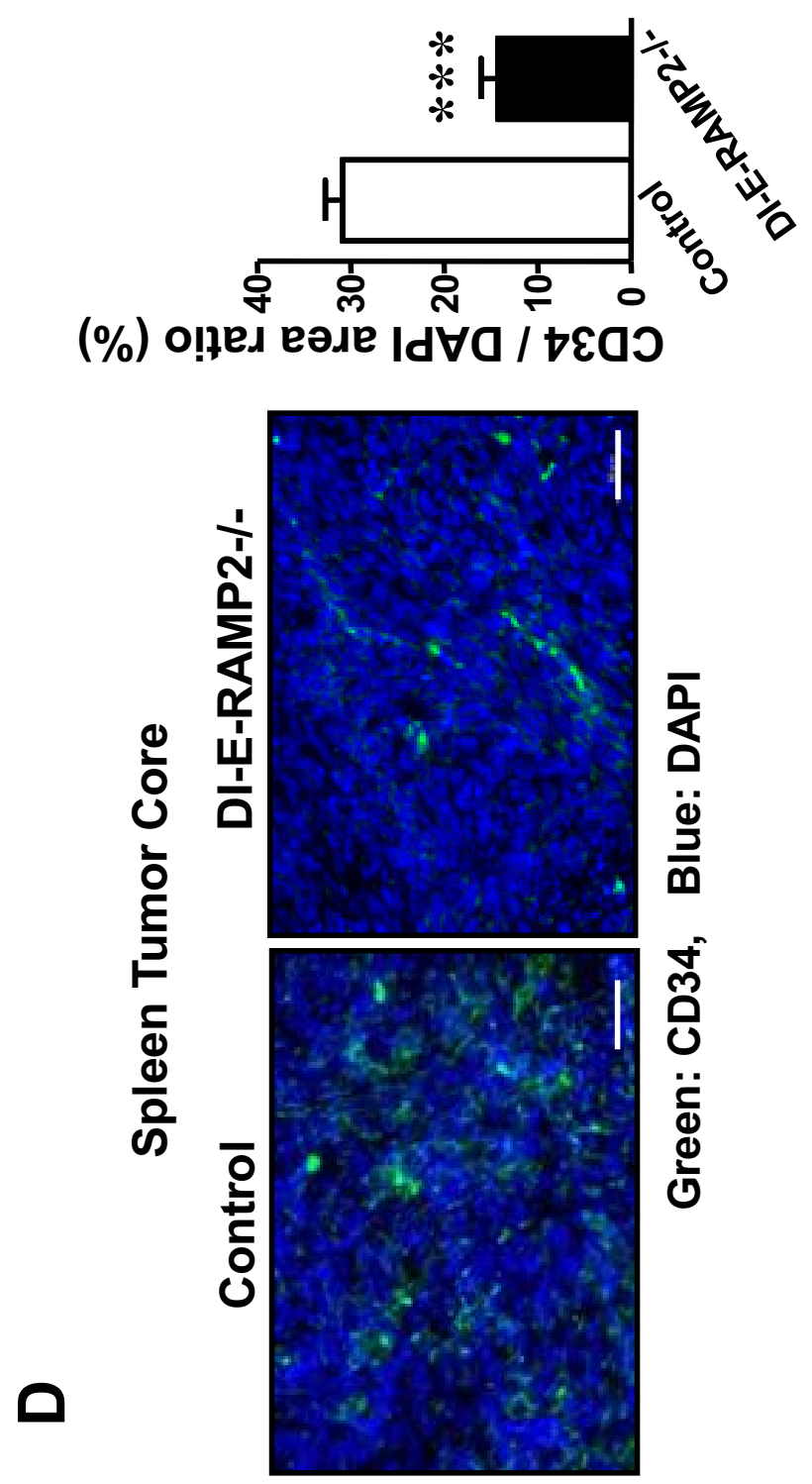


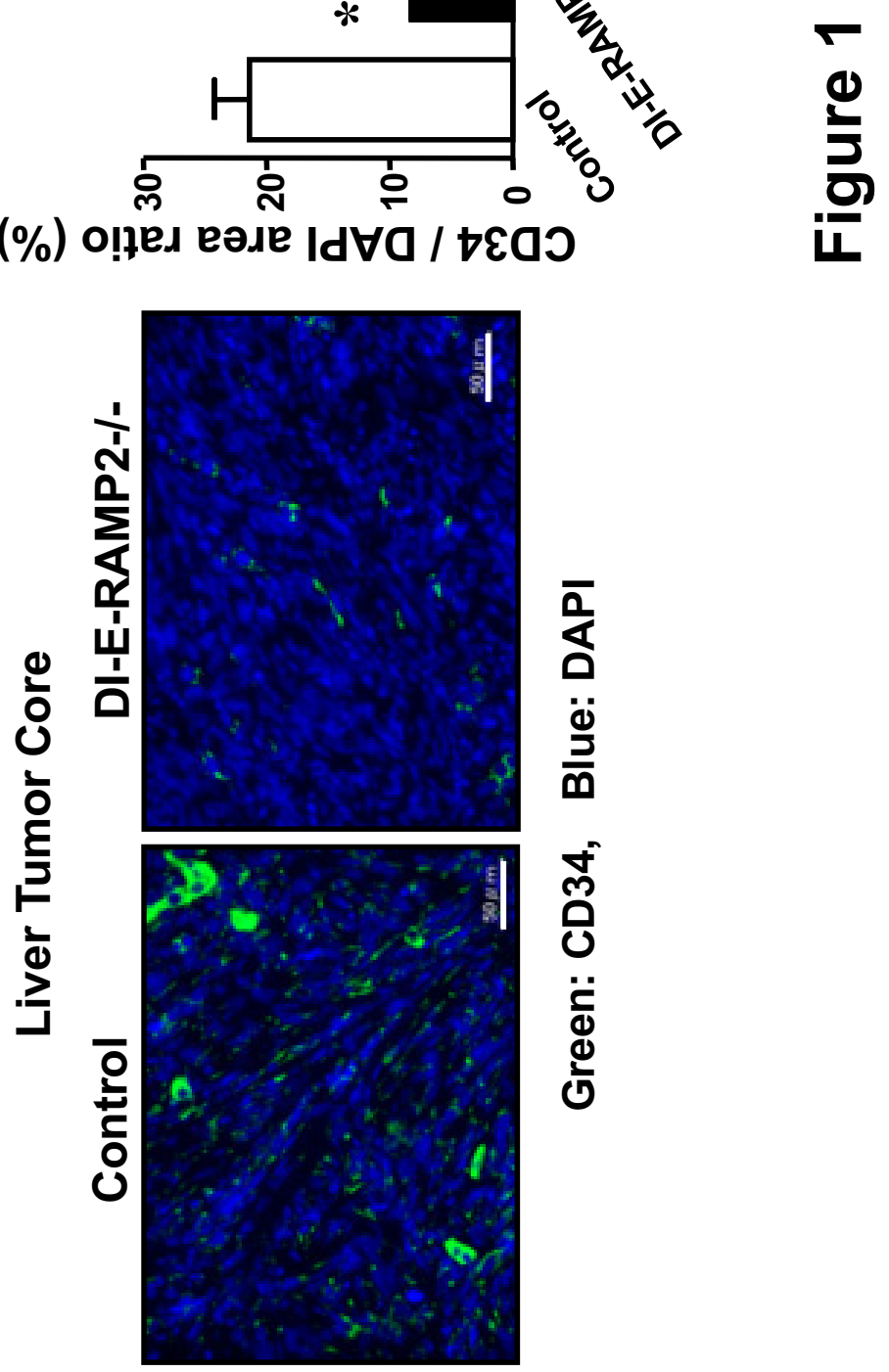

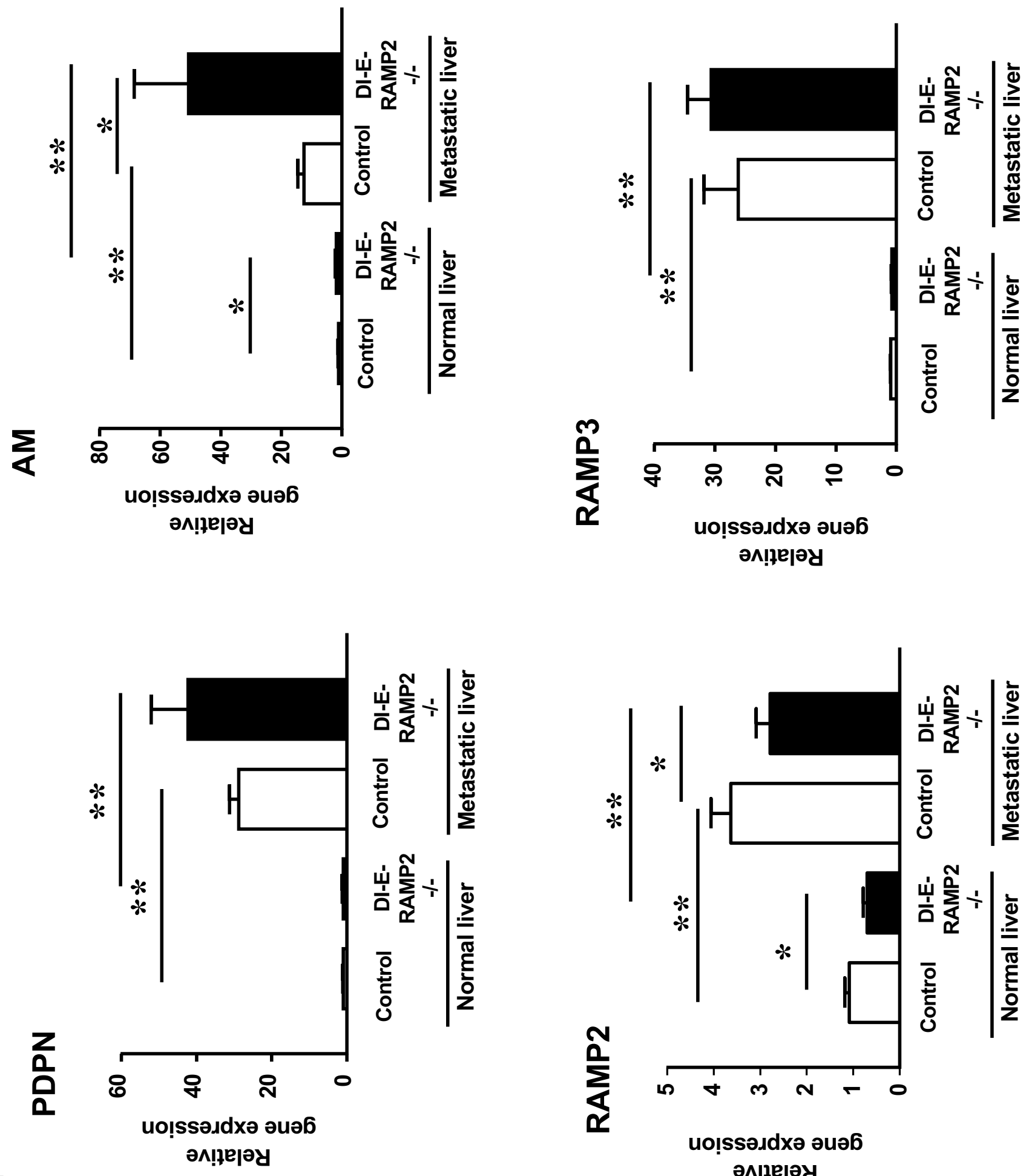

L

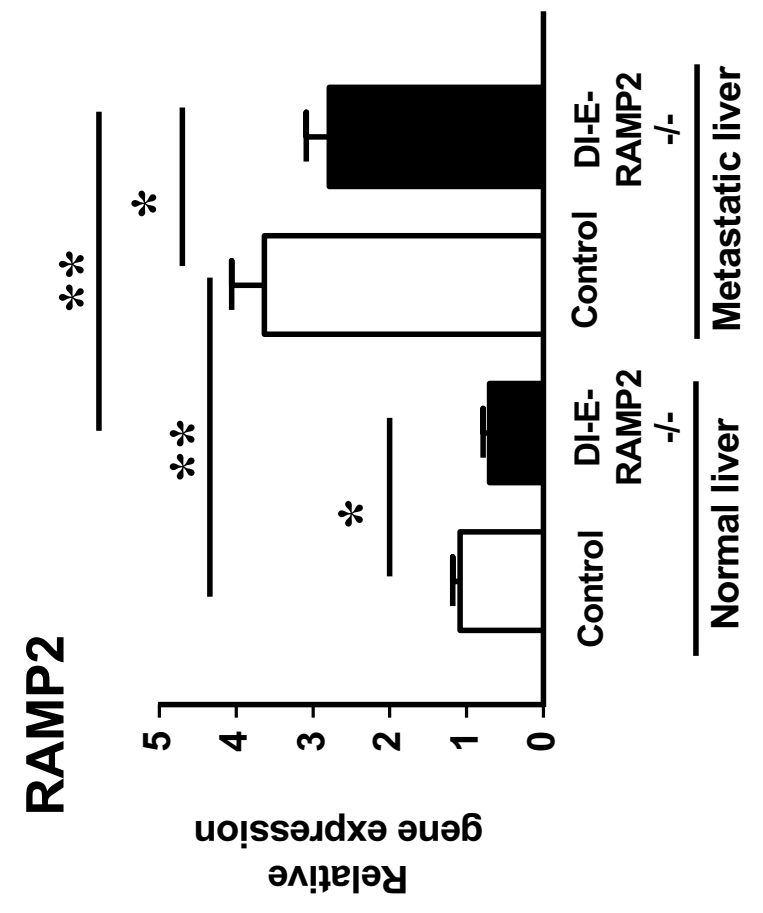



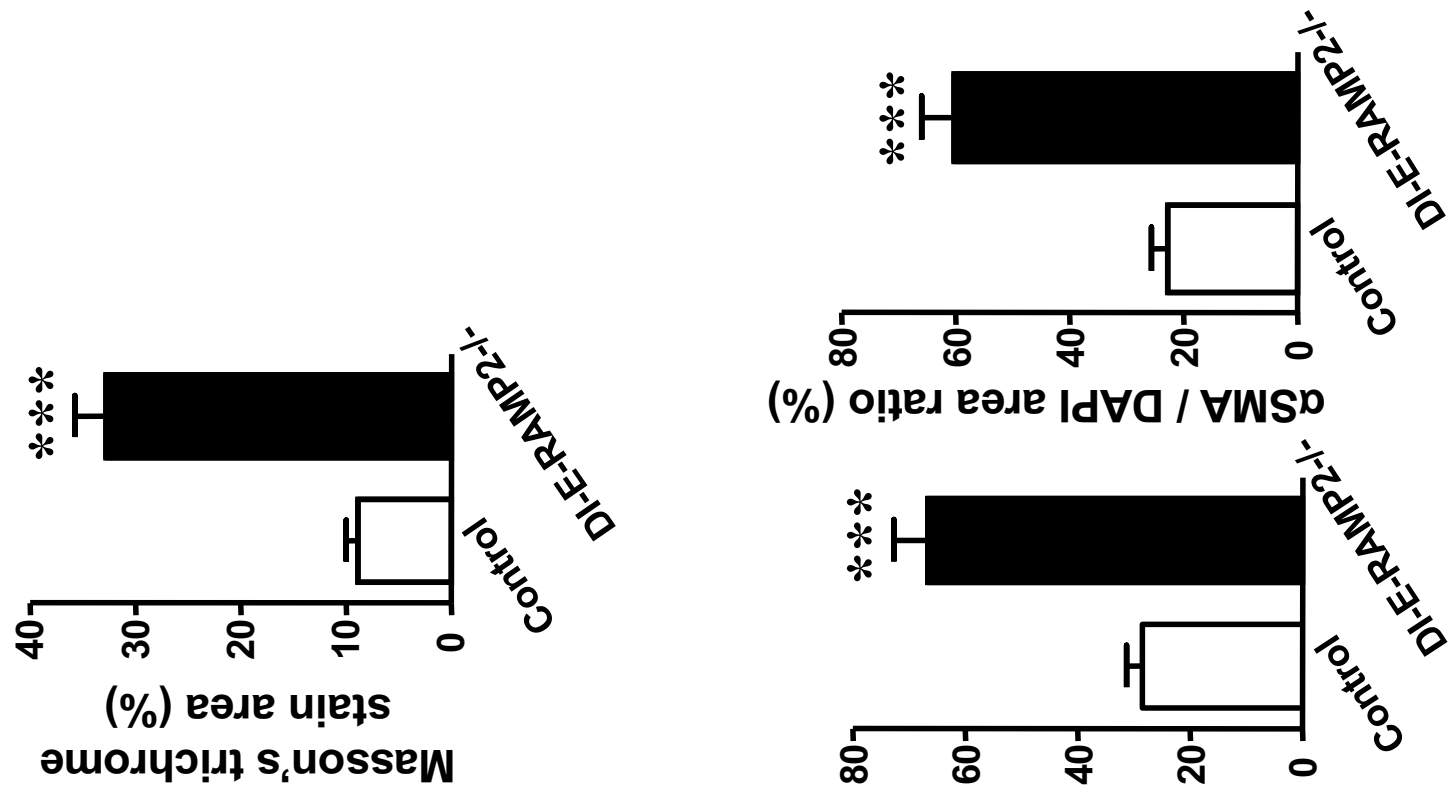

(\%) O!̣ed eəde Id $\forall \mathrm{O} / \forall W S$

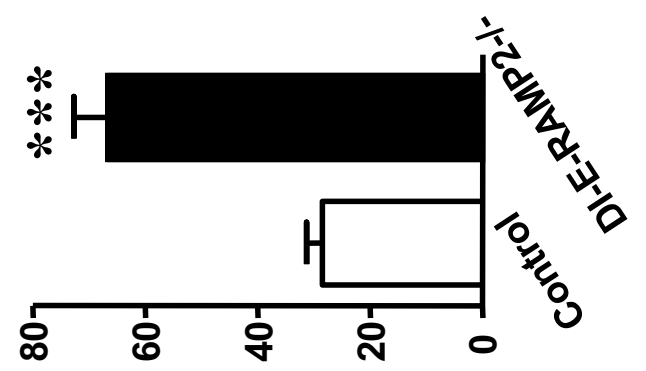

(\%) O!̣ed eəde Id $\forall$ Q / NdOd
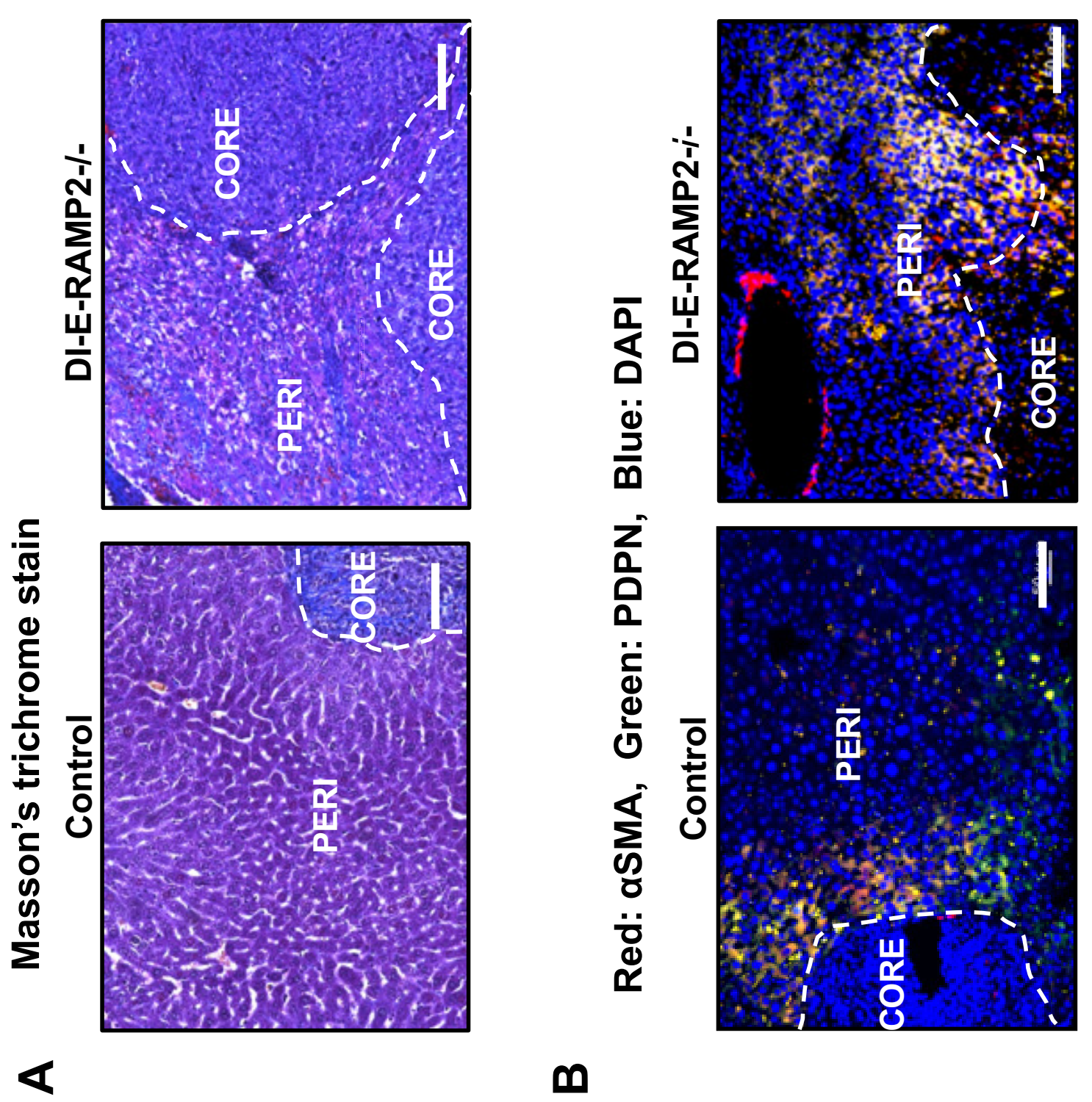

인
몬

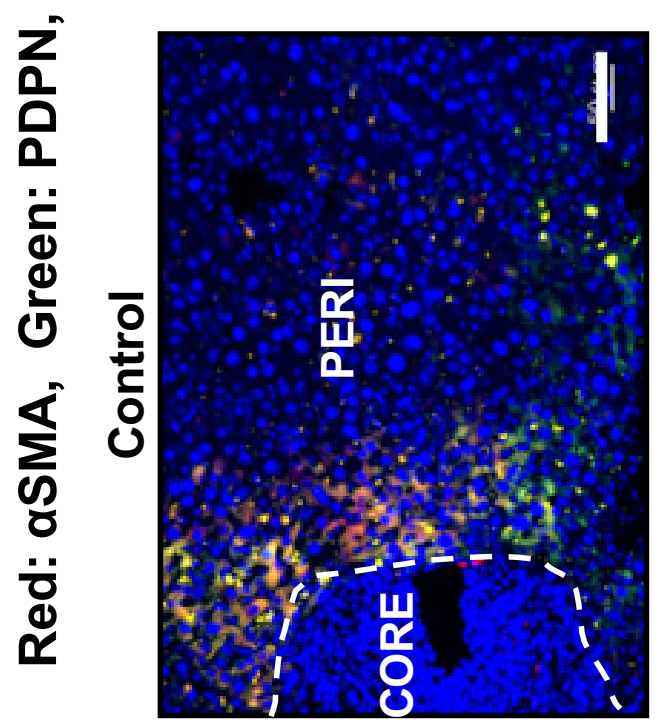



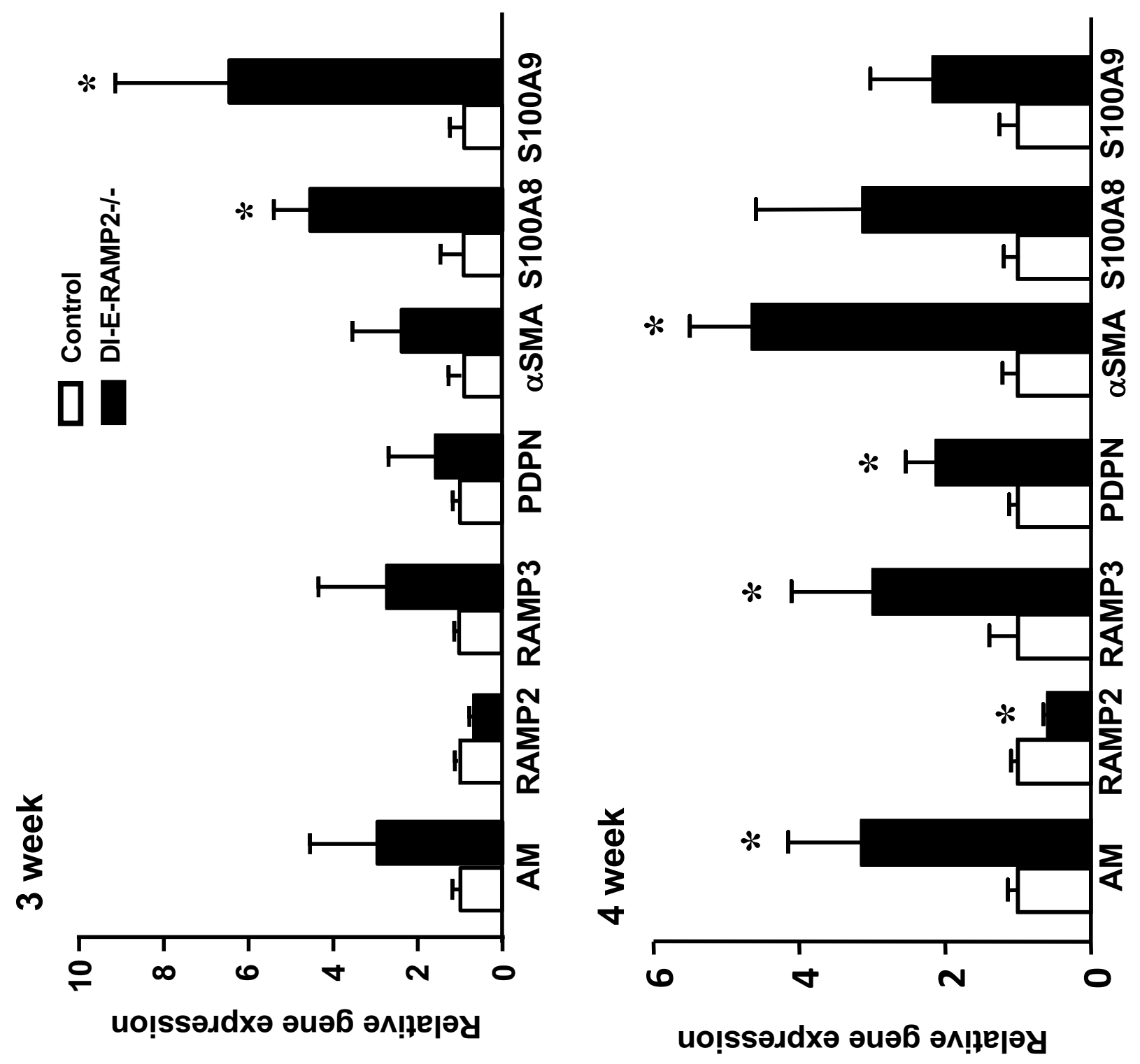

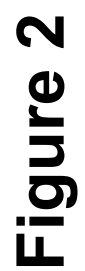

0 

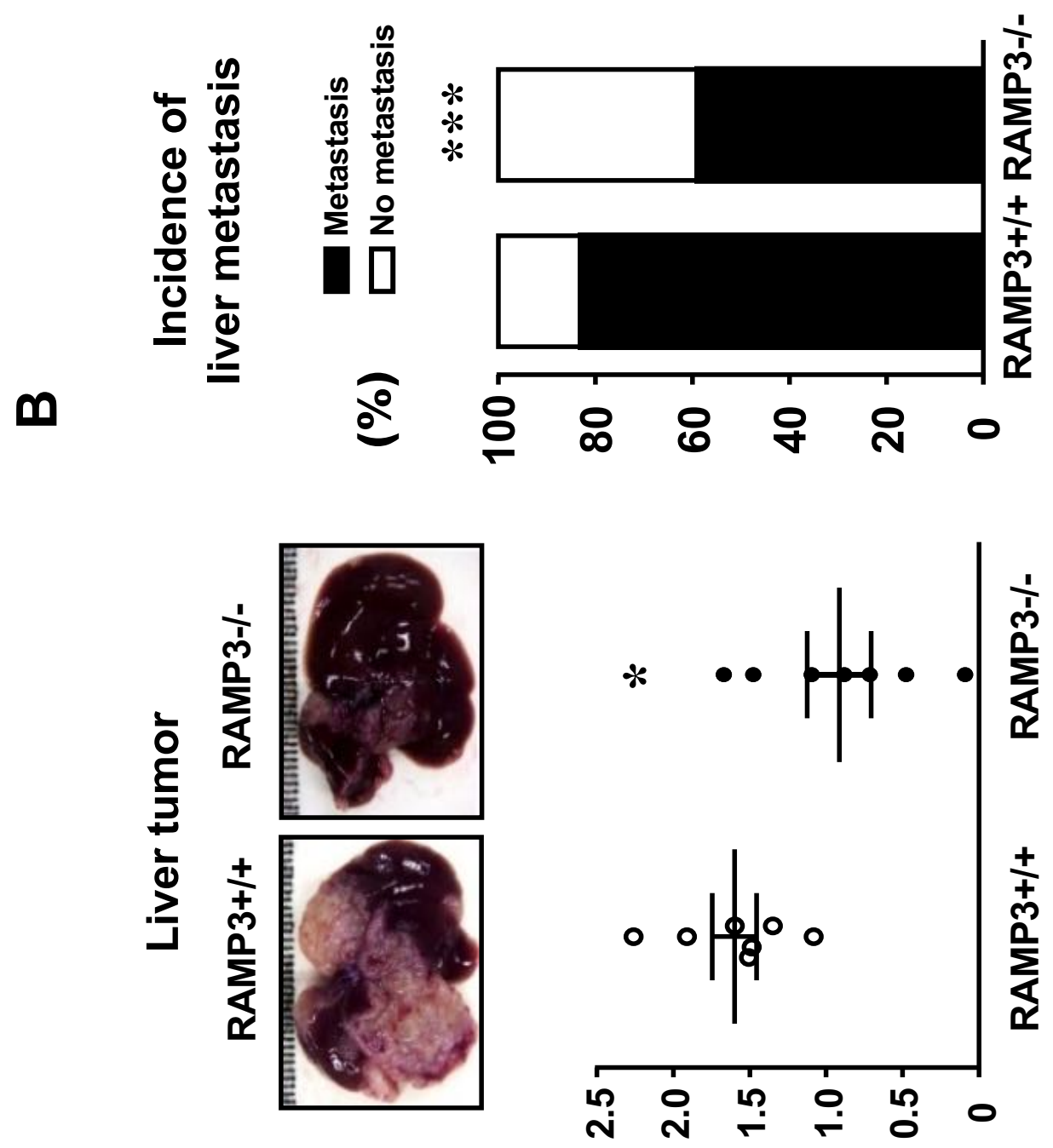



(6) 746 !
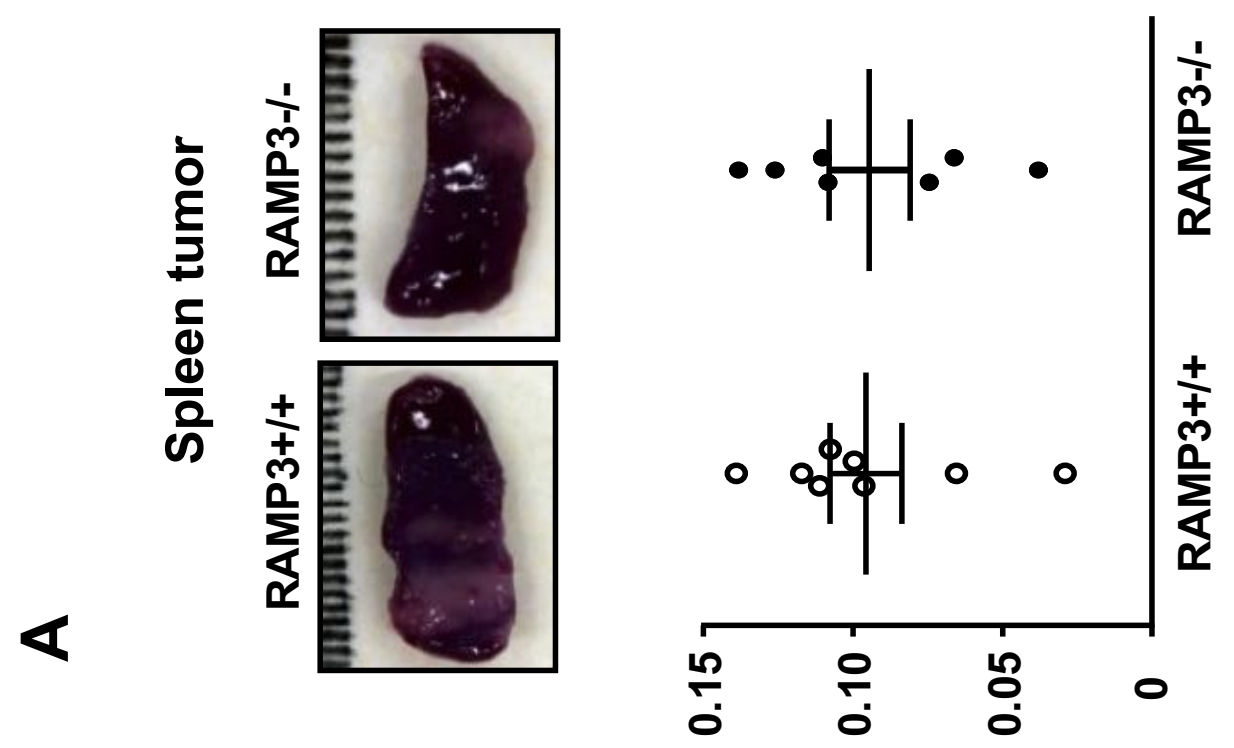

(6) $746 !$ 

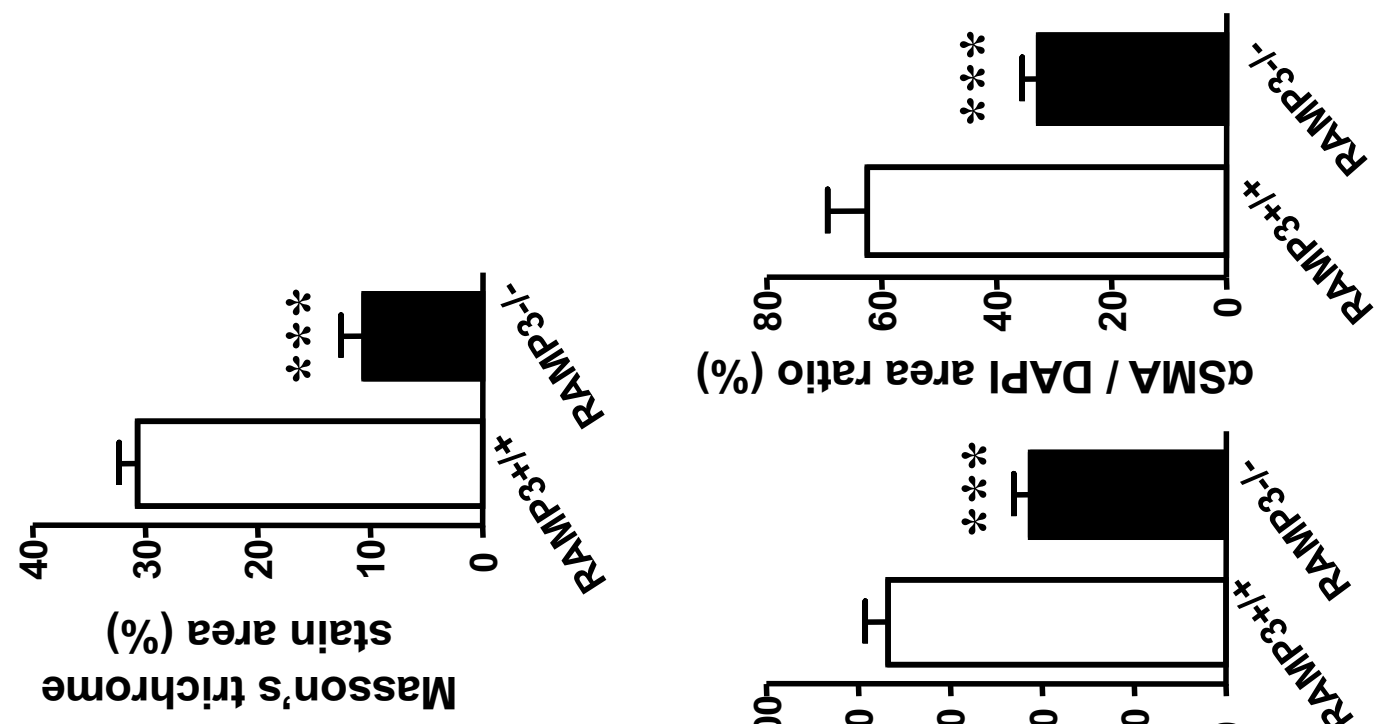

(\%) о!̣es еәле Id $\forall 0$ / $\forall W S$

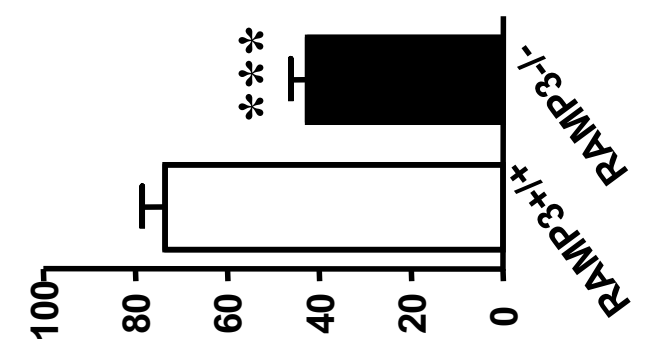

(\%) O!̣es eәse Id $\forall$ Q / NdOd
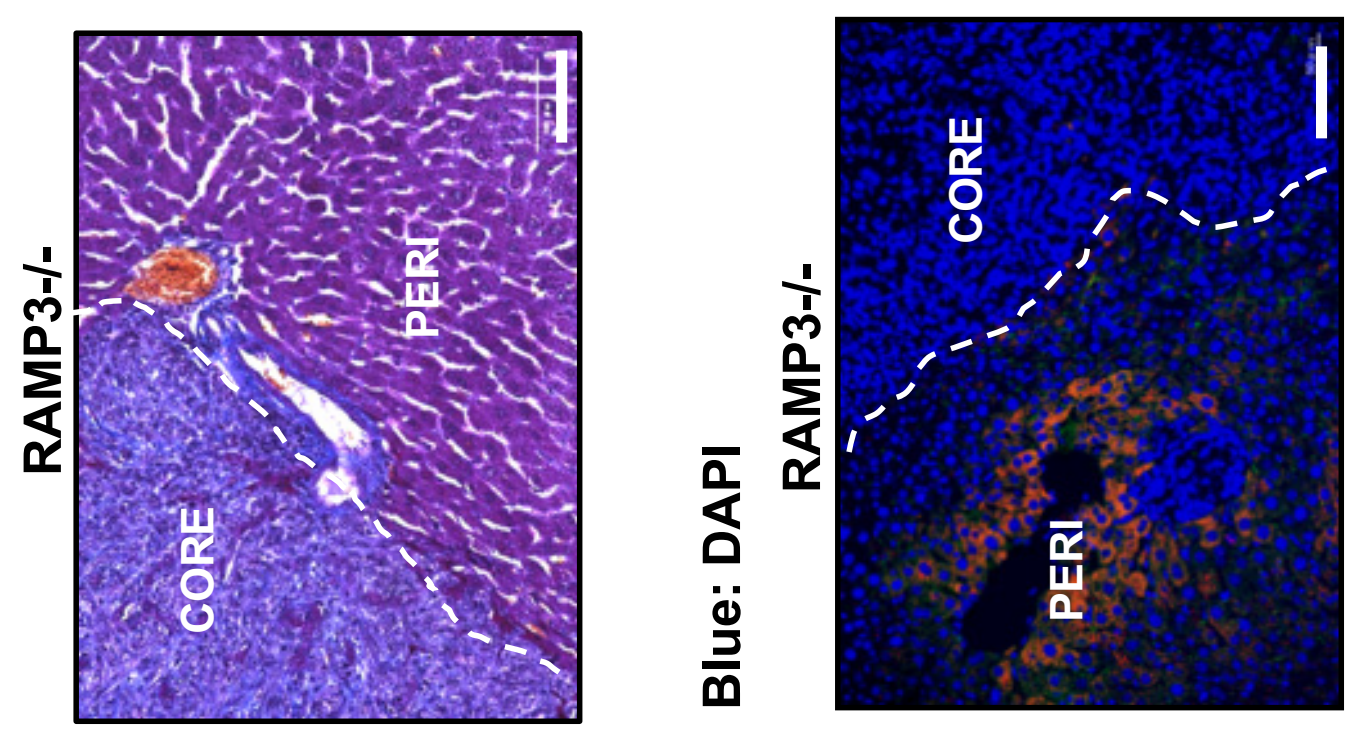

m
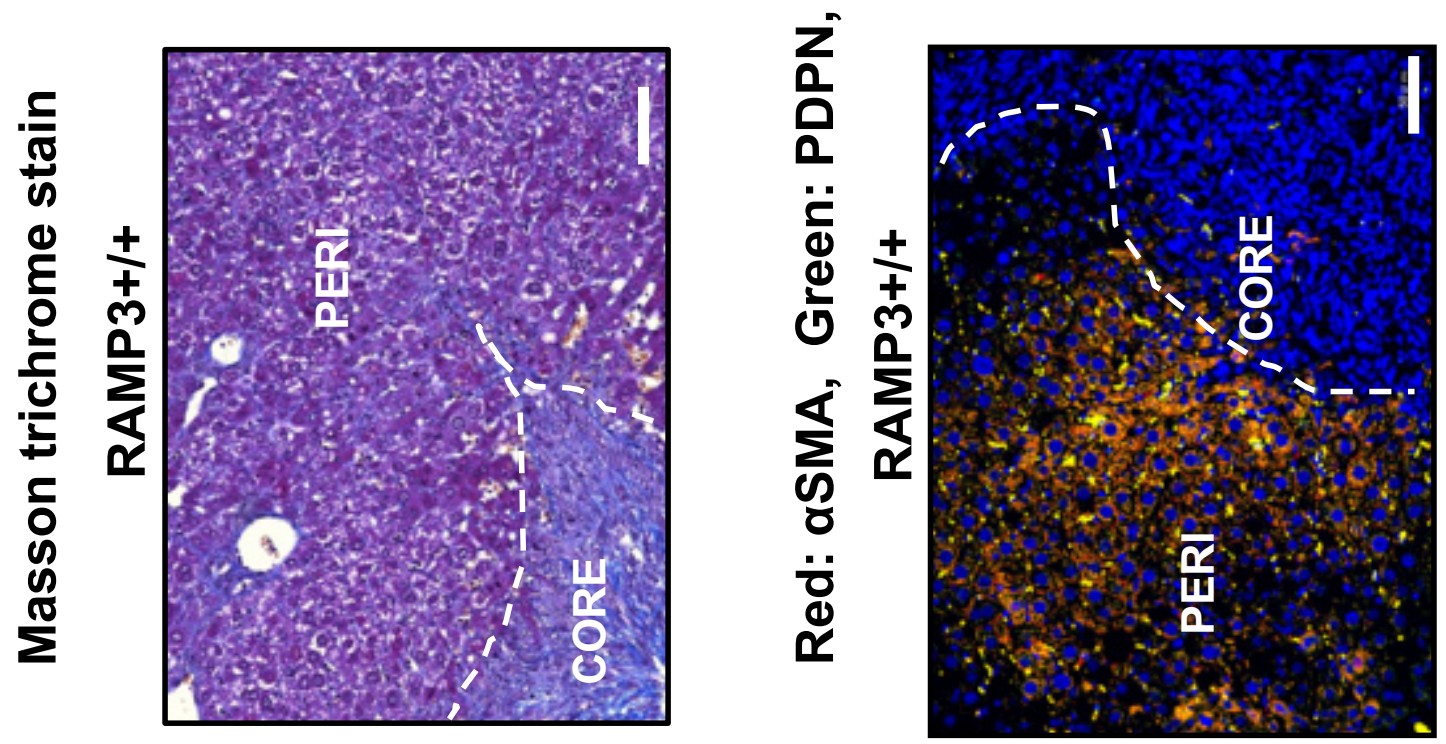


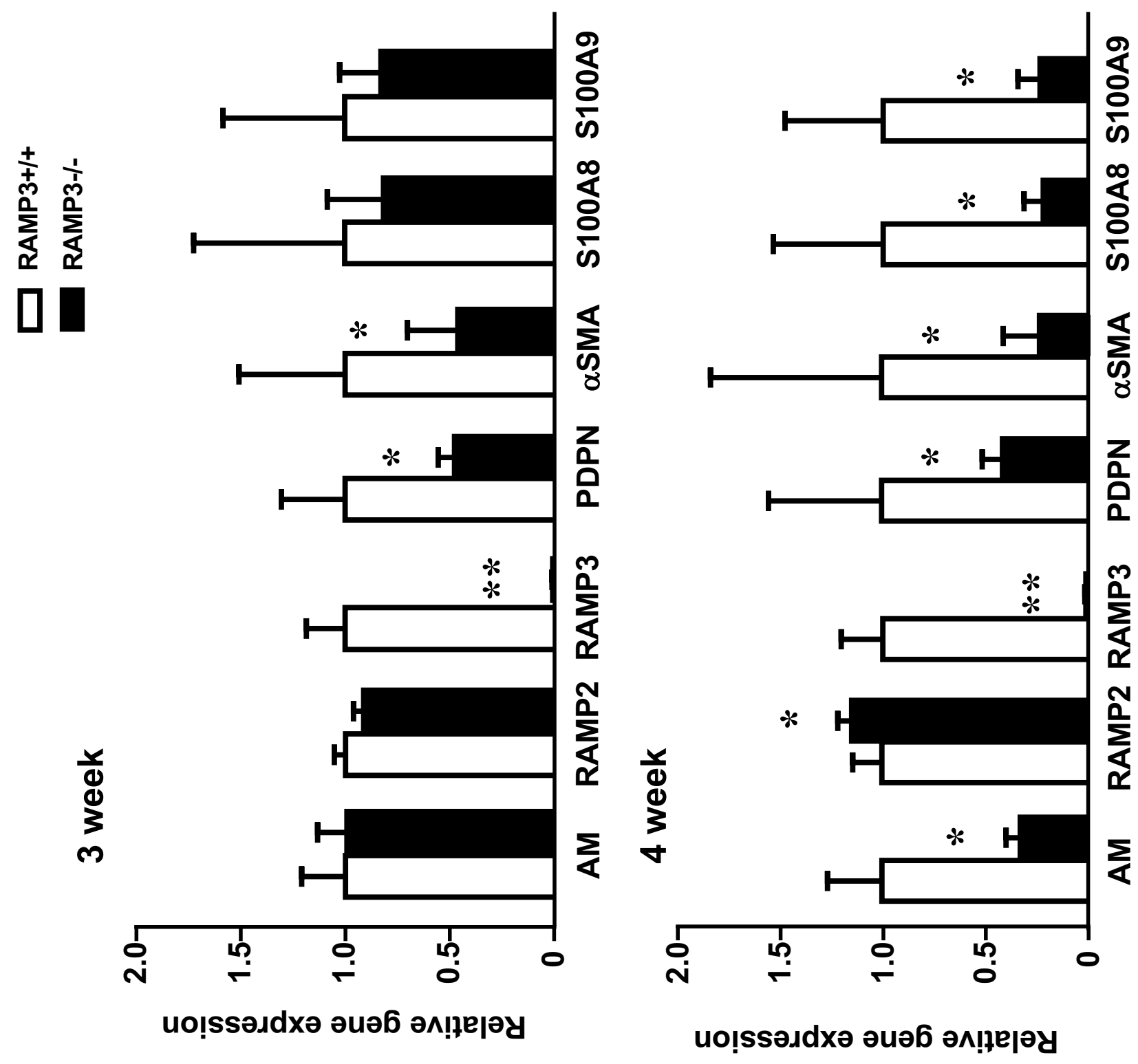

m

Ш 

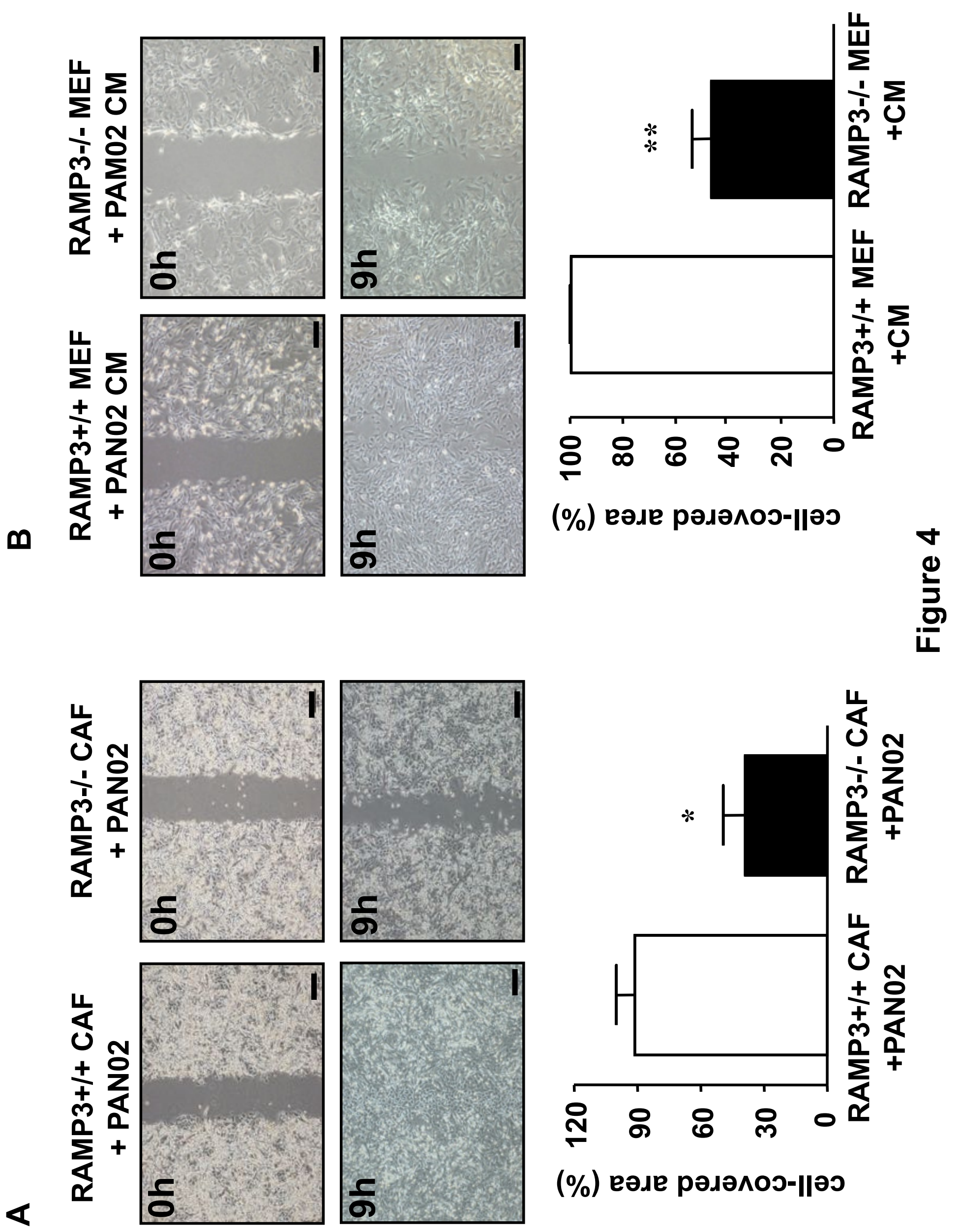

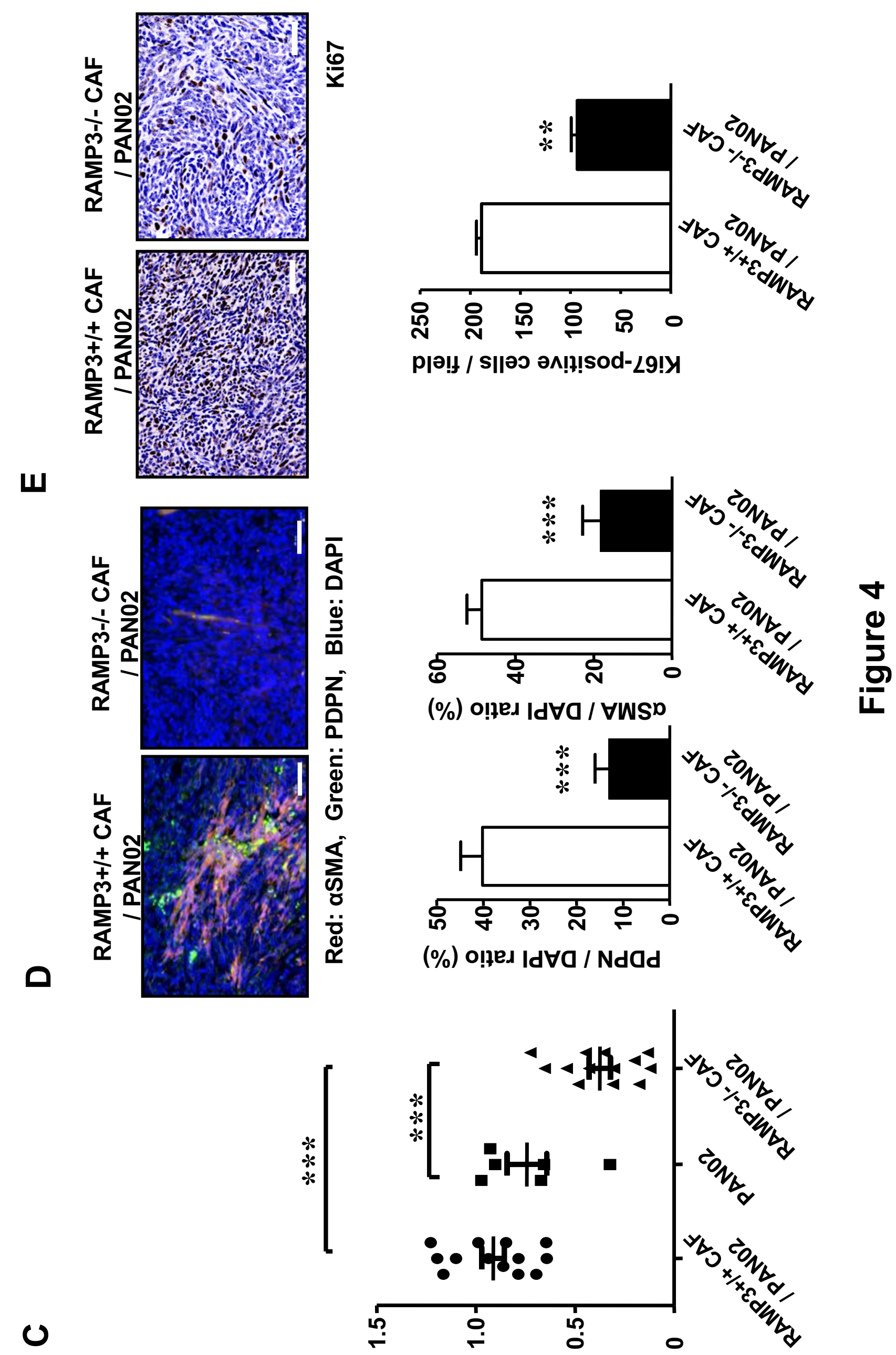

(6) $746 !$ 


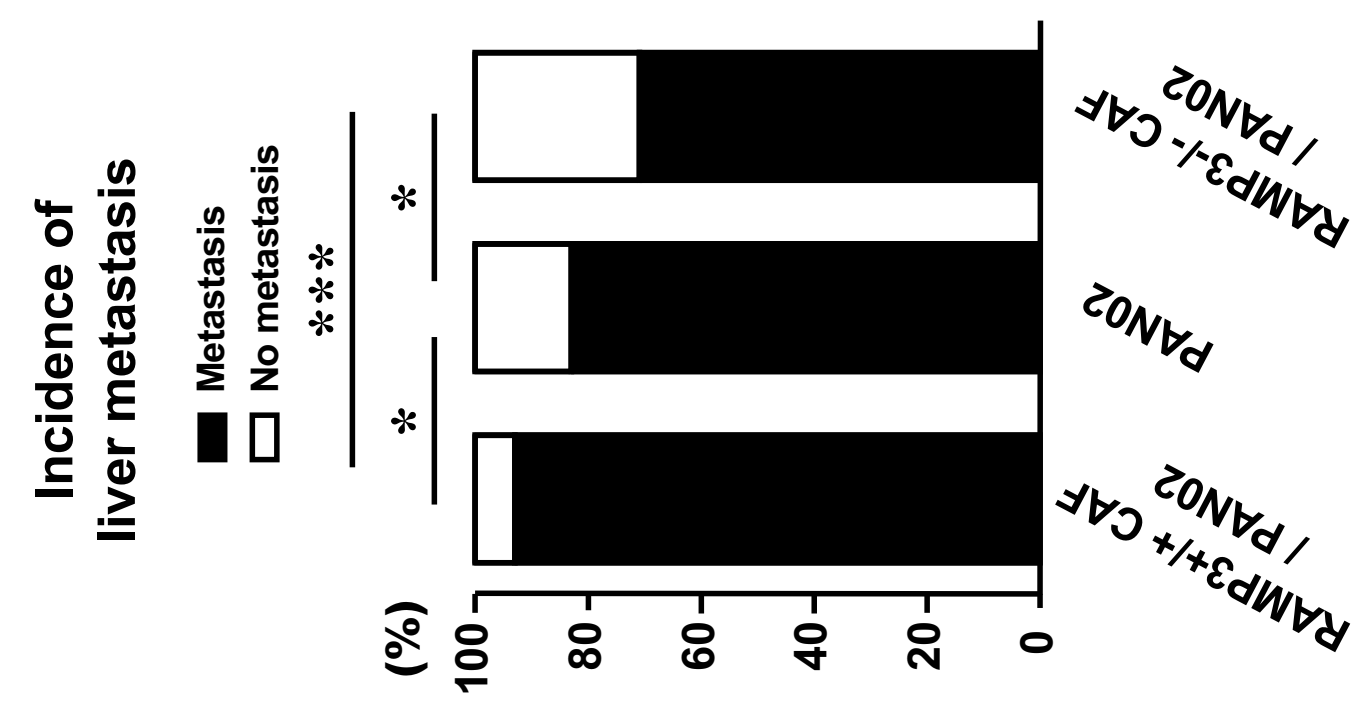

0

혼

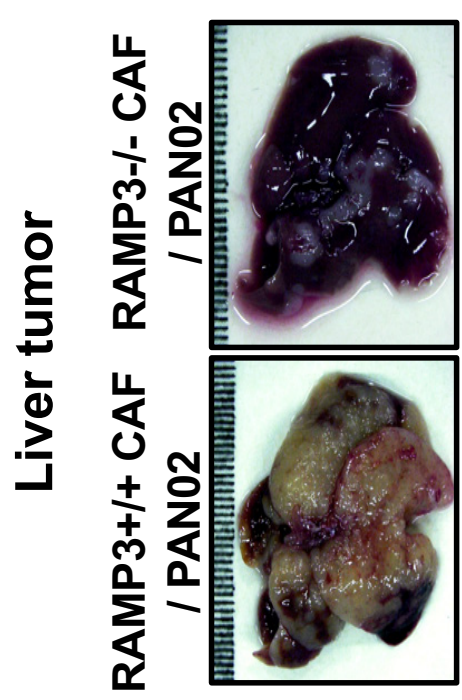

L

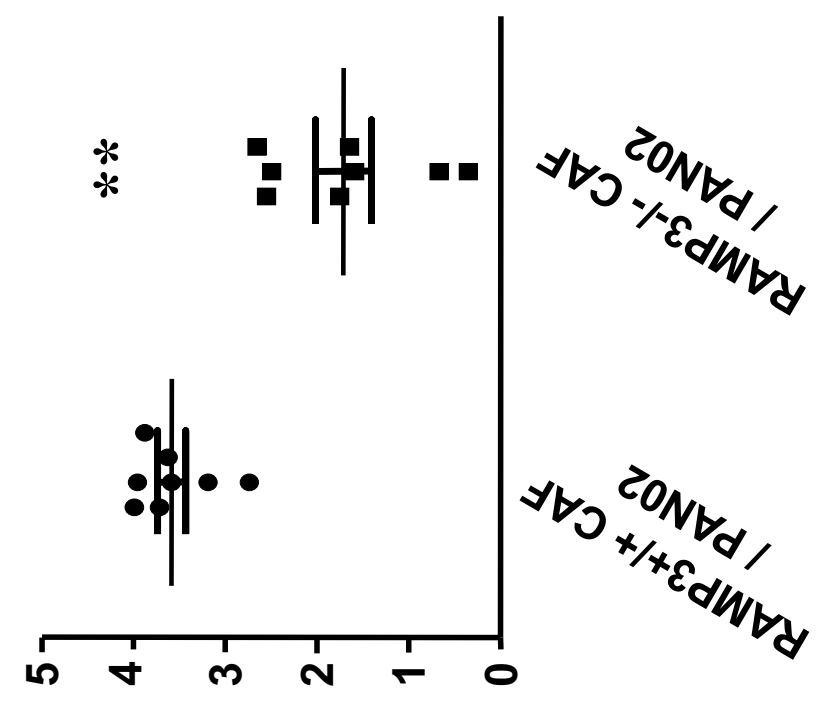

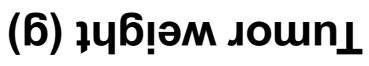




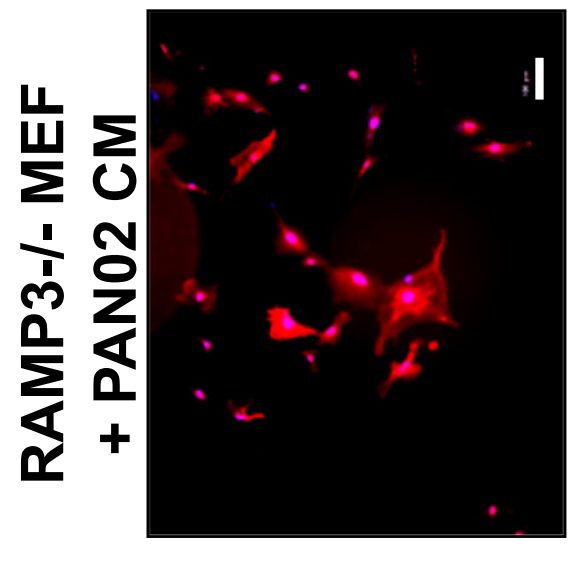

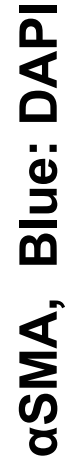

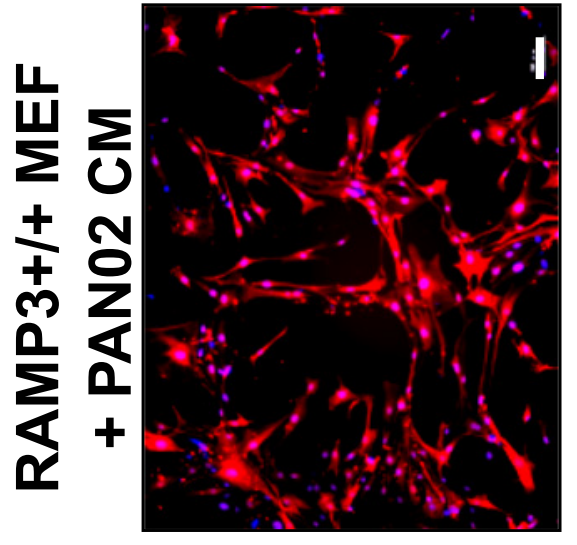

$m$

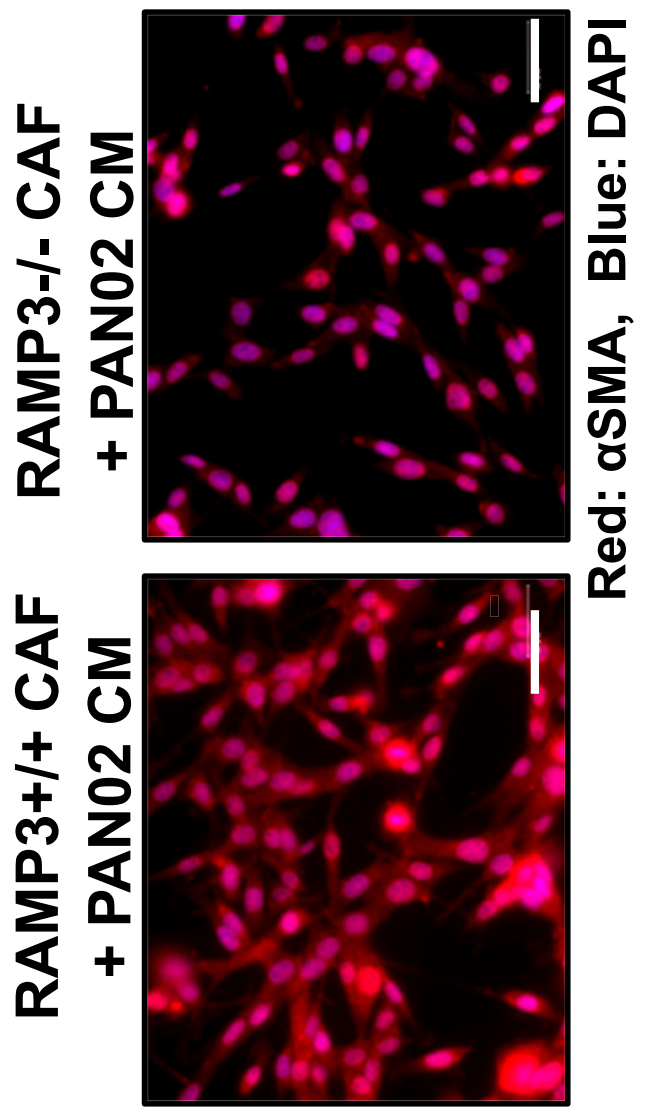

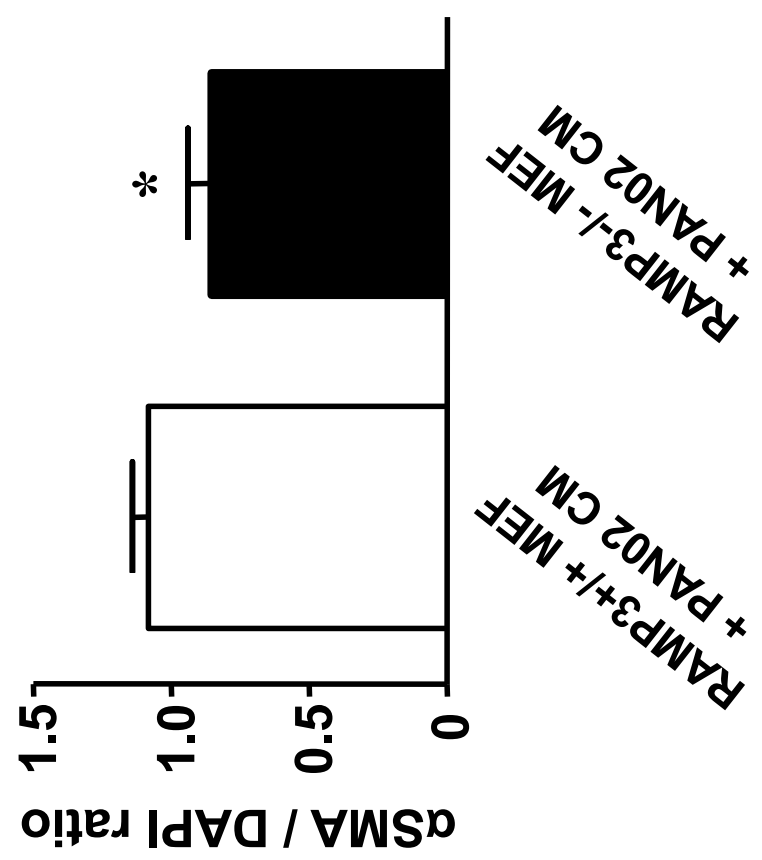

10

인

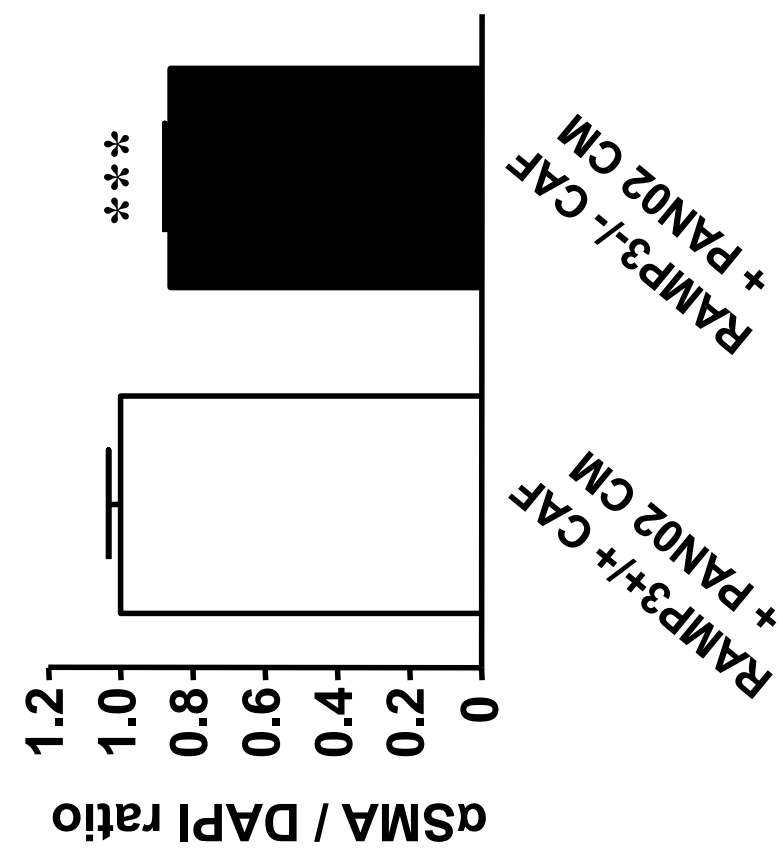

$\varangle$ 

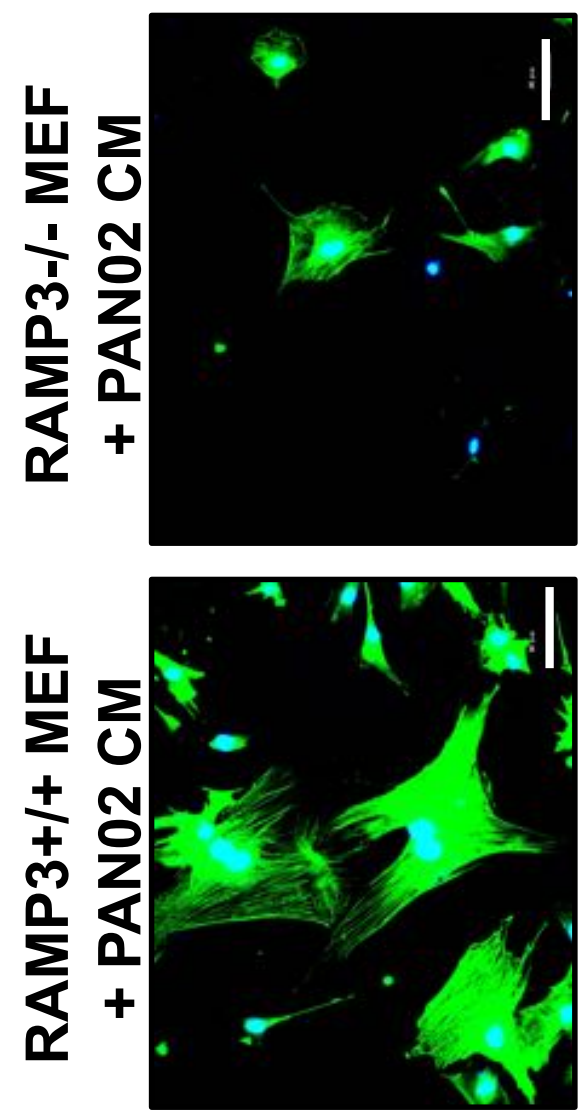

ص
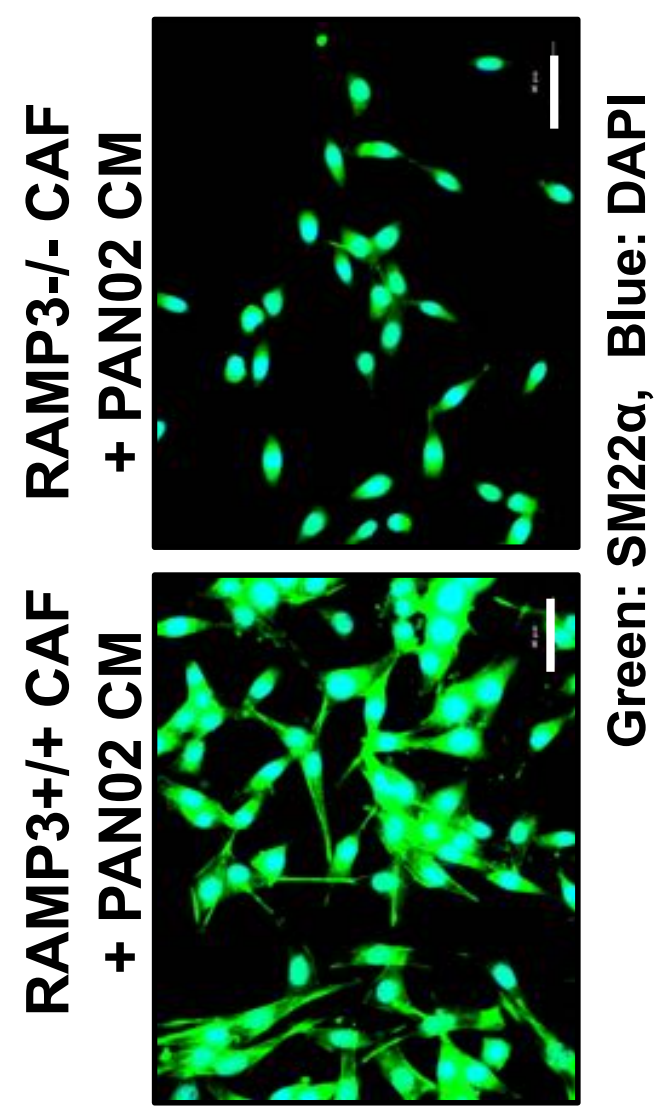

$\frac{\pi}{8}$



ก

$\frac{0}{5}$

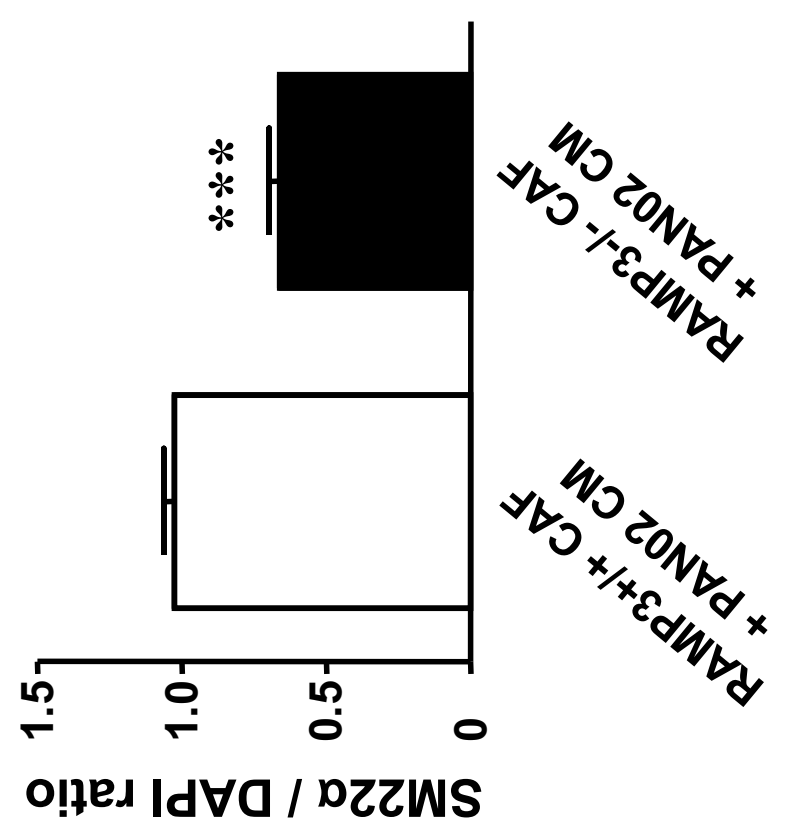




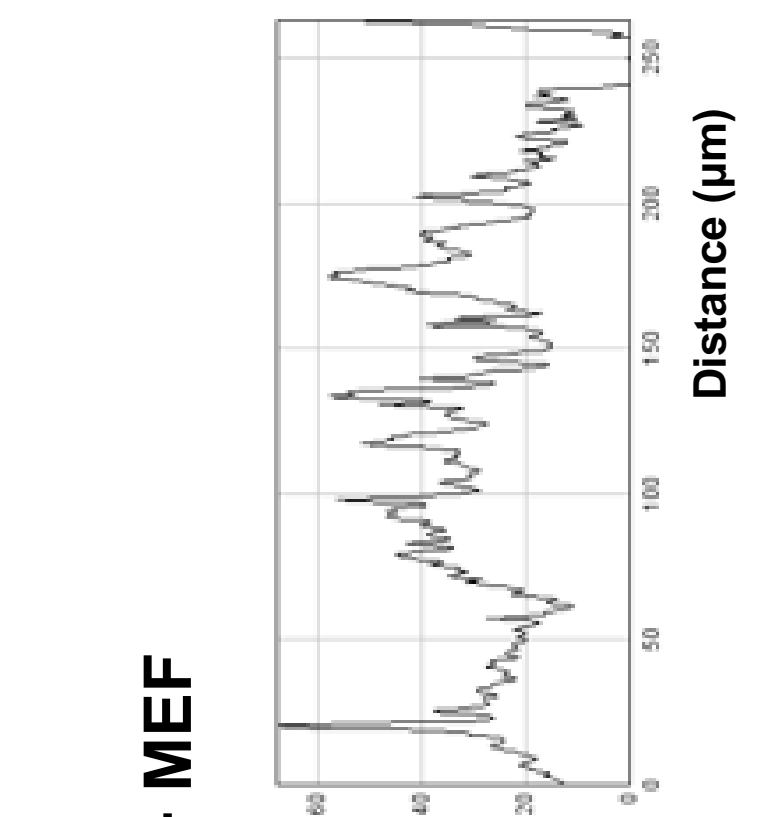

$\boldsymbol{L}$
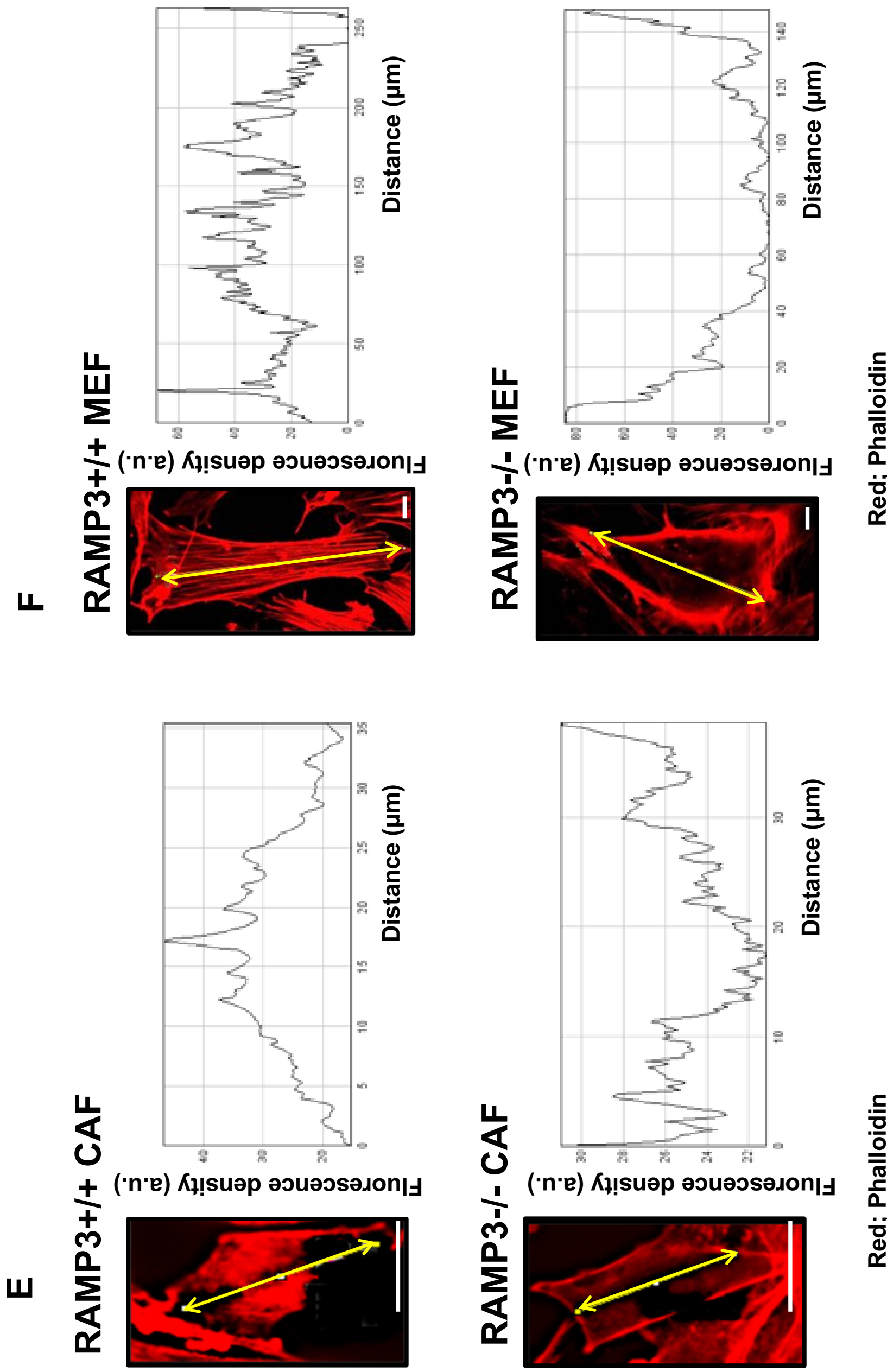

\begin{tabular}{l}
0 \\
은 \\
$\frac{2}{6}$ \\
\hline 12
\end{tabular}

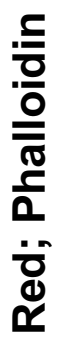




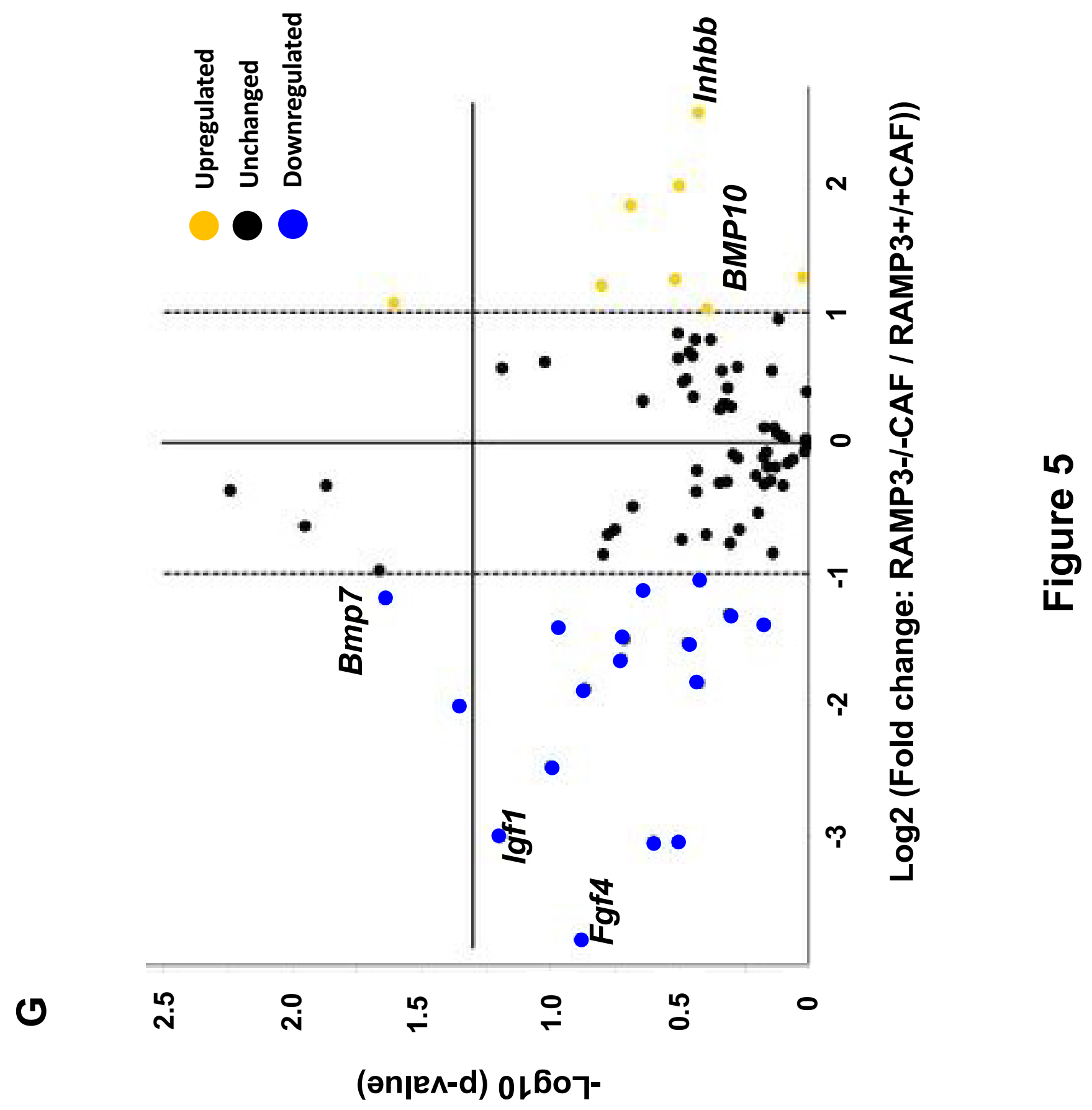




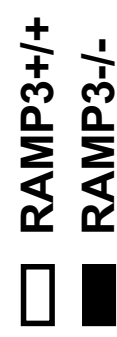

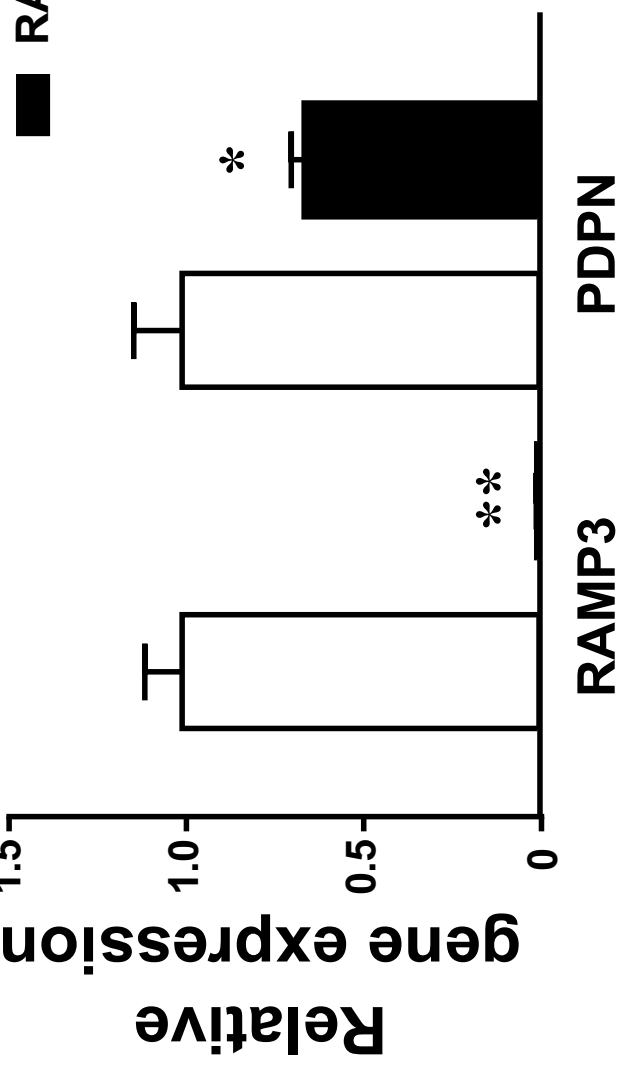

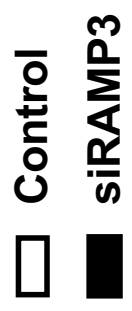
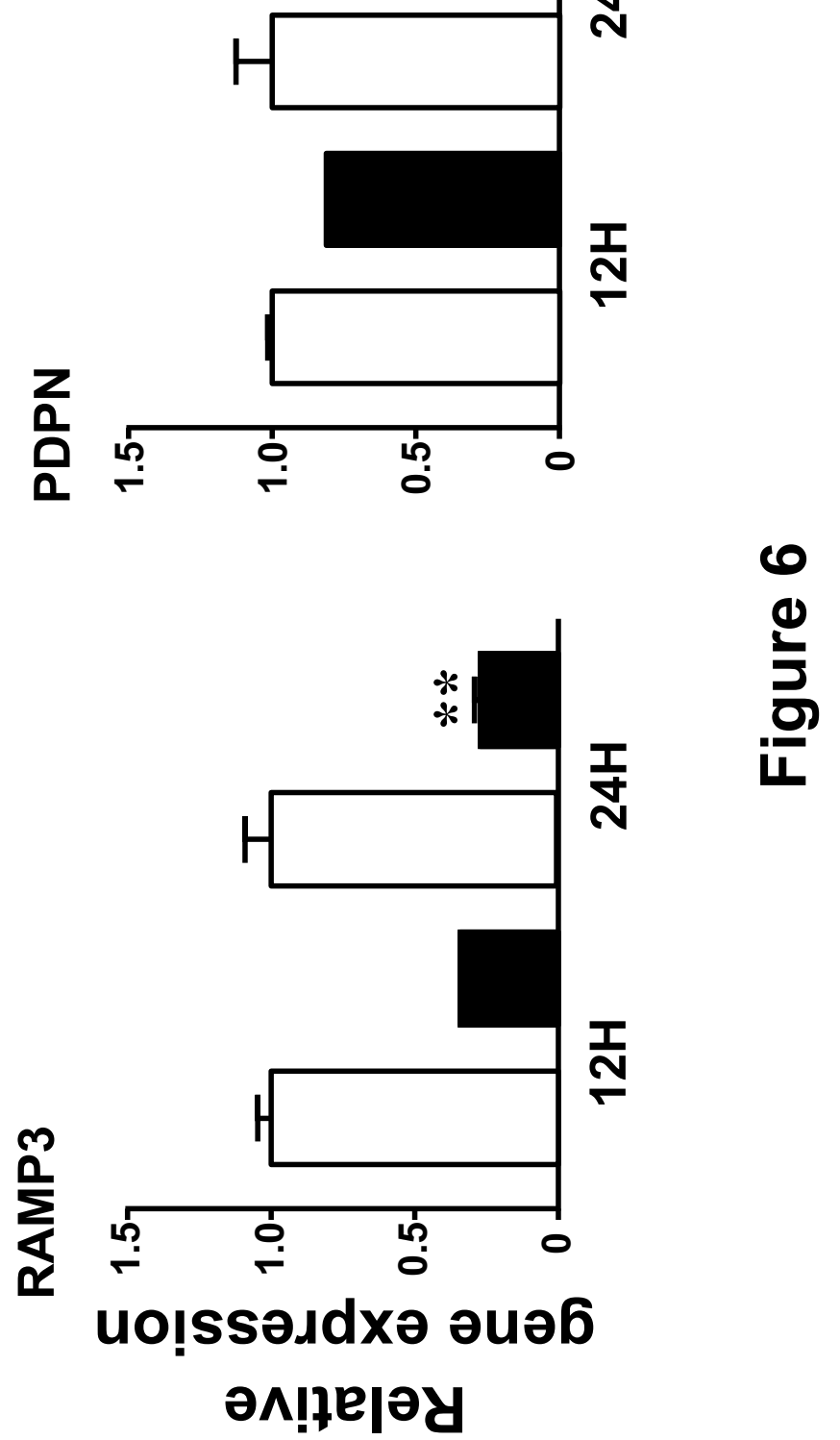

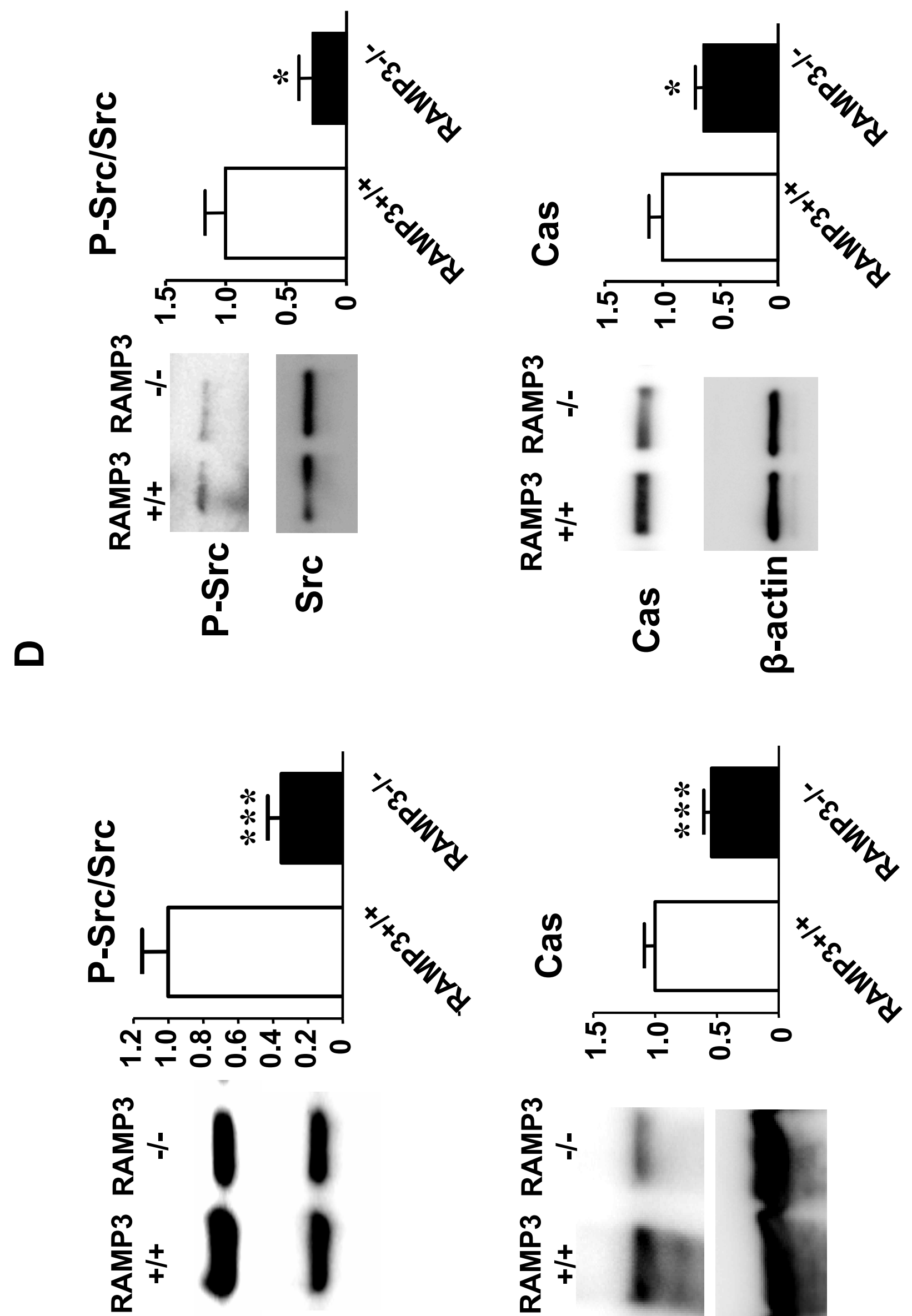

$0 \quad \frac{0}{\infty} \quad \frac{1}{\infty}$

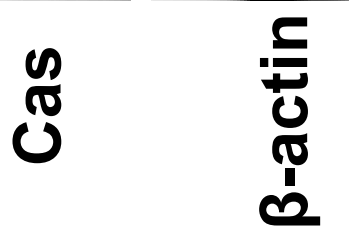




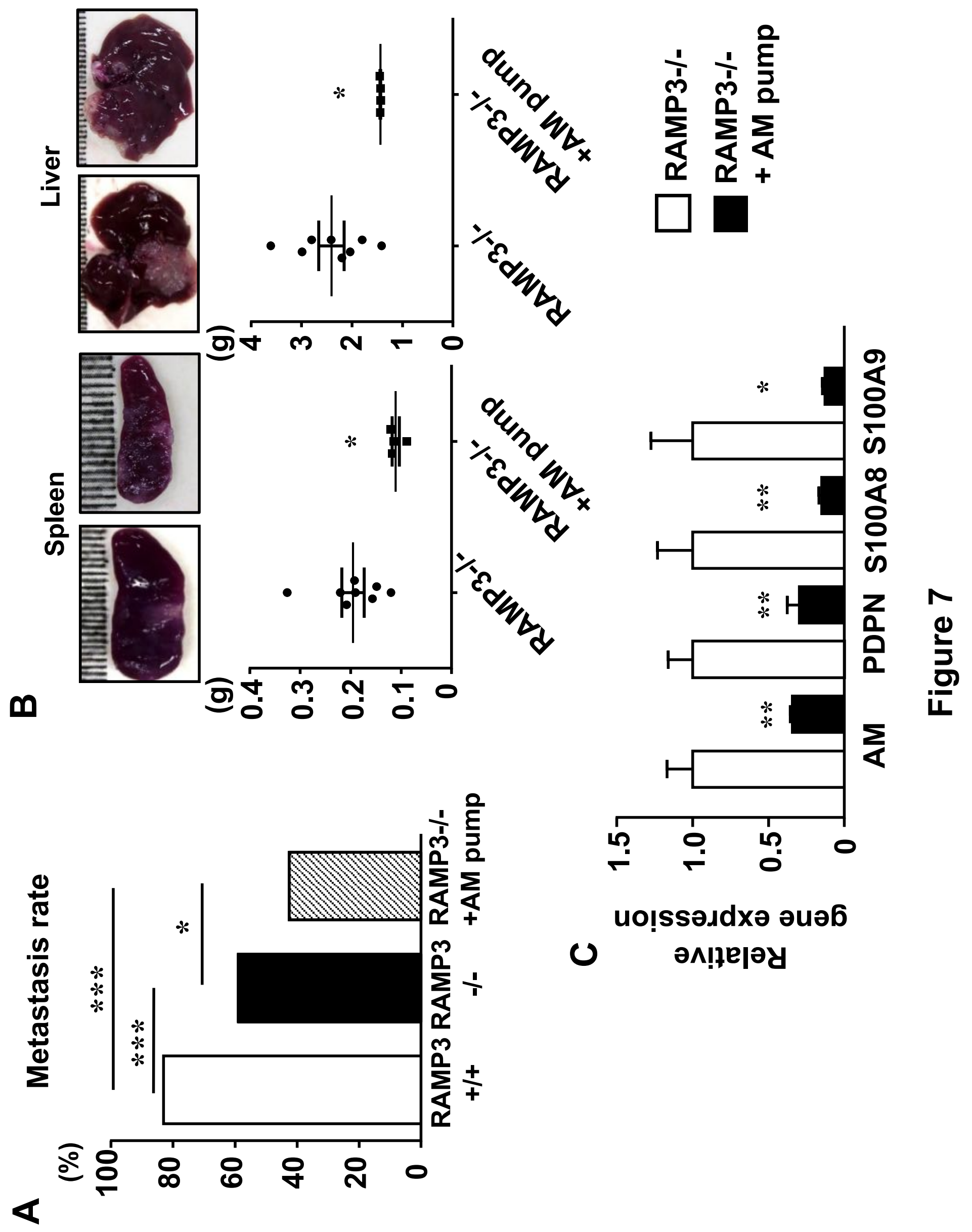




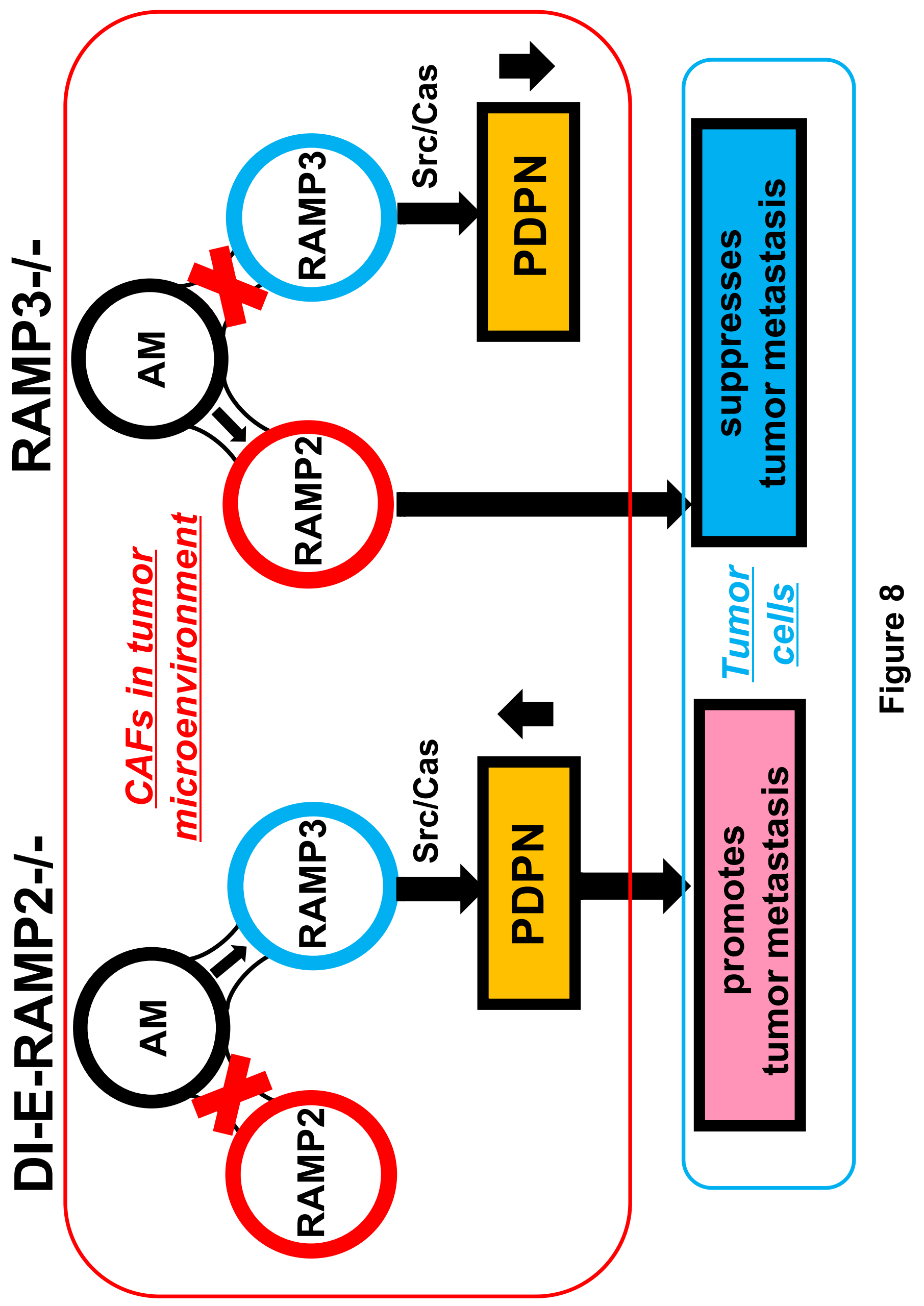




\title{
Supplementary information
}

\section{Deficiency of the adrenomedullin-RAMP3 system suppresses metastasis through modification of cancer-associated fibroblasts}

\author{
Kun Dai $^{1,2^{*}}$, Megumu Tanaka ${ }^{1,2^{*}}$, Akiko Kamiyoshi ${ }^{1,2}$, Takayuki Sakurai1,2, \\ Yuka Ichikawa-Shindo ${ }^{1,2}$, Hisaka Kawate ${ }^{1,2}$, Nanqi Cui ${ }^{1,2}$, Yangxuan Wei ${ }^{1,2}$, \\ Masaaki Tanaka ${ }^{1,3}$, Shinji Kakihara ${ }^{1,3}$, Shuhei Matsui ${ }^{1,4}$, Takayuki Shindo ${ }^{1,2+}$
}

${ }^{1}$ Department of Life Innovation, Institute for Biomedical Sciences, Interdisciplinary Cluster for Cutting Edge Research, Shinshu University, Japan

${ }^{2}$ Department of Cardiovascular Research, Shinshu University School of Medicine, Japan

${ }^{3}$ Department of Ophthalmology, Shinshu University School of Medicine, Japan

${ }^{4}$ Department of Anesthesiology, Shinshu University School of Medicine, Japan

"Shared first authorship

${ }^{+}$Corresponding author

Running title: RAMP3 deficiency suppresses metastasis by modulating CAF 


\section{Supplementary Figure Legend}

\section{Supplementary Figure 1}

Tumor angiogenesis does not differ between RAMP3-/- and RAMP3+/+ mice

A, Histological evaluation of angiogenesis within tumors in the spleen (upper panels) and liver (lower panels). Sections were fluorescently immunostained for CD34 (green), DAPI (blue). Scale bars $=50 \mu \mathrm{m} . \mathbf{B}$, Quantitative real-time PCR analysis of AM-RAMP systems, PDPN and CD34 in tumors from the spleen ( $\mathrm{n}=5$ each) and liver ( $\mathrm{n}=7$ for RAMP3+/+ and $\mathrm{n}=8$ for RAMP3-/-). The mean of the RAMP3+/+ group was assigned a value of 1 . Bars are means \pm SEM. $* \mathrm{P}<0.05, * * \mathrm{P}<0.01$. P-values were calculated using the Mann-Whitney U test.

\section{Supplementary Figure 2}

\section{Stromal fibroblasts isolated from sections of metastatic liver tumor periphery} exhibit the characteristics of CAFs

A, Fluorescent immunostaining of primary cultured CAFs. Cells were immunostained for FSP-1 (green), Vimentin (green), aSMA (red), CK19 (green), E-cadherin (red) and DAPI (blue). Vimentin, FSP-1 and $\alpha$ SMA were used as mesenchymal markers, while CK19 and E-cadherin were used as epithelial markers. Scale bars $=100 \mu \mathrm{m}$. Primary cultured CAFs stained for mesenchymal markers, but not epithelial markers. B, Quantitative real-time PCR analysis of RAMP3 and PDPN expression in PAN02 cells and CAFs ( $\mathrm{n}=2$ for PAN02 cells, $\mathrm{n}=3$ each for CAFs). The mean of the PAN02 cells was assigned a value of 1 for RAMP3 expression, and the mean of the RAMP3+/+ 
CAFs was assigned a value of 1 for PDPN expression. Bars are means \pm SEM.

\section{Supplementary Figure 3}

\section{RAMP3-/- CAF / PAN02 cell mixture exhibits less migration}

Scratch assays carried out after suppressing cell proliferation using mitomycin C (10 $\mu \mathrm{g} / \mathrm{ml})$. Shown are representative photomicrographs of scratch assays with cocultures of CAFs and PAN02 cells (ratio, 1:1; total of $5 \times 10^{5}$ cells). Scale bars $=200 \mu \mathrm{m}$. Calculated percent cell-covered areas are displayed below ( $n=3$ in each). Bars are means \pm SEM. $* * \mathrm{P}<0.01$. P-value was calculated by Student's t-test.

\section{Supplementary Figure 4}

\section{PAN02 cells stimulated by conditioned medium from RAMP3-/- CAFs exhibits}

\section{less migration}

A, Scratch assay of PAN02 cells $\left(5 \times 10^{5}\right.$ cells $)$ stimulated by conditioned medium $(\mathrm{CM})$ from RAMP3-/- CAFs or RAMP3-/- CAFs. Scale bars $=200 \mu \mathrm{m}$. Calculated percent cell-covered area is displayed below ( $\mathrm{n}=4$ in each). B, Fluorescent immunostaining of PAN02 cells stimulated with CM from RAMP3-/- CAFs or RAMP3-/- CAFs: green, vimentin; red, phalloidin; blue, DAPI. Scale bars $=50 \mu \mathrm{m}$. Vimentin-positive / DAPI-positive area ratios are displayed below ( $\mathrm{n}=9$ views from 3 cultured dishes). Bars are means \pm SEM. ${ }^{*} \mathrm{P}<0.05,{ }^{* * *} \mathrm{P}<0.001$. P-values were calculated using the Mann-Whitney U test. 
RAMP3 deficiency suppresses metastasis by modulating CAF

\section{Supplementary Figure 5}

\section{Altered actin distribution in RAMP3-/- MEFs}

MEFs cultured from RAMP3+/+ and RAMP3-/- mice were stained with rhodamine-phalloidin to visualize F-actin. Scale bars $=100 \mu \mathrm{m}$. Quantitation of central actin fiber density is shown below ( $\mathrm{n}=24$ views from 3 cultured dishes). Bars are means \pm SEM. $* * * \mathrm{P}<0.001 . \mathrm{P}$-value was calculated using the Mann-Whitney $\mathrm{U}$ test.

\section{Supplementary Figure 6}

\section{Comprehensive gene expression analysis of RAMP3+/+ and RAMP3-/- CAFs}

A, Clustergram showing the results of a real-time PCR array analysis of growth factors in primary cultured RAMP3+/+ CAFs or RAMP3-/- CAFs ( $\mathrm{n}=3$ each). Each column shows the results from one mouse. Red and green colors represent higher and lower gene expression, respectively. B, Top 5 growth factors downregulated or upregulated in RAMP3-/- CAFs as compared to RAMP3+/+ CAFs. 

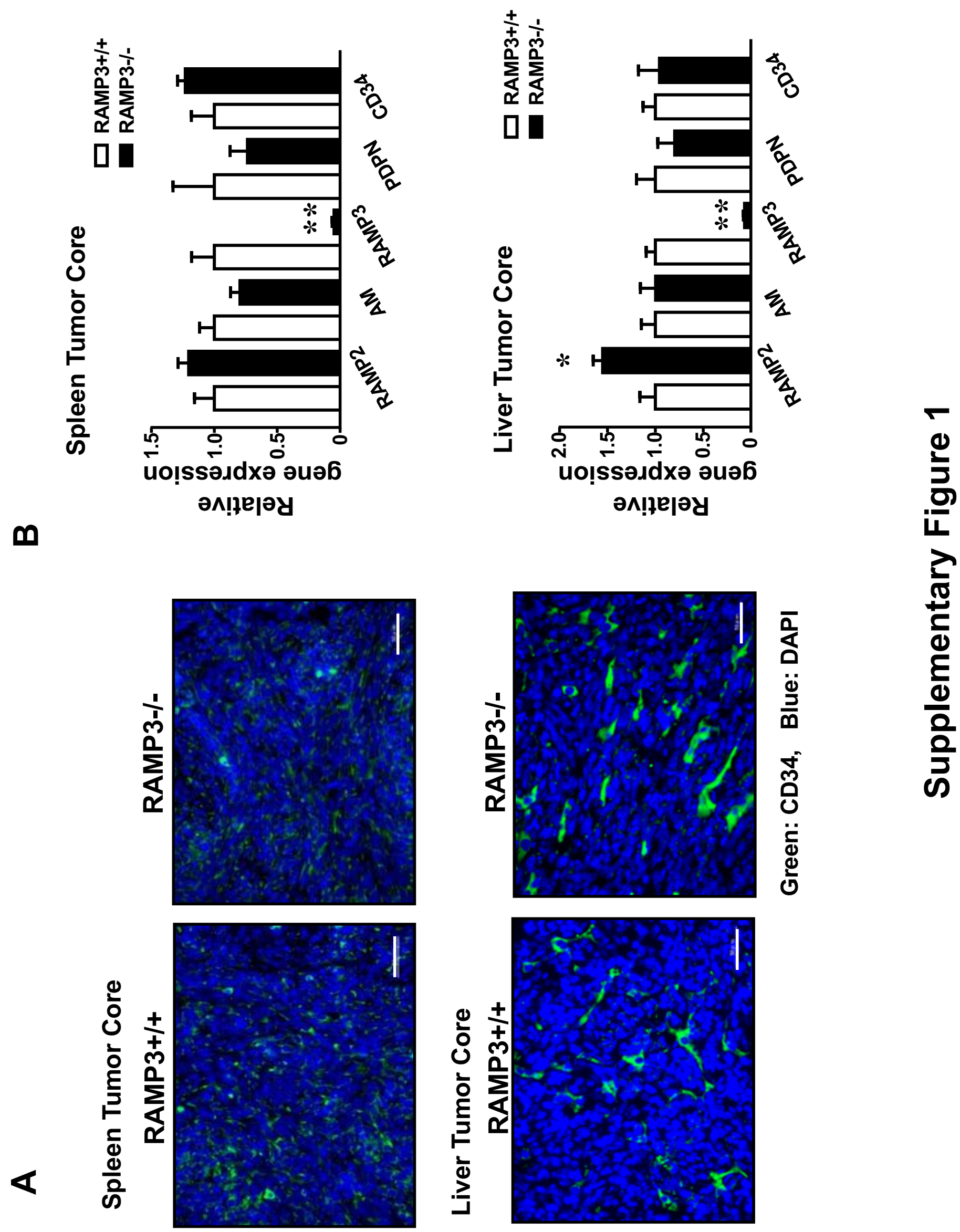

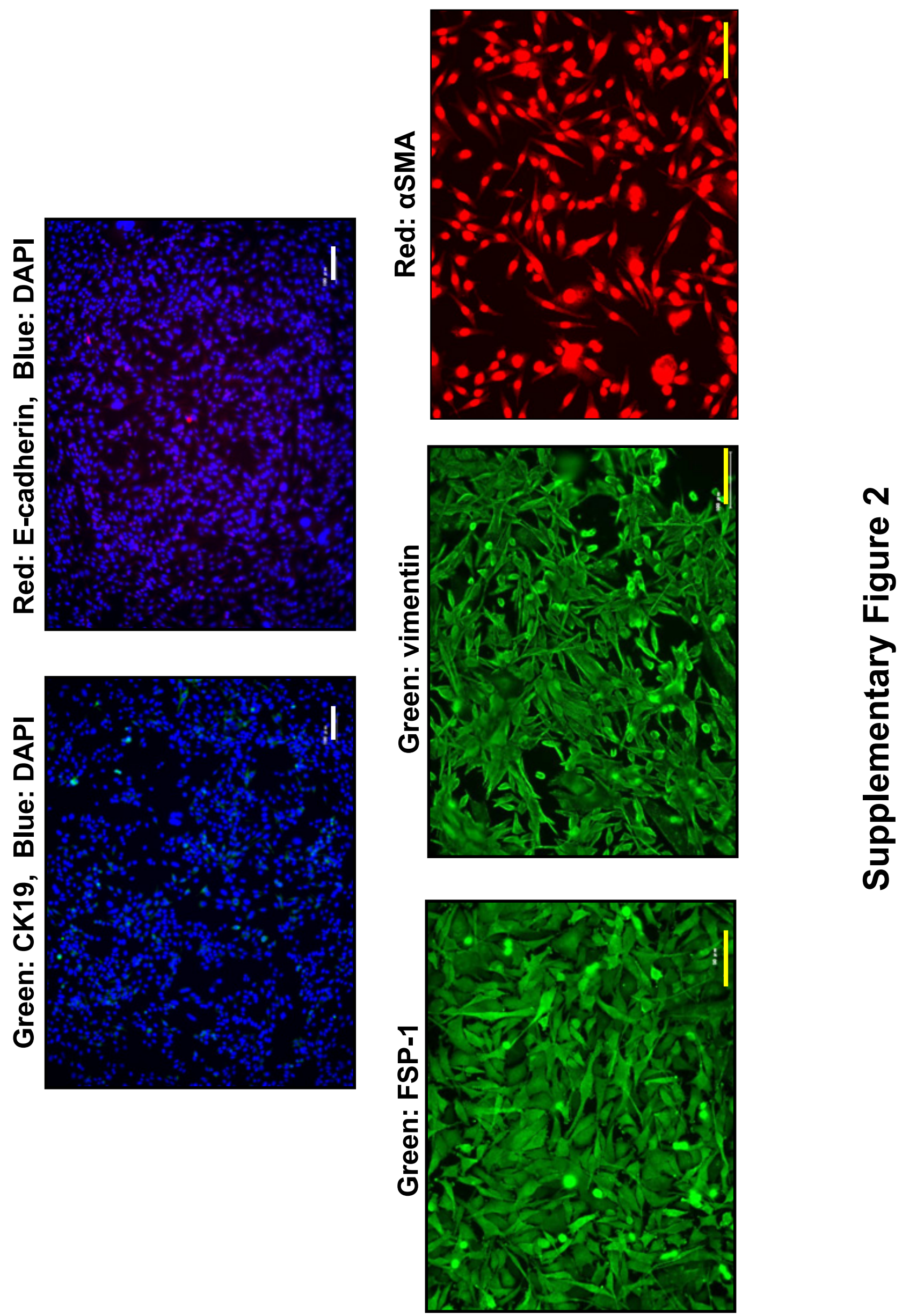


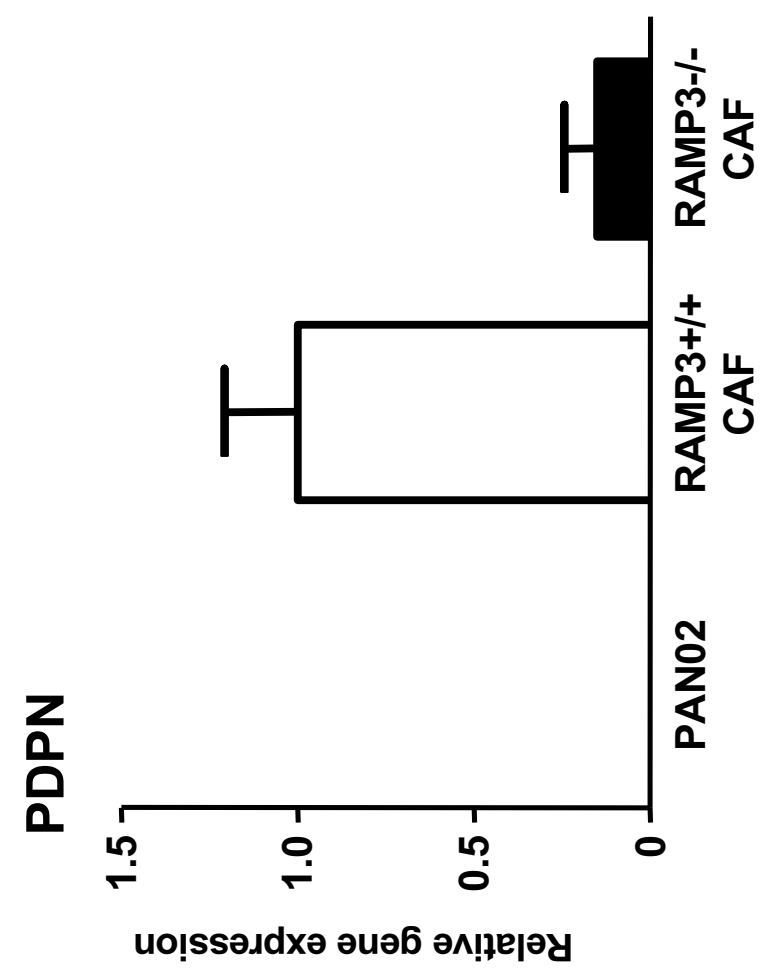

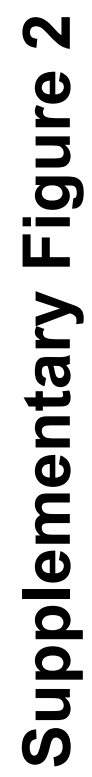

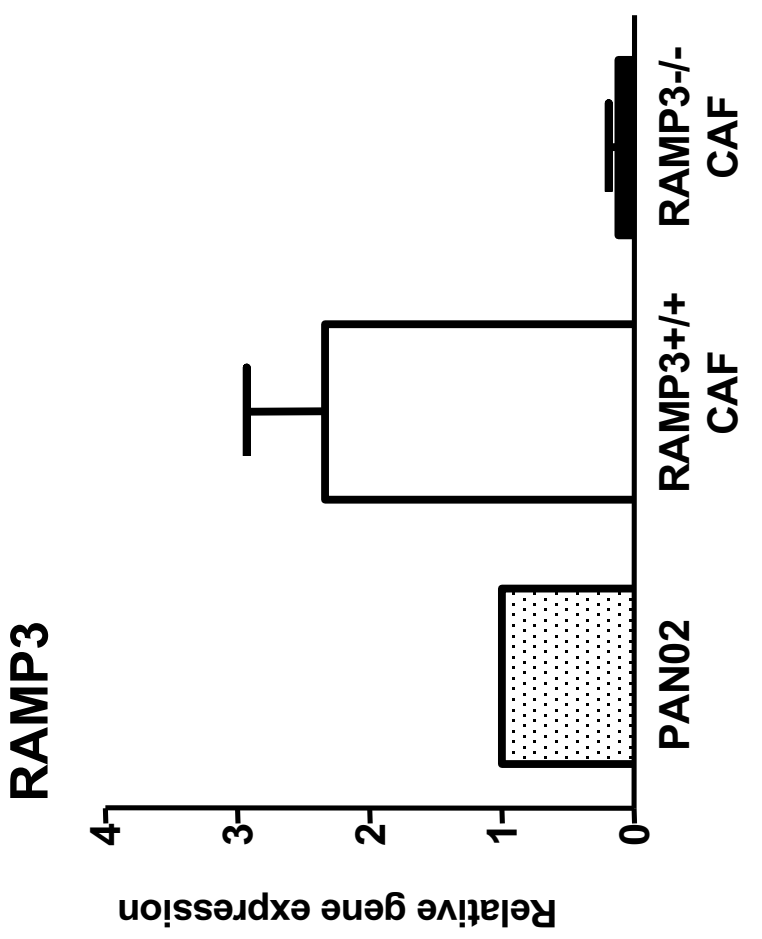



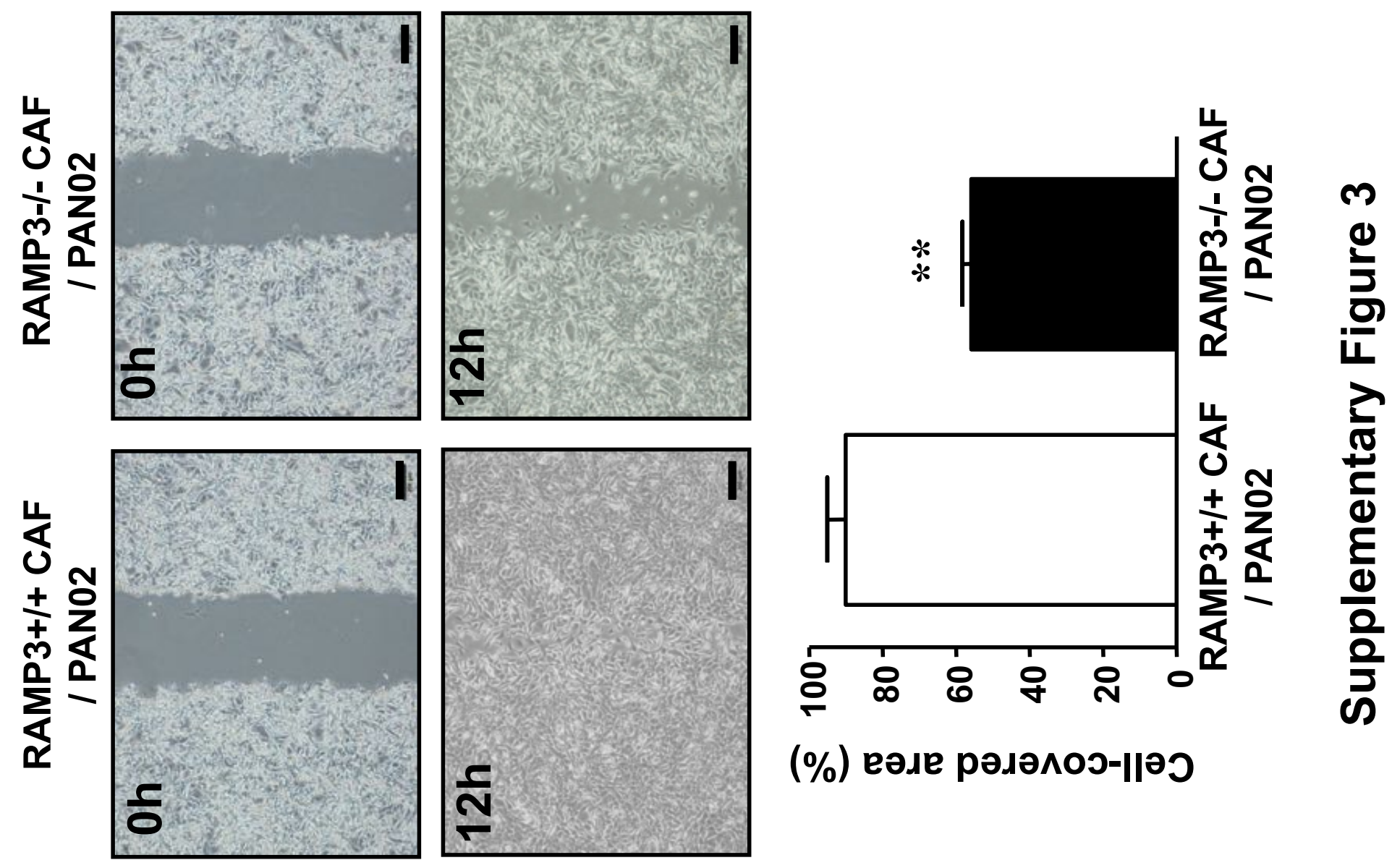

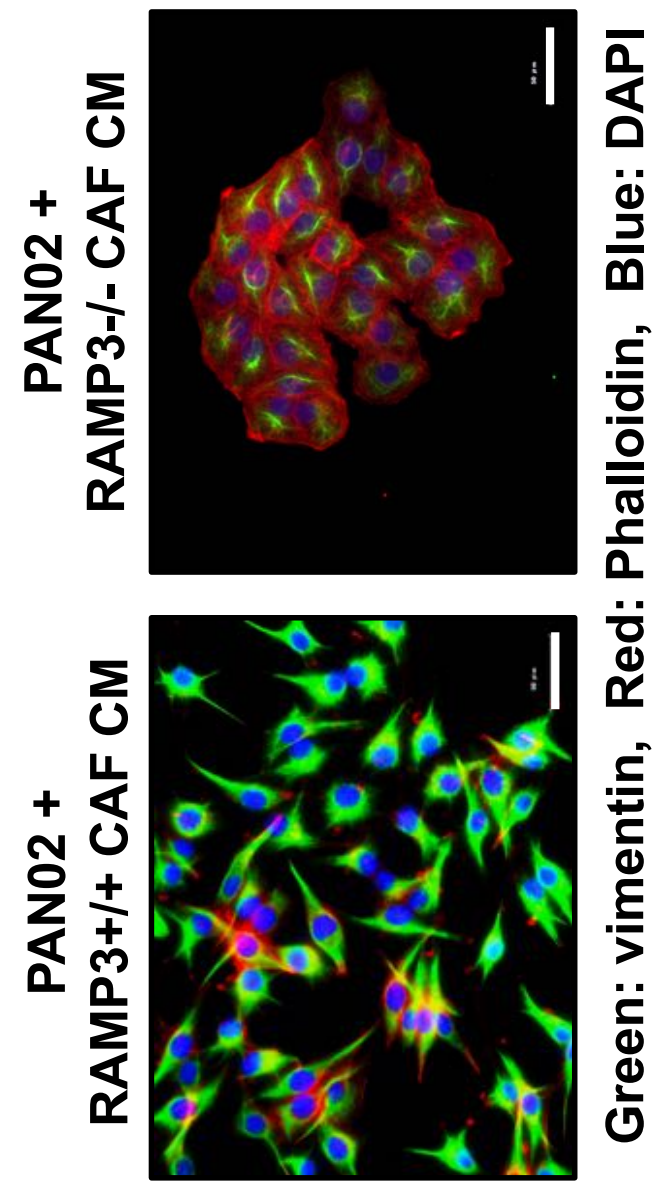

$\boldsymbol{m}$
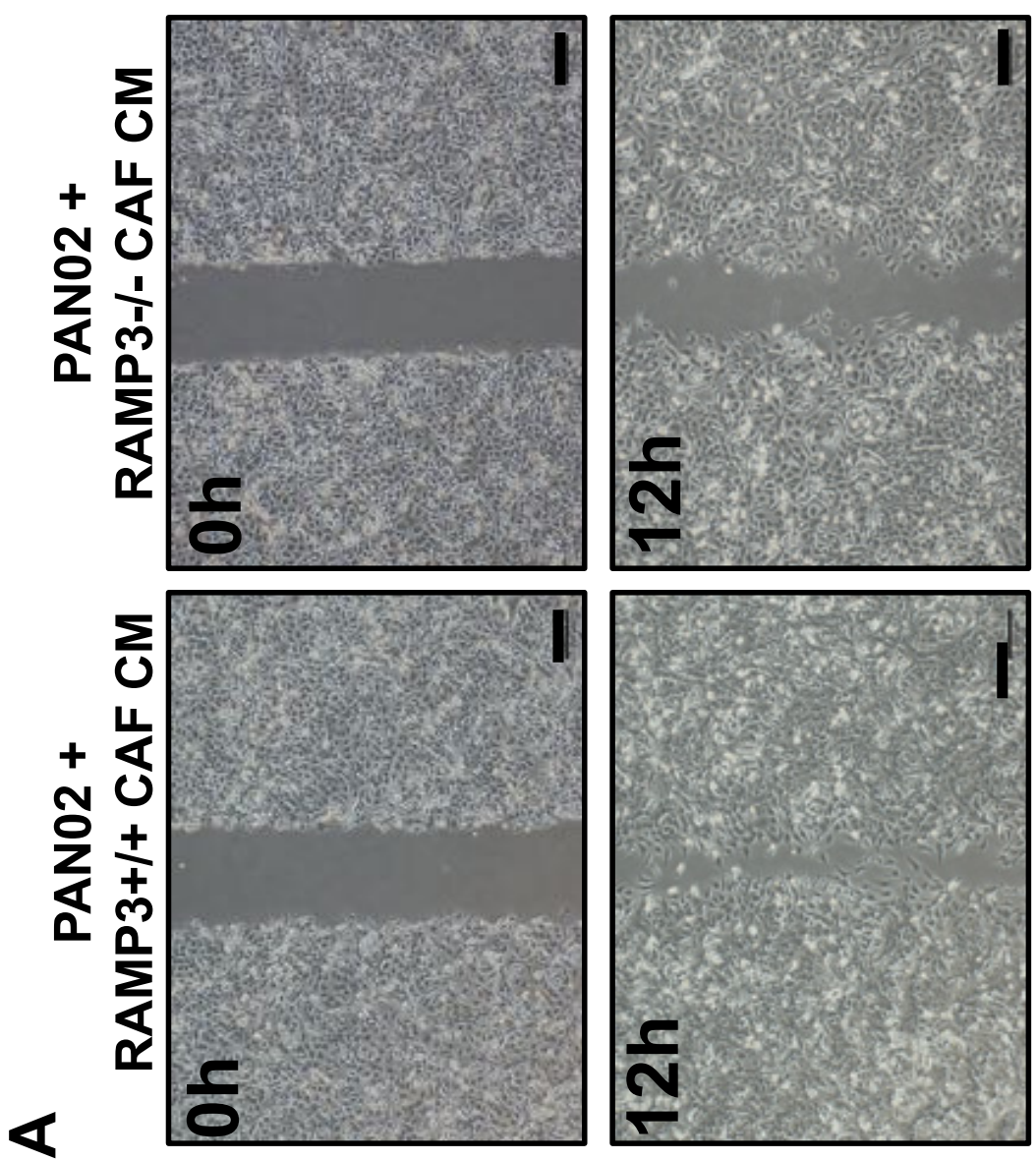

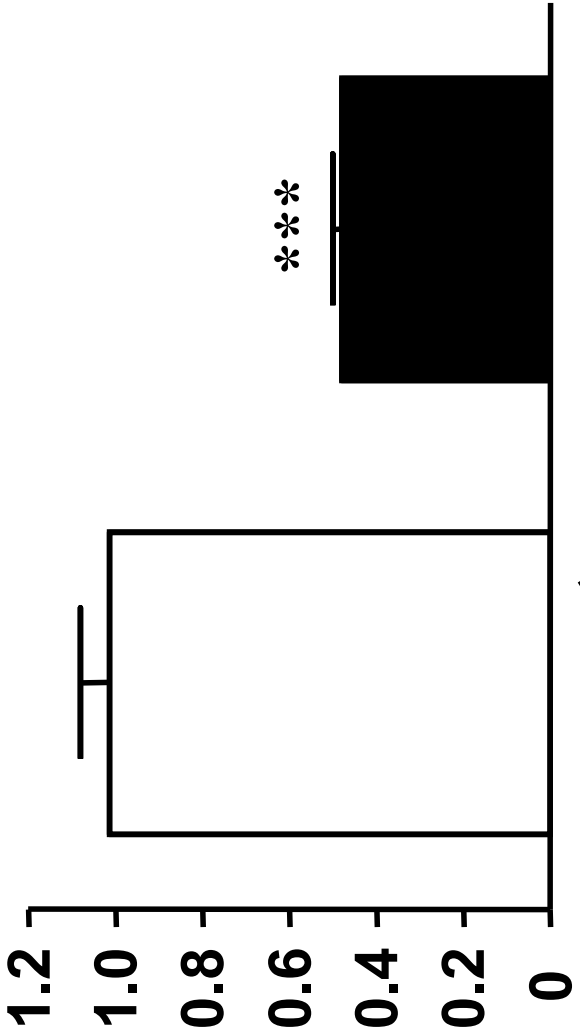

$\%$

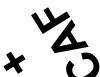

Oे

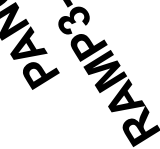

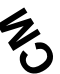

$\times$ o $x$ 告就

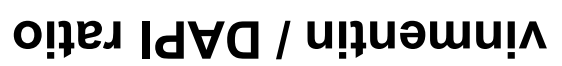

o!fed Id $\forall 0$ / u!łuәuu!̣
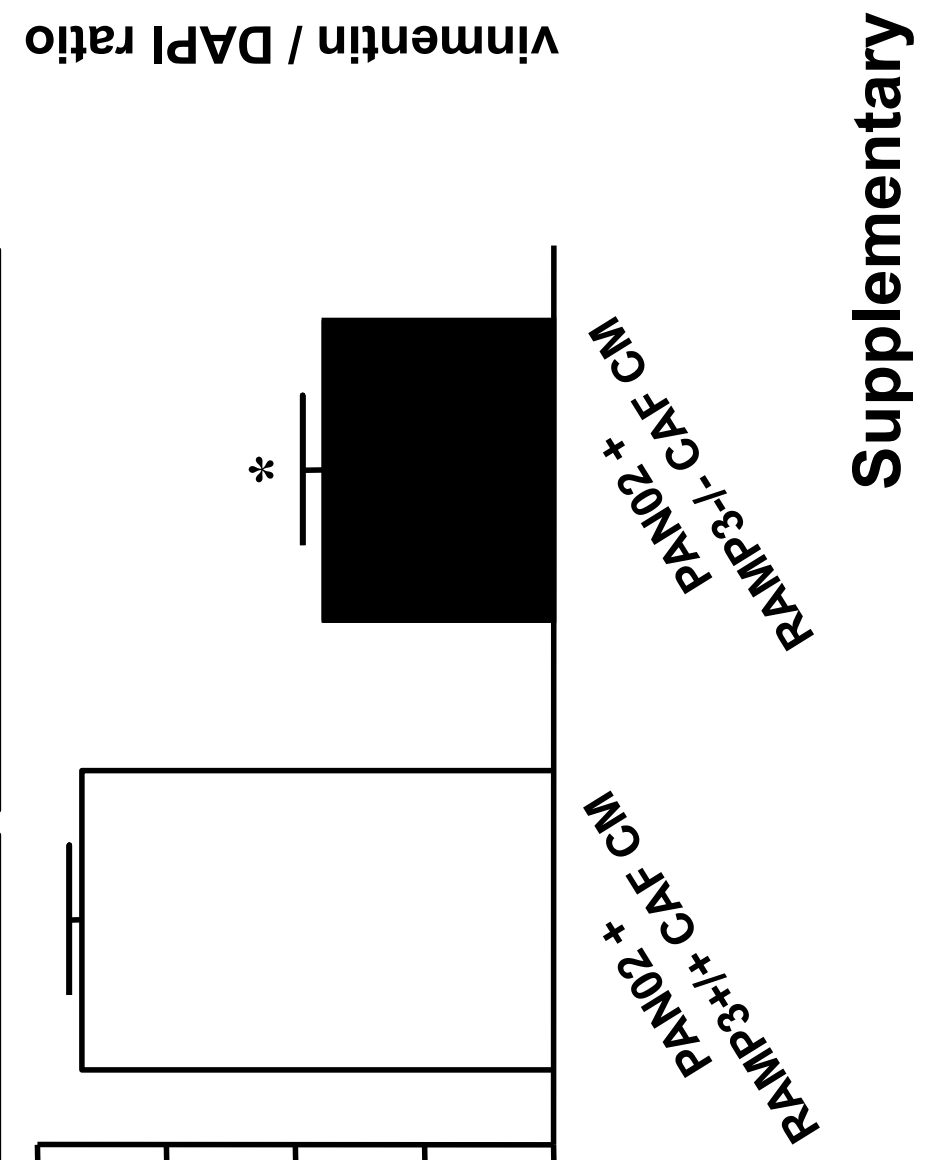

$๑$ \& กิ 0

(\%) еәле рәләлоэ-||әэ 


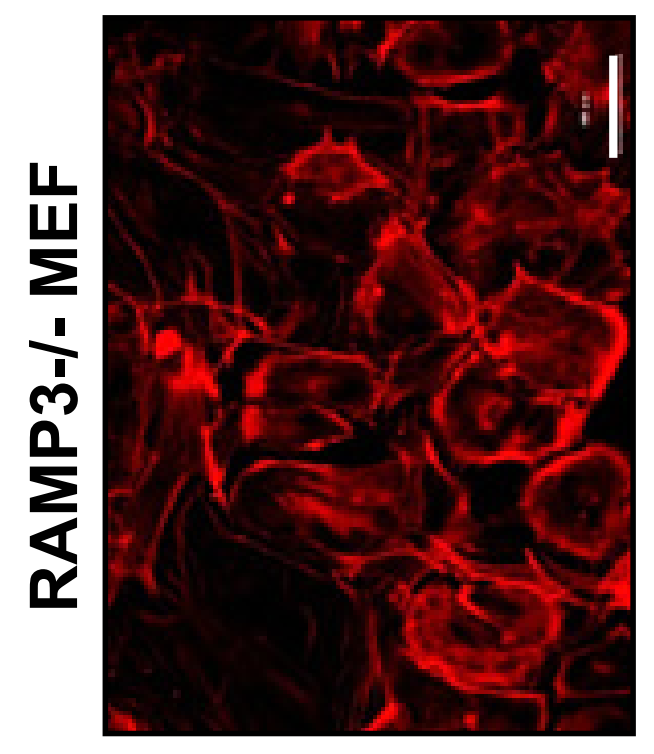

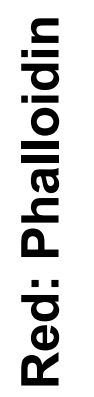
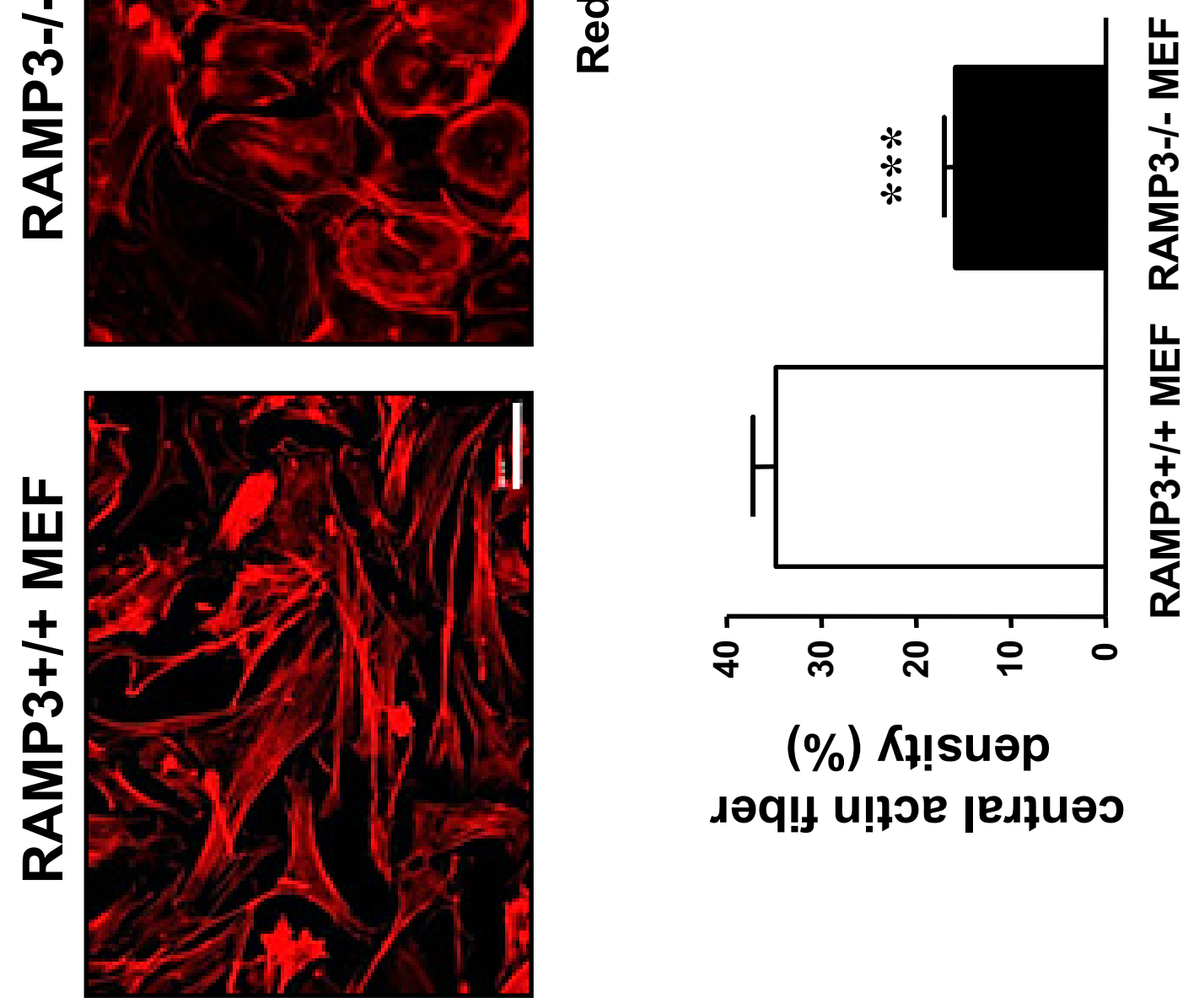

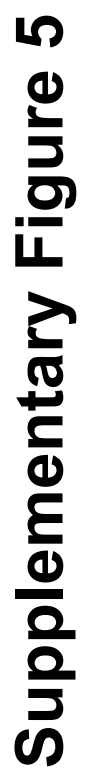

\author{
(\%) Kł!suәp \\ ләq!f u!‡әе ןелұиәо
}




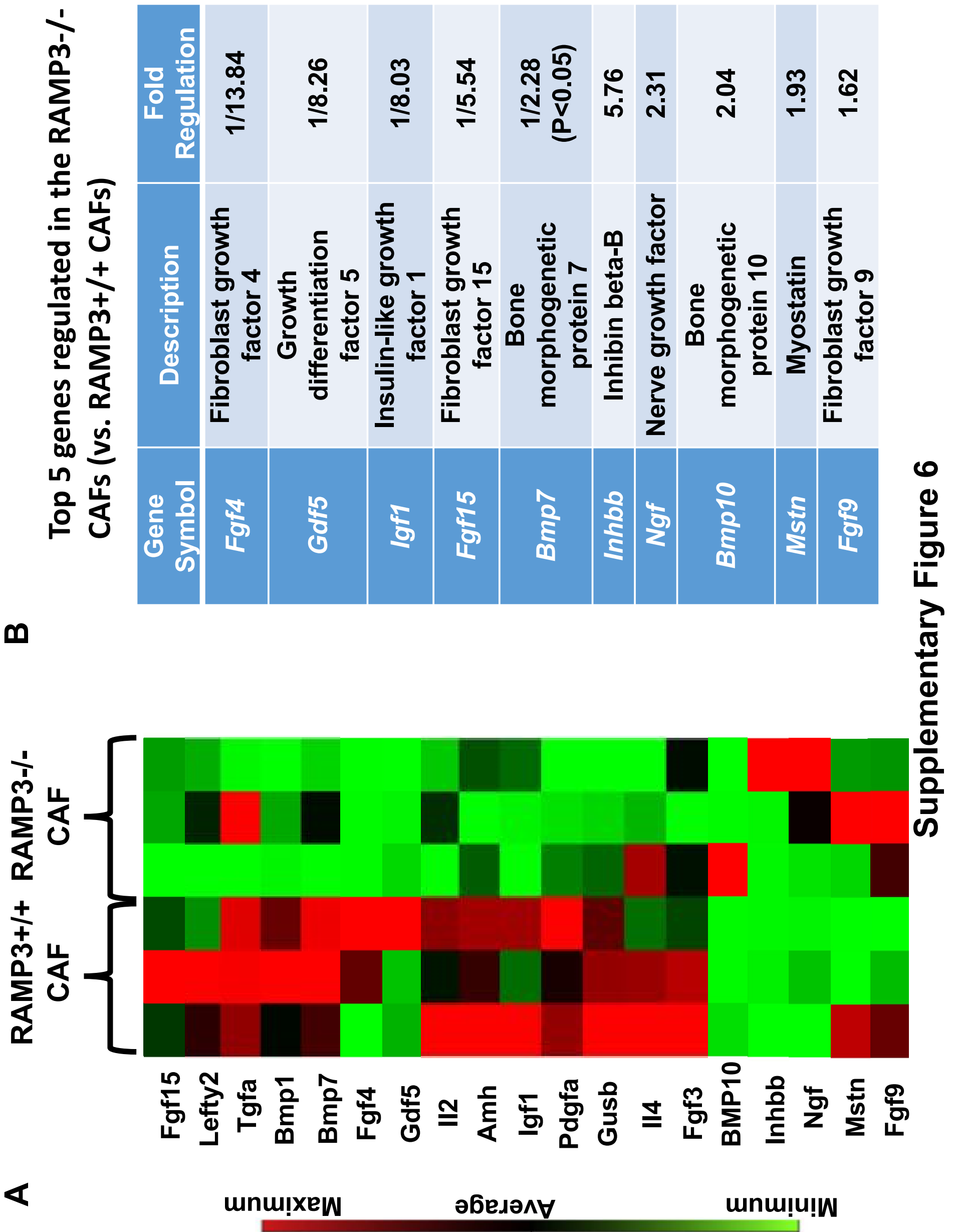

